Distinct neural mechanisms for the control of thirst and salt appetite in the subfornical organ

Matsuda, Takashi

Doctor of Philosophy

Department of Basic Biology

School of Life Science

SOKENDAI (The Graduate University for Advanced Studies) 



\title{
Distinct neural mechanisms for the control of thirst and salt appetite in the subfornical organ
}

\author{
Matsuda, Takashi
}

SOKENDAI

(THE GRADUATE UNIVERSITY FOR ADVANCED STUDIES)

SCHOOL OF LIFE SCIENCE

DEPARTMENT OF BASIC BIOLOGY

A THESIS SUBMITTED FOR THE DEGREE OF

DOCTOR OF PHILOSOPHY 


\section{Contents}

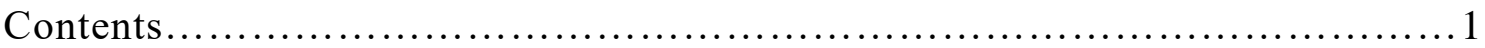

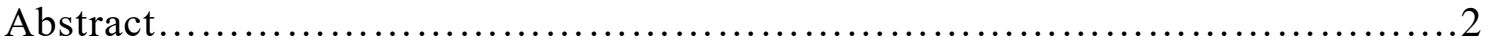

Abbreviations................................................................ 5

Chapter I General introduction ......................................

Figures.......................................................... 12

Chapter II Roles of AT1a signals in thirst and salt-appetite generation............15

Introduction ..................................................... 16

Materials and Methods............................................ 18

Results.........................................................23

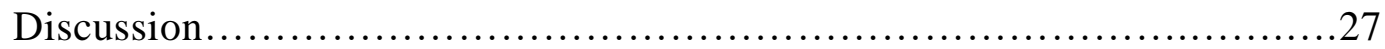

Figures.......................................................... 30

Chapter III Distinct neural pathways for the control of thirst and salt appetite in the subfornical organ......................................................40

Introduction ................................................ 41

Materials and Methods...........................................43

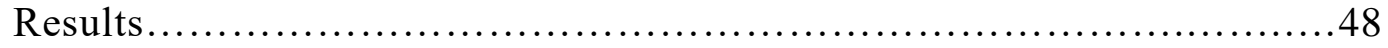

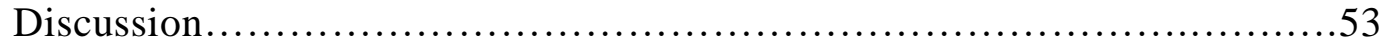

Figures............................................................. 56

Chapter IV Modulations of the neuronal activities of the water and salt neurons in

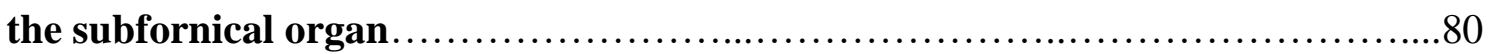

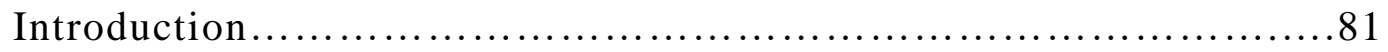

Materials and Methods.............................................. 82

Results........................................................... 84

Discussion........................................................ 88

Figures............................................................. 90

Chapter V Summary and conclusion.......................... 97

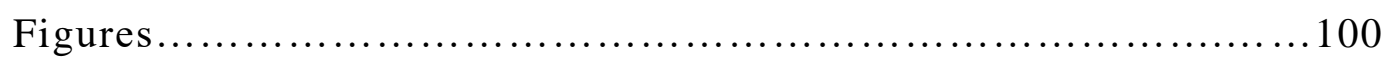

Chapter VI References...................................... 102

Acknowledgements.......................................................... 112 


\section{Abstract}

Body-fluid conditions are continuously monitored in the brain to regulate thirst and salt-appetite sensations. The central monitoring of body-fluid conditions is considered to be mediated by sensory circumventricular organs (sCVOs), brain regions that lack a blood-brain barrier, but harbor neuronal cell bodies. sCVOs consist of the subfornical organ (SFO), organum vasculosum of the lamina terminalis (OVLT), and area postrema.

$\mathrm{Na}^{+}$-levels in body fluids are sensed by $\mathrm{Na}_{x}$ channels expressed in specific glial cells in the SFO. The activation of $\mathrm{Na}_{\mathrm{x}}$ stimulates the glial cells to release lactate, which functions as a gliotransmitter that activates GABAergic inhibitory neurons in the SFO. It has been postulated that the activation of the GABAergic neurons suppress salt appetite. On the other hand, angiotensin II (Ang II) drives both thirst and salt appetite; however, the neural mechanisms underlying selective water- and salt-intake behaviors remain unknown.

To investigate water- and salt-intake behaviors, I established water- and/or Na-depleted conditions in mice by dehydration (water-depleted), furosemide treatment (water- and Na-depleted), or combining furosemide treatment with water satiation (Na-depleted), respectively. Blood Ang II levels increased to similar levels in all of the three conditions. Under the water-depleted and Na-depleted conditions, the expression of Fos, a marker for neuronal activity, was specifically increased in Ang II receptor type 1a (AT1a)-positive neurons in the SFO and OVLT.

To examine the contribution of the SFO and OVLT to water- and salt-intake behaviors, AT1a gene was site-specifically deleted in the SFO and/or OVLT. The local deletion of AT1a in the SFO resulted in significant reductions in water intake under the 
water- and Na-depleted condition and in salt intake under the Na-depleted condition. In contrast, the local deletion of AT1a in the OVLT resulted in marked reductions in water intake under the water- and Na-depleted condition, but not salt intake under the Na-depleted condition. These results suggest that AT1a signals in the SFO are involved in both water and salt intake, whereas those in the OVLT are involved only in water intake.

My anatomical analyses revealed that AT1a-positive neurons in the SFO were largely glutamatergic, and they had projections to the OVLT, ventral part of the bed nucleus of the stria terminalis (vBNST), and so on. Notably, Fos-positive neurons under the water-depleted condition overlapped well with the SFO neurons projecting to the OVLT $[\mathrm{SFO}(\rightarrow \mathrm{OVLT})$ neurons]. In contrast, the SFO neurons projecting to the vBNST $[\mathrm{SFO}(\rightarrow \mathrm{vBNST})$ neurons] expressed Fos under the Na-depleted condition. Furthermore, I tested whether optical manipulations of the specific neural pathways by using channelrhodopsin 2 and archearhodopsin 3 can control the specific intake behaviors. As was expected, water- and salt-intake behaviors were selectively controlled by optogenetic manipulations of neuronal activities of the respective neuronal groups. From these results, I conclude that the $\mathrm{SFO}(\rightarrow \mathrm{OVLT})$ neurons and $\mathrm{SFO}(\rightarrow \mathrm{vBNST})$ neurons control thirst and salt appetite, respectively.

To examine the relationship between $\mathrm{Na}_{\mathrm{x}}$ signals and AT1a-dependent control of salt appetite, I examined whether the activity of the $\mathrm{SFO}(\rightarrow \mathrm{VBNST})$ neurons is regulated by $\mathrm{Na}_{\mathrm{x}}$ signals through GABAergic neurons. As previously reported, $N a_{x}$-knockout (KO) mice did not show salt aversion under the water-depleted condition. Increased Fos expression was observed in the $\mathrm{SFO}(\rightarrow \mathrm{vBNST})$ neurons of the $N a_{x}$-KO mice compared with wild-type mice. In addition, electrophysiological experiments 
demonstrated that the Ang II-induced firing activity of the SFO $(\rightarrow$ vBNST $)$ neurons was suppressed dependent on the activity of GABAergic neurons by a hypertonic $\mathrm{Na}$ solution. The Na-dependent responses were absent in brain slices prepared from $N a_{x}$-KO mice. Thus, $\mathrm{Na}_{\mathrm{x}}$ signals suppressed the activity of the $\mathrm{SFO}(\rightarrow \mathrm{vBNST})$ neurons through activation of GABAergic neurons in the SFO.

In addition, I explored inhibitory signals that suppress the activity of the $\mathrm{SFO}(\rightarrow \mathrm{OVLT})$ neurons. I tested cholecystokinin (CCK) because it reportedly inhibits water intake. I found that the Ang II-induced firing activity of the $\mathrm{SFO}(\rightarrow$ OVLT $)$ neurons was suppressed by application of CCK through activation of GABAergic neurons in the SFO. In line with this finding, CCK levels in the SFO were increased under the Na-depleted condition. Of note, CCK did not affect the activity of the GABAergic neurons which made synapse onto the $\mathrm{SFO}(\rightarrow$ vBNST $)$ neurons. These results indicate that CCK levels in the SFO modulate the activity of the $\mathrm{SFO}(\rightarrow \mathrm{OVLT})$ neurons through activation of another population of GABAergic neurons.

In summary, I demonstrate that the AT1a-positive SFO neurons projecting to the OVLT and vBNST encode thirst and salt appetites, respectively. I named these two population of driving neurons "water neuron" and "salt neuron", respectively. The thirst and salt-appetite behaviors are separately controlled dependent on body-fluid conditions. This would provide substantial explanations for the neural mechanisms in the SFO that generate appropriate water- and salt-intake behaviors based on body-fluid conditions. 


\section{Abbreviations}

\begin{tabular}{|c|c|}
\hline AAV & adeno-associated virus \\
\hline aca & anterior commissure, anterior \\
\hline AcbC & core region of the accumbens nucleus \\
\hline AcbSh & shell region of the accumbens nucleus \\
\hline$\alpha-\mathrm{CHCA}$ & $\alpha$-cyano-4-hydroxycinnamic acid \\
\hline Ang II & angiotensin II \\
\hline AP & area postrema \\
\hline ArchT & archearhodopsin 3 \\
\hline AT1a & angiotensin II receptor type 1a \\
\hline AT1b & angiotensin II receptor type $1 b$ \\
\hline AT2 & angiotensin II receptor type 2 \\
\hline CCK & cholecystokinin \\
\hline CCKAR & cholecystokinin A receptor \\
\hline CCKBR & cholecystokinin B receptor \\
\hline ChR2 & channelrhodopsin 2 \\
\hline $\mathrm{CPu}$ & caudate putamen \\
\hline $\mathrm{CTb}-555$ & alexa555-conjugated cholera toxin subunit b \\
\hline CSF & cerebrospinal fluid \\
\hline Cre & cre recombinase \\
\hline DIO & double-floxed inverted orientation \\
\hline DMD & dorsal part of the dorsomedial hypothalamic nucleus \\
\hline EDTA & ethylenediaminetetraacetic acid \\
\hline EGFP & enhanced green fluorescent protein \\
\hline GABA & 4-aminobutanoic acid \\
\hline GAD67 & glutamic acid decarboxylase 67 \\
\hline HSD2 & $11 \beta$-hydroxysteroid dehydrogenase \\
\hline HiRet & highly efficient retrograde gene transfer lentivirus \\
\hline IPSC & inhibitory postsynaptic currents \\
\hline $\mathrm{KO}$ & knockout \\
\hline LH & lateral hypothalamic area \\
\hline loxP & locus of crossing-over in phage $\mathrm{P} 1$ \\
\hline LSD & dorsal part of the lateral septal nucleus \\
\hline MSCV & murine stem cell virus \\
\hline h & medial forebrain bundle \\
\hline
\end{tabular}




\begin{tabular}{|c|c|}
\hline $\mathrm{MnPO}$ & median preoptic nucleus \\
\hline MPA & medial preoptic area \\
\hline MPO & medial preoptic nucleus \\
\hline MRI & magnetic resonanse imaging \\
\hline $\mathrm{Na}$ & sodium \\
\hline Na-D & Na-depleted \\
\hline NLS & nuclear localization signal \\
\hline nNOS & neural nitric oxide synthase \\
\hline NTS & nucleus of the solitary tract \\
\hline Opt & optical exposure \\
\hline OVLT & organum vasculosum of the lamina terminalis \\
\hline PBS & phosphate-buffered saline \\
\hline PCR & polymerase chain reaction \\
\hline PET & positron emission tomography \\
\hline PVN & paraventricular nucleus \\
\hline RFP & red fluorescent protein \\
\hline RIA & radioimmunoassay \\
\hline RNA & ribonucleic acid \\
\hline sCVOs & sensory circumventricular organs \\
\hline SFO & subfornical organ \\
\hline SON & supraoptic nucleus \\
\hline $\mathrm{SSC}$ & saline sodium citrate \\
\hline TRITC & Tetramethylrhodamine isothiocyanate \\
\hline vBNST & ventral part of the bed nucleus of the stria terminalis \\
\hline Vgat & vesicular GABA transporter \\
\hline Vglut2 & vesicular glutamate transporter 2 \\
\hline VLPO & ventrolateral preoptic nucleus \\
\hline VTA & ventral tegmental area \\
\hline W-D & water-depleted \\
\hline W/Na-D & water- and Na-depleted \\
\hline WPRE & woodchuck hepatitis virus response element \\
\hline WT & wild-type \\
\hline
\end{tabular}




\section{Chapter I}

\section{General introduction}




\section{Thirst and salt appetite are controlled according to the body-fluid conditions}

Terrestrial animals including humans are generally exposed to the risks of dehydration and salt deficiency. Severe deficits of water and salt in body fluids cause the seeking and ingestion of water and salty substances in order to replenish lost water and salt. Early studies predominantly investigated the water appetite (thirst) on animal behaviors. Dehydrated animals show excessive drinking rapidly (Thracher et al., 1981; McKinley et al., 1983), and this rapid effect also occurs when animals drank hypertonic $\mathrm{NaCl}$ solution (Holmes and Gregersen, 1950). Increases in plasma osmolality reflected by plasma $\mathrm{Na}^{+}$levels $\left(\left[\mathrm{Na}^{+}\right]\right)$cause proportional increases in water intake in animals (Fitzsimons, 1963). In addition, dehydrated mice exhibit an aversion to saline at concentrations over $0.15 \mathrm{M}$, more than the physiological level, because of high $\left[\mathrm{Na}^{+}\right]$in body fluids (Watanabe et al., 2000).

On the other hand, salt appetite is known to be caused by considerable deficits in body salt, including pregnancy, vomiting, sweating, hemorrhage, diarrhea, and long-term maintenance on a Na-deficient diet (Hurley and Johnson, 2015). Salt appetite is satisfied by ingesting $\mathrm{Na}$ but not chloride (Rowland et al., 2004). In experimental conditions, systemic administrations of diuretic agents such as furosemide and of colloids such as polyethylene glycol have been reported to induce salt intake behavior only for several hours (Thunhorst and Johnson, 1994). During the loss of body salt, natriorexigenic hormones and mineralocorticoid hormones are secreted from peripheral tissues, and they stimulate salt-intake behavior and renal reabsorption of $\mathrm{Na}^{+}$(Fitzsmons, 1998).

Impairment of thirst in elderly people causes severe dehydration and increases risk of death (Kenney and Chiu, 2001). In addition, excessive dietary salt intake by 
humans has been strongly implicated in the development of heart, renal and liver failure, as well as salt-sensitive hypertension (Geerling and Loewy, 2008; Gabor and Leenen, 2012).

\section{Sensory circumventricular organs monitor the body-fluid conditions}

$\mathrm{Na}^{+}$is the main cation in body fluids (such as plasma and the cerebrospinal fluid) and the main determinant of osmolality. $\left[\mathrm{Na}^{+}\right]$in body fluids is continuously monitored in the brain to maintain it within the physiological range (Johnson, 2007). The central monitoring of body-fluid conditions is considered to be mediated by sensory circumventricular organs (sCVOs), brain regions that lack a blood-brain barrier, but harbor neuronal cell bodies (McKinley et al., 2003). sCVOs are situated in the walls of third and fourth ventricles and accessed the body fluids through a single layer of ependymal cells. These cells have characteristic structures of permeable capillary networks and facilitate tissue penetration to monitor circulating substances (Johnson and Gross, 1993). sCVOs consist of the subfornical organ (SFO), organum vasculosum of the lamina terminalis (OVLT) and area postrema (AP) (Fig. I.1; McKinley et al., 2003). Multiple neuronal populations reside in the SFO, and some of them are known to have connections with distinct brain regions such as the OVLT, median preoptic nucleus (MnPO), paraventricular nucleus (PVN), supraoptic nucleus (SON), and so on (Johnson, 2007; McKinley et al., 2003).

\section{$\mathrm{Na}_{\mathrm{x}}$ channel modulates salt appetite according to the body-fluid conditions}

The $\mathrm{Na}_{\mathrm{x}}$ channel is an atypical $\mathrm{Na}$ channel with low homology to other voltage-gated sodium channels: It shows significant differences of amino acid sequence in the voltage 
sensors compared with voltage-gated sodium channels (Fig. I.2A; Goldin et al., 2000). $\mathrm{Na}_{\mathrm{x}}$ lacks some positive charges in the $\mathrm{S} 4$ segment, which are important for voltage sensitivity (Fig. I. 2B). By using $S c n 7 a$-knockout (KO) $\left(N a_{x}-\mathrm{KO}\right)$ mice, Prof. Noda's laboratory identified $\mathrm{Na}_{\mathrm{x}}$ channels specifically expressed in the glial cells (ependymal cells and astrocytes) of the SFO and OVLT as a brain $\left[\mathrm{Na}^{+}\right]$sensor that detects $\left[\mathrm{Na}^{+}\right]$ elevations in body fluids within the physiological range (Hiyama et al., 2002; Noda and Hiyama, 2005; Noda, 2006; Watanabe et al., 2006; Noda and Sakuta, 2013; Noda and Hiyama, 2015a; Noda and Hiyama, 2015b). The sensitivity of $\mathrm{Na}_{\mathrm{x}}$ to $\left[\mathrm{Na}^{+}\right]$was revealed to be upregulated by endothelin-3 through activation of endothelin receptor B (Hiyama et al., 2013). Noda and his colleagues subsequently revealed that the SFO is the principal site for sensing $\left[\mathrm{Na}^{+}\right]$in body fluids to generate salt-avoidance behavior in dehydrated animals (Watanabe et al., 2000; Hiyama et al., 2004; Hiyama et al., 2010). Afterward, they found that the activation of $\mathrm{Na}_{\mathrm{x}}$ leads to upregulation of $\mathrm{Na}^{+} / \mathrm{K}^{+}$-ATPase in the glial cells to release lactate, which functions as a gliotransmitter that activates GABAergic inhibitory neurons in the SFO (Shimizu et al., 2007). From these results, I hypothesized that the GABAergic neurons may suppress the activity of putative neurons encoding salt appetite in the SFO (Fig. I. 3).

\section{Angiotensin II stimulates thirst and salt appetite}

Angiotensin II (Ang II) is widely known as an octapeptide that causes vasoconstriction and a subsequent increase in blood pressure (Paul et al., 2006). On the other hand, Ang II has been also known as a powerful stimulus to thirst and salt appetite, because intracranial injections of Ang II have been shown to induce an immediate increase in water intake followed by a slower increase in salt intake (Buggy and Fisher, 1974; 
Fitzsmons, 1998). sCVOs in the brain have been suggested as the major sites for the signal transduction of circulating Ang II to neural signals, because Ang II receptors (Ang II receptor type 1a (AT1a), AT1b and AT2 in rodents; AT1 and AT2 in humans) are strongly expressed in sCVOs (Premer et al., 2013). However, the Ang II-dependent neural mechanisms underlying selective water- and salt-intake behaviors remain unknown. Therefore, I considered that functional characterization of the neurons expressing Ang II receptors in sCVOs may reveal neural mechanisms to generate thirst and salt appetite.

In this thesis, I visualized and characterized AT1a-positive neurons in sCVOs by using ATla $a^{\text {lacZ/+ }}$ mice in which Agtrla encoding AT1a was knocked-out by inserting the lacZ reporter gene in-frame (Sugaya et al., 1995), and demonstrated by using optogenetical and electrophysiological techniques that thirst and salt appetites were controlled by different groups of the AT1a-positive neurons in the SFO. This study explains the neural mechanisms in the SFO that generate appropriate water- and salt-intake behaviors based on body-fluid conditions. 


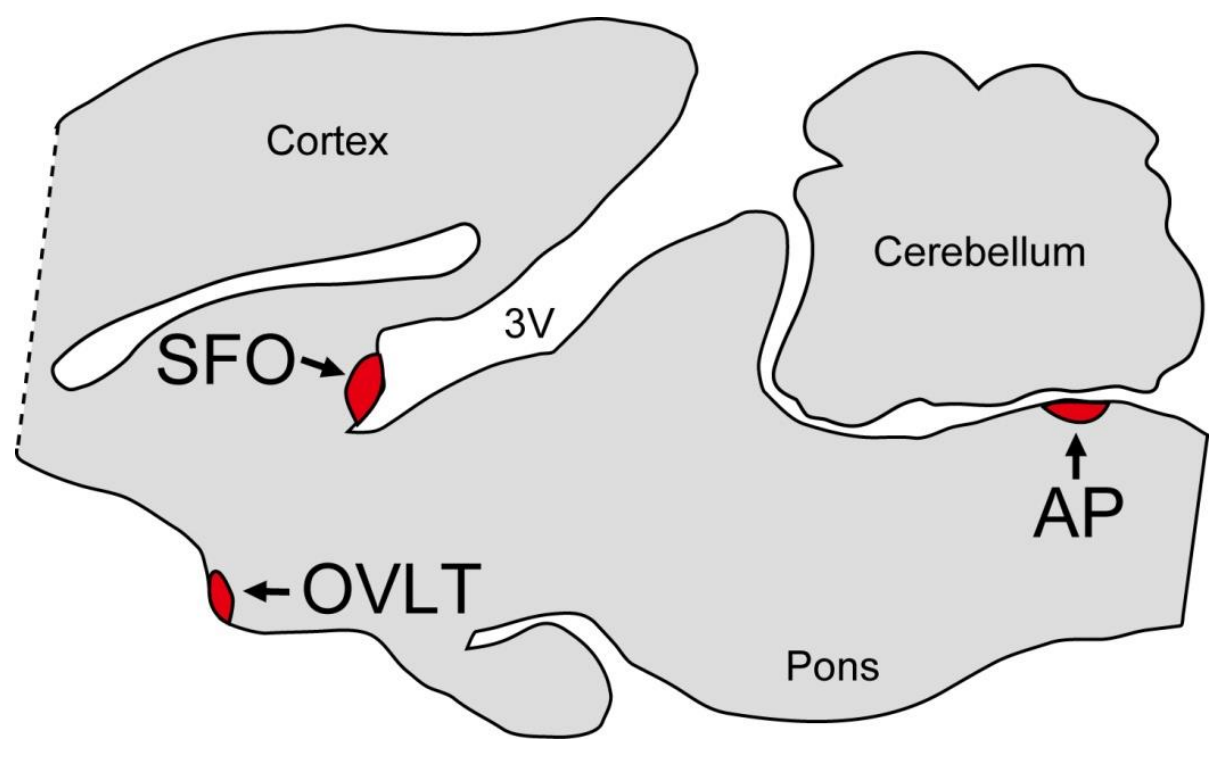

Figure I.1 Sensory circumventricular organs.

A schematic drawing of the sensory cicumventricular organs (sCVOs) in the mid sagittal section of mouse brain. sCVOs consist of the subfornical organ (SFO), organum vasculosum of the lamina terminalis (OVLT), and area postrema (AP). These loci are situated in the wall of third and fourth ventricules. $3 \mathrm{~V}$, third ventricules. Adapted from Noda and Hiyama, Pflugers. Arch. - Eur. J. Physiol. 467, 465-474 (2015). 
A

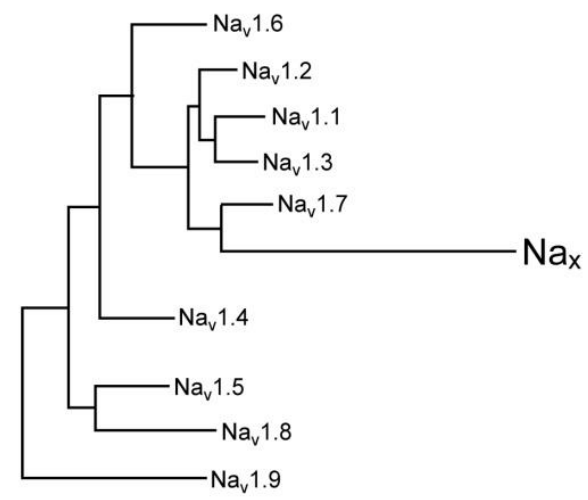

B

\section{Extracellular side}

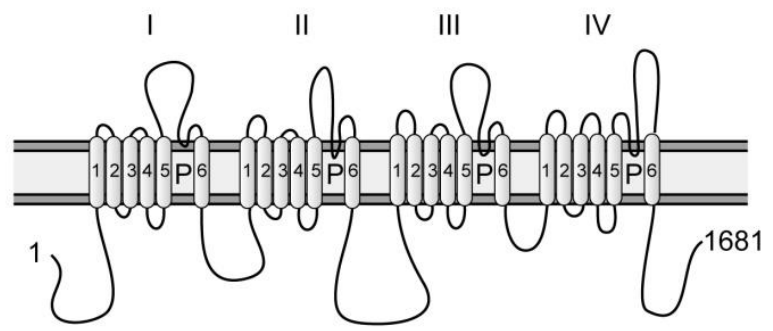

Intracellular side

Figure I.2 $\mathrm{Na}_{\mathrm{x}}$ channel is a member of the sodium channel family.

(A) Phylogenetic tree of mammalian voltage-gated $\mathrm{Na}$ channel $\alpha$-subunits.

(B)

Schematic illustrations of $\mathrm{Na}_{\mathrm{x}}$ channel. The numbers represent amino acid residues. 1-6, putative transmembrane segment (S1-S6) in each repeat (I-IV); $\mathrm{P}$, putative pore-forming regions. Adapted from Goldin et al., Neuron 28, 365-368 (2000) (A), and Shimizu et al., Neuron 54, 59-72 (2007) (B). 


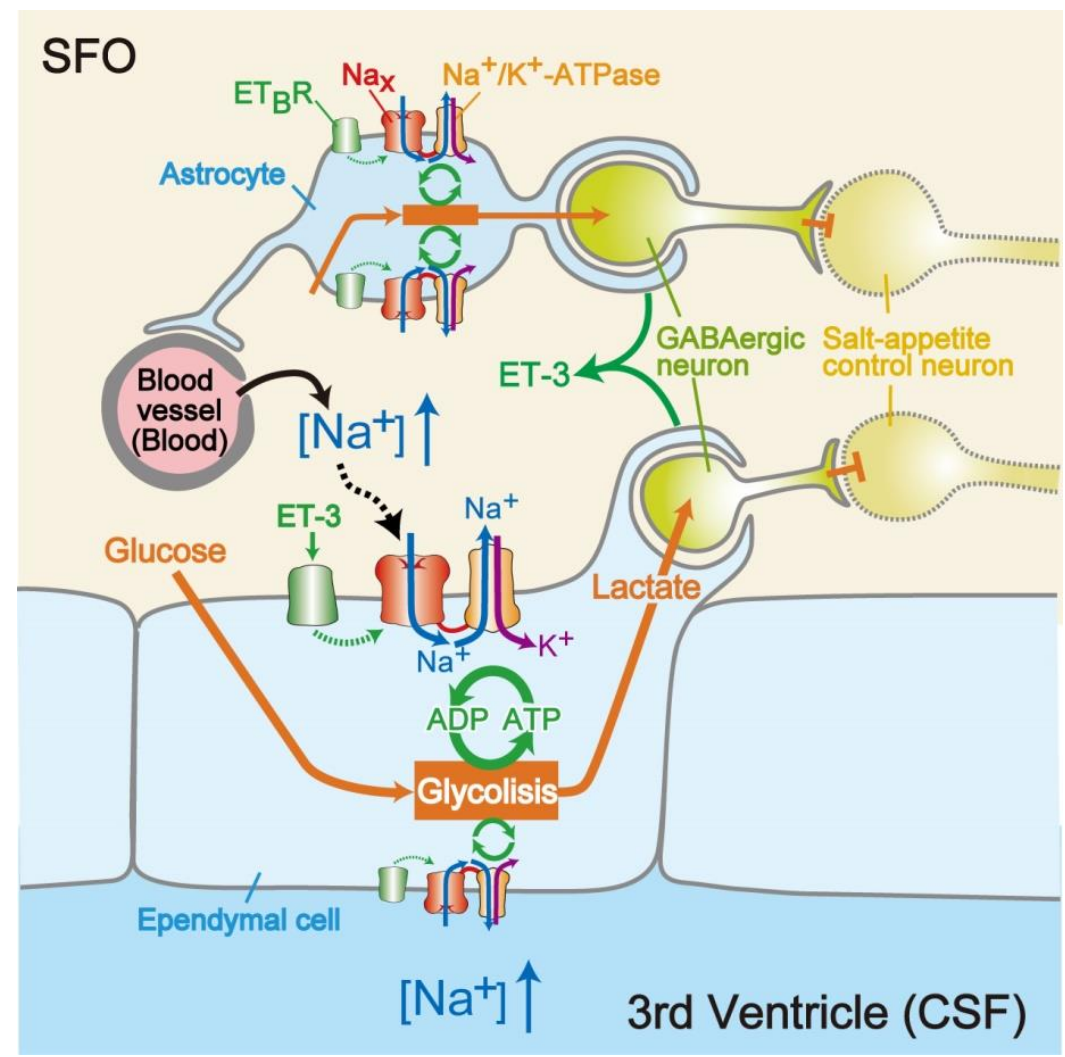

\section{Figure I.3 Overview of the $\mathrm{Na}^{+}$-sensing mechanism.}

A schematic drawing of $\mathrm{Na}^{+}$-sensing mechanism and $\mathrm{Na}_{\mathrm{x}}$-dependent regulation of neuronal activities of the salt-appetite control neurons in the SFO. ET-3, endothelin-3; ET $_{\mathrm{B}} \mathrm{R}$, endothelin receptor B. Adapted from Noda and Hiyama, Pflugers. Arch. - Eur. J. Physiol. 467, 465-474 (2015). 


\section{Chapter II}

\section{Roles of AT1a signals in thirst and salt-appetite generation}




\section{II.1 Introduction}

Ang II, an octapeptide hormone, is generated from the precursor molecule, angiotensinogen which is produced in the liver (McKinley and Johnson, 2004). When the renal blood flow is reduced, prorenin in the juxtaglomerular cells in the kidneys is converted to renin, and secreted into the circulation (Sealey et al., 1986). Renin cleaves angiotensinogen and produces Ang I. Subsequently, Ang I is further cleaved to form Ang II by angiotensin converting enzyme (Fitzsimons, 1998). Two receptor subtypes for Ang II, subtype 1 (AT1) and subtype 2 (AT2), have been identified in mammals (Timmermans et al., 1992). Rodents possess two AT1 receptor isoforms, named AT1a and AT1b (Sasamura et al., 1992). A previous study using transgenic mice with overexpression of AT1a in the brain revealed the importance of AT1a for the control of thirst and salt appetite (Lazartigues et al., 2008). However, effects of knockout of the Agtrla gene encoding AT1a on drinking behaviors have not been reported so far.

Intracranial injection of Ang II stimulates the neural activity of sCVOs and induces water and salt intake (Buggy and Fisher 1974; Avrith and Fitzsimons 1980; Rowland et al., 1996; Sunn et al., 2003). Previous studies reported that some neurons in the sCVOs, where AT1a is abundantly expressed, are activated by systemic Na depletion (Fitzsimons, 1998) and that the neural activities in Na-depleted animals are supressed by intracerebroventricular injection of AT1a antagonists along with the reduction of salt-intake behaviors (Geerling and Loewy, 2008). In the sCVOs, there also exists neurons activated by water depletion (Fitzsimons, 1998), and electrolytic lesions of the sCVOs reduced dipsogenic effects of Ang II (Simpson and Routtenberg, 1975; Lind and 
Johnson, 1983). These results indicate that the sCVOs are involved in drinking behaviors. However, it has not been elucidated what sCVOs are involved in thirst and/or salt appetite. Moreover, it is not known whether AT1a-positive neurons in the sCVOs are directly involved in the generations of thirst and salt appetite.

In the first chapter, in order to reveal functional differences among the sCVOs, I established water- and/or Na-depleted conditions in mice and examined their waterand/or salt-intake behaviors. Agtrla-KO (ATla-KO, ATla $a^{\text {lacZlacZ }) ~ m i c e ~(S u g a y a ~ e t ~ a l ., ~}$ 1995) and loxP-flanked Agtrla (ATla $a^{\text {floxflox }}$ ) mice (Matsusaka et al., 2010) were used to know the effects of global or site-specific deletion of AT1a on the water- and/or salt-intake behaviors. I used the ATl $a^{1 a c Z /+}$ mouse, in which Agtrla locus was replaced with the lacZ gene, to visualize AT1a-positive cells in the sCVOs. 


\section{II.2 Materials and Methods}

\section{Experimental animals}

All experimental protocols with animals were performed according to the guidelines of the National Institutes of Natural Sciences, Japan (approval numbers 12A051, 13A082, 14A149, 15A164, and 16A025). Adult male mice (>8 weeks old) were used in the present study. Wild-type (C57BL/6J, CLEA Japan), Agtrla-lacZ (ATla lacZ/+ and AT1a $a^{\text {lacZlacZ }}$ (Sugaya et al., 1995), loxP-flanked Agtrla (AT1a $\left.a^{\text {loxP/loxP }}\right)$ (Matsusaka et al., 2010) mice were used. Mice were housed under a constant room temperature $\left(23^{\circ} \mathrm{C}\right)$ on am 8:00-to-20:00 light cycle with water and mouse chow available ad libitum (Rodent Diet CA-1, CLEA Japan) unless otherwise noted. All the behavioral experiments were performed during the light period after mice had been housed individually at least $3 \mathrm{~d}$. All animals had no special previous history before the surgeries or behavioral analyses.

\section{Reagents}

Furosemide (F4381, Sigma-Aldrich) and losartan (120-06111, Wako Pure Chemical Industries) were used.

\section{Quantification of blood $\mathrm{Na}^{+}$and plasma Ang II concentrations}

Mice were killed by decapitation and blood samples were collected. Blood $\mathrm{Na}^{+}$levels were measured with a blood analyzer (i-STAT, Fuso Pharmaceutical Industries), as previously described (Hiyama et al., 2010). Plasma Ang II levels were determined as previously described (Hiyama et al., 2013), with minor modifications. Briefly, blood samples were collected from unrestrained mice in polypropylene tubes with $0.1 \%$ 
EDTA. Blood plasma was obtained by centrifugation. Ang II was extracted from the plasma with acetone and diethyl ether. This sample was dried in a vacuum chamber, and then dissolved in RIA buffer supplied with the radioimmunoassay (RIA) kit (Peninsula Laboratories, San Carlos, CA). Measurements were performed according to the instructions provided for the kit.

\section{Immunohistochemistry}

Mice were perfused transcardially with phosphate-buffered saline (PBS) followed by fixation with $20 \%$ formalin neutral buffer solution. Coronal sections of the brain were cut at a thickness of $50 \mu \mathrm{m}$ with a vibratome (VT-1000S, Leica) or cryostat (CM 3050S, Leica). After blocking with blocking buffer containing 5\% normal donkey serum and $0.1 \%$ Triton $\mathrm{X}-100$ in PBS at room temperature for $1 \mathrm{~h}$, brain sections were incubated with primary antibodies at $4^{\circ} \mathrm{C}$ for $2 \mathrm{~d}$ and then washed twice in PBS. Sections were reacted with secondary antibodies at $4^{\circ} \mathrm{C}$ for $1 \mathrm{~d}$. The primary antibodies used in this chapter were as follows: rabbit anti- $\beta$-gal (1:1,000, 55976, Cappel), goat anti-Fos (1:500, sc-52G, Santa Cruz Biotechnology), and mouse anti-Cre recombinase (1:1,000, MAB3120, Millipore). Brain sections were mounted on slides, and z-stack and tiled images were captured on a Zeiss LSM 710 confocal microscope, Nikon A1Rs confocal microscope, or Zeiss AXIO fluorescence microscope using a 10× or 20× objective.

\section{Recombinant Viral Vectors}

AAV (with serotype 5 or DJ, Cell Biolabs) $\left(>1.0 \times 10^{10}\right.$ Genomic Copies $/ \mathrm{mL}$ ) was used for gene transfer in vivo. AAV5-CAGGS-NLS-Cre was used for the expression of 
Cre recombinase. CAGGS, cytomegalovirus (CMV) early enhancer element and chicken $\beta$-actin promoter; $N L S$, nuclear localization signal.

\section{Surgery}

Mice were anesthetized with sodium pentobarbital $(50 \mathrm{mg} / \mathrm{kg}$ body weight, i.p. injection) and placed in a stereotactic frame (Narishige). After exposing the skull via a small incision, a small hole was drilled for injections or infusions. An intracerebroventricular infusion with an osmotic pump was performed as described previously (Hiyama et al., 2013). Briefly, mice were implanted with 30-gauge stainless steel cannulas (330OP, Plastics One) stereotaxically aimed at the lateral ventricle (anteroposterior, $-0.2 \mathrm{~mm}$; lateral, $+1.0 \mathrm{~mm}$; ventral, $+2.5 \mathrm{~mm}$; relative to the bregma). A subcutaneous pocket was then prepared on the back of the mouse, and the osmotic pump was placed into the pocket. The external part of the cannula was fixed to the skull with dental cement, and the wound was sutured. Animals were allowed to recuperate for $3 \mathrm{~d}$ before behavioral testing. Osmotic minipumps (1002, ALZET) were used to continuously deliver losartan $(40 \mathrm{mg} / \mathrm{mL})$ or vehicle solutions at a rate of 0.25 $\mu \mathrm{L} / \mathrm{h}$; vehicle was modified Ringer solution containing (in $\mathrm{mM}$ ): $140 \mathrm{NaCl}, 2.5 \mathrm{KCl}, 2$ $\mathrm{CaCl}_{2}, 1 \mathrm{MgCl}_{2}, 10 \mathrm{HEPES}, 10$ glucose and $5 \mathrm{NaOH}(\mathrm{pH} 7.3$ with $\mathrm{HCl})$.

Viral injections were performed as described previously, with minor modifications (Hiyama et al., 2004). Briefly, a pulled-glass pipette with a tip diameter of 20-40 $\mu \mathrm{m}$ was inserted into the brain, and virus was injected with a microsyringe pump (Ultra Micro Pump III, World Precision Instruments; AAV, $0.1 \mu \mathrm{L} / \mathrm{min}$ for $5 \mathrm{~min}$ ). The coordinates for the viral injection relative to the bregma were as follows: the SFO (anteroposterior, $-0.6 \mathrm{~mm}$; lateral, $\pm 0.0 \mathrm{~mm}$; ventral, $+2.5 \mathrm{~mm}$ ), and OVLT 
(anteroposterior, $+0.7 \mathrm{~mm}$; lateral, $\pm 0.0 \mathrm{~mm}$; ventral, $+5.0 \mathrm{~mm}$ ). After the glass micropipette was withdrawn, the skin incision was sutured, and animals were allowed to recover.

Behavioral experiments were performed more than 4 week after the virus injection. All stereotaxic injection sites were verified by immunohistochemistry after behavioral tests. When the virus infection to the target site turned out to be unsuccessful, behavioral data obtained from such individuals were excluded from the analyses.

\section{Behavioral Assays}

The amounts of fluid intake were automatically monitored by measurements were performed using a previously described system (Hiyama et al., 2004). Mice were acclimated to the spouts providing distilled water and salt solutions for more than $3 \mathrm{~d}$ before the tests. Two-bottle test was conducted in absence of food in the $2 \mathrm{~h}$ at the beginning of the dark period.

To generate the water- and Na-depleted condition, mice received subcutaneous injections of furosemide (a loop diuretic; $10 \mathrm{mg} / 25 \mathrm{~g}$ body weight) and were housed without food or water for $3 \mathrm{~h}$. Mice were then housed with free access to the Na-deficient diet (CLEA Diet No. 010, Clea Japan) and distilled water for $24 \mathrm{~h}$ to generate the Na-depleted condition: Water intake during the first $6 \mathrm{~h}$ was measured. Mice were housed with free access to the normal diet without water for $48 \mathrm{~h}$ to generate the water-depleted condition. 


\section{Statistical analysis}

Sample sizes were determined by power calculations using G*Power3.1 (Department of Experimental Psychology, Heinrich-Heine-University, Düsseldorf, Germany) to allow for robust statistical analyses of the data. For each analysis, sample size was determined using a Power $>0.8$ and alpha error $=0.05$. Values are means \pm s.e.m. Statistical analyses were performed by two-sided Mann-Whitney tests or Pearson correlation analysis, using Kyplot (Kyence). Data distribution was assumed to be normal, but this was not formally tested.

\section{Data collection and analysis.}

Testing groups for behavioral cohorts were balanced by age and genotype, and randomization of experimental groups was not performed. Intake volumes were monitored automatically and analyses were not performed blind to the conditions of the experiments. 


\section{II.3 Results}

\section{Roles of AT1a signals in thirst and salt-appetite generation}

I established water- and/or Na-depleted conditions in mice by dehydration, furosemide treatment, or a combination of furosemide treatment with water satiation, respectively. Firstly, in order to produce the water- and Na-depleted condition, WT mice were subcutaneously injected with furosemide, and then, they were depleted of water and $\mathrm{Na}$ in $3 \mathrm{~h}$ (Fig. II.1A). This treatment decreased blood $\left[\mathrm{Na}^{+}\right]$by $\sim 5 \mathrm{mM}$, and increased Ang II levels $\sim 3$ fold after $3 \mathrm{~h}$ (Fig. II.1A). Secondly, to produce the Na-depleted condition without thirst, mice were allowed free access to water and the Na-deficient diet for $24 \mathrm{~h}$ after the furosemide injection (Fig. II.1B); during this period, intensive water intake for first $6 \mathrm{~h}$, along with subsequent reduction afterward, were observed. After $24 \mathrm{~h}$, blood $\left[\mathrm{Na}^{+}\right]$decreased below normal levels, whereas Ang II levels remained high (Fig. II.1B). Thirdly, to produce the water-depleted condition, WT mice were dehydrated for 2 days; blood $\left[\mathrm{Na}^{+}\right]$increased by $\sim 15 \mathrm{mM}$ and plasma Ang II levels increased $\sim 4$ fold (Fig. II.1C). Notably, the Ang II levels in blood increased to similar levels in all of the three conditions.

I then examined thirst and salt appetite responses of the mice under these conditions; mice were subjected to a two-bottle test in which they were offered water and $0.3 \mathrm{M}$ $\mathrm{NaCl}$ in the absence of food (Fig. II.2). Firstly, the water- and Na-depleted mice consumed abundant volumes of water together with $0.3 \mathrm{M} \mathrm{NaCl}$ in $2 \mathrm{~h}$ (Fig. II.2A). Under the same condition, water intake by $A T l a-\mathrm{KO}$ mice was significantly less than, but still approximately half of, that by WT mice, indicating that water intake is at least in part AT1a-dependent (Fig. II.2A). In contrast, salt intake by ATla-KO mice was almost negligible, indicating the critical role of AT1a signaling by Ang II in the 
generation of salt-intake behavior under the water- and Na-depleted condition (Fig. II.2A). Secondly, under the Na-depleted condition, the induction of salt intake, but not water intake, was selectively observed in WT, whereas neither was induced in ATIa-KO mice (Fig. II.2B). This indicates again that salt intake is AT1a-dependent. Thirdly, under the water-depleted condition, WT mice consumed abundant volumes of water together with less amount of $0.3 \mathrm{M} \mathrm{NaCl}$ (Fig. II.2C): Salt intake was evidently less than water intake, reflecting "salt avoidance", due to high $\left[\mathrm{Na}^{+}\right]$in body fluids by dehydration. Under the same conditions, ATla-KO mice consumed abundant volumes of water to the same level as WT mice, whereas the intake of $0.3 \mathrm{M} \mathrm{NaCl}$ was negligible, as was observed under the water- and Na-depleted, and Na-depleted conditions (Fig. II.2). These data suggest that salt intake is completely and water intake is partly AT1a-dependent.

\section{Roles of AT1a neurons in the SFO and OVLT in thirst and salt appetite}

I next explored the brain nuclei that are responsible for the generation of thirst and salt appetite mediated by the AT1a signaling. First, I examined the distribution of AT1a-positive neurons in the brain by immunostaining $\beta$-galactosidase in the ATla $a^{\text {lacZ/+ }}$ mice. They were distributed in several brain nuclei, including the three sCVOs (Fig. II.3). The AT1a-positive neurons were successfully visualized together with their neurites by the immunohistochemistry.

The expression of Fos, a marker for neuronal activity, was almost negligible in AT1a-positive neurons in the $A T 1 a^{l a c Z /+}$ mice under the normal water/salt-satiated condition (Fig. II.4A and II.5). Under the Na-depleted condition, in contrast, the number of Fos-positive neurons was significantly increased in the SFO and OVLT but 
not in AP or PVN, and they were largely AT1a positive: SFO, $81.6 \pm 2.9 \%$ AT1a-positive; OVLT, $65.1 \pm 3.9 \%$ AT1a-positive (Fig. II.4A and Fig. II.5). Notably, Fos expression was not observed in these two loci in ATla-KO mice under the same conditions (Fig. II.4B). Continuous intracerebroventricular infusion of losartan, an AT1 blocker, consistently caused a loss of Fos expression in the SFO and OVLT (Fig. II.6A), and abolished salt intake under the Na-depleted condition (Fig. II.6B).

Under the water-depleted condition, the number of Fos-positive neurons in the $A T 1 a^{\text {lacZ/+ }}$ mice was further increased in the SFO and OVLT (Fig. II.4A) compared to what I observed under the Na-depleted condition, and the fractions of $\beta$-galactosidase-positive (namely, AT1a-positive) neurons in Fos-positive neurons were $49.7 \pm 4.0 \%$ in the SFO and $32.7 \pm 2.8 \%$ in the OVLT. Notably, in ATla-KO mice under the same condition, a number of Fos-positive neurons were also observed in the SFO and OVLT (Fig. II.4B), but the fractions of AT1a-positive neurons were $27.4 \pm$ $3.3 \%$ in the SFO and $19.6 \pm 1.0 \%$ in the OVLT. This finding supports my observation that ATla-KO mice indeed drank water after dehydration (Fig. II.2C). The difference in the neuronal activity between $A T 1 a^{l a c Z /+}$ and $A T l a-\mathrm{KO}$ mice may therefore be attributable to the presence or absence of AT1a expression.

To achieve the site-specific deletion of the Agtrla in the SFO or OVLT, an adeno-associated virus (AAV) carrying the gene encoding Cre-recombinase with a nuclear localization signal (NLS) (AAV-Cre) was injected into the respective brain nuclei of $A T 1 a^{\text {loxP/loxP }}$ mice (Fig. II.7A, D, and II.8): $A T 1 a^{\text {loxP/loxP }}$ mice (normal for AT1a expression) showed normal salt and water intakes under the Na-depleted condition (data not shown). The local deletion of the Agtrla in the SFO and OVLT resulted in significant reductions in water intake after the furosemide injection (Fig. II.7B and E): 
Here, WT mice injected with the same virus were used as the control mice to estimate the effects of the AAV-Cre injection itself.

When Agtrla was deleted from the SFO $\left[A T 1 a^{\operatorname{lox} P / l o x P}-C r e(\mathrm{SFO})\right]$, I observed marked reductions in water and $0.3 \mathrm{M} \mathrm{NaCl}$ intake were observed in the two-bottle test (Fig. II.7C). A linear correlation was observed between reductions in $0.3 \mathrm{M} \mathrm{NaCl}$ intake and the number of Cre-positive cells in the SFO (Fig. II.7C); notably, in the most effective case, salt intake disappeared. In contrast, when Agtrla was deleted from the OVLT $\left[A T 1 a^{\text {loxP/loxP }}-\right.$ Cre (OVLT)], no effects were observed on $0.3 \mathrm{M} \mathrm{NaCl}$ intake (Fig. II.7F). These results indicate that the AT1a signals in the SFO are involved in both water and salt intake, whereas those in the OVLT are involved only in water intake. 


\section{II.4 Discussion}

In this chapter, I established the three different body-fluid conditions followed by increases in plasma Ang II levels. The two-bottle tests of mice and Fos expression in the sCVOs under these conditions revealed that salt intake is completely and water intake is partially dependent on AT1a signals. Moreover, the local deletion of Agtrla in the SFO and OVLT demonstrated that the AT1a signals in the SFO are involved in both thirst and salt appetite, whereas those in the OVLT are involved only in thirst.

Increases in plasma renin activity and Ang II in body fluids are caused by a deficiency in water and/or $\mathrm{Na}$ in the body (i.e. dehydration, hypovolemia, or hyponatremia) (Fitzsimons, 1998). The SFO has been reported to sense circulating Ang II to elicit water-drinking and salt-intake behaviors (Simpson and Routtenberg, 1973). The OVLT also has been reported to be involved in water-drinking behavior (McKinley and Johnson, 2004). An intravenous infusion of Ang II induces the expression of Fos in the SFO and OVLT neurons (McKinley, 1992), and AT1a was consistently expressed in the neurons of the SFO and OVLT (Fig. II.3). In this study, ATla-KO mice showed reduction of salt and water intake induced by furosemide treatment (Fig. II.2A and B). Moreover, the Fos expression under the water-depleted and Na-depleted conditions were decreased in AT1a-positive neurons in the SFO and OVLT of ATla-KO mice (Fig. II.4). These results demonstrate that AT1a signals in these nuclei are involved in thirst and salt appetite. Consistently, a lesion in the SFO caused decreases in Ang II-induced water drinking and salt intake in rat (Simpson and Routtenberg, 1975), and a lesion in the OVLT also attenuated osmotically-induced water drinking in dog (Thrasher et al., 1982). 
AT1a neurons in the SFO play important roles in the water intake induced by furosemide treatment, because the deletions of the Agtrla in the whole body (Fig. II.2A) and locally in the SFO (Fig. II.7B) both reduced water intake by half. It is possible to consider that the remaining half of the water intake is mediated by AT2 neurons, because $A T 2-\mathrm{KO}$ mice showed a reduction in water intake induced by central injection of Ang II (Li et al., 2003). In contrast, the water intake by dehydration was not reduced in ATla-KO mice at all (Fig. II.2C). In the water-depleted condition, $A T 1 a^{\text {lacZ/+ }}$ and AT1 $a^{\text {lacZ/lacZ }}$ mice showed similar levels of Fos expression in the SFO and OVLT; however, the fraction of originally AT1a-positive neurons in the Fos-positive neurons in ATla-KO mice was less than half of that in ATla lacZ/+ mice (Fig. II.4). These results may indicate that AT2-receptor dependent mechanism compensates the lack of the Agtrla in ATla-KO mice by unknown mechanisms, and the same level of water intake was observed as in WT mice under the dehydrated condition (Fig. II.2C).

Besides the SFO, the OVLT has been reported to monitor the levels of $\mathrm{Na}^{+} /$osmolality and dipsogenic hormones in body fluids to evoke water-intake behaviors (Johnson, 2007). Consistently, deletions of the Agtrla in the OVLT markedly reduced the furosemide-induced water intake (Fig. II.7E). In addition, prof. Noda's laboratory recently found that $\mathrm{Na}_{\mathrm{x}}$ signals were also involved in the immediate induction of water intake evoked by an intracerebroventricular administration of a hypertonic $\mathrm{NaCl}$ solution (Sakuta et al., 2016); Here, $\mathrm{Na}_{\mathrm{x}}$ in the OVLT appears to mediate this function (unpublished observation in prof. Noda's laboratory). Moreover, activation of OVLT neurons expressing vasopressin receptor 1a is reported to be involved in water intake to prevent anticipatory thirst during sleep period (Gizowski et al., 2016). These results 
may imply that the OVLT have a functional role to regulate drinking behavior independently of the SFO.

In the present study, the genetic deletion of the Agtrla in the SFO reduced water intake and abolished salt intake induced by the furosemide treatment (Fig. II.7A-C), indicating that the SFO is not a relay point but the principal site for sensing Ang II in blood. In line with this view, a research group recently reported that activation of excitatory neurons in the SFO induced both water and salt intake (Nation et al., 2016). 
A Water- and Na-depleted condition (W/Na-D)
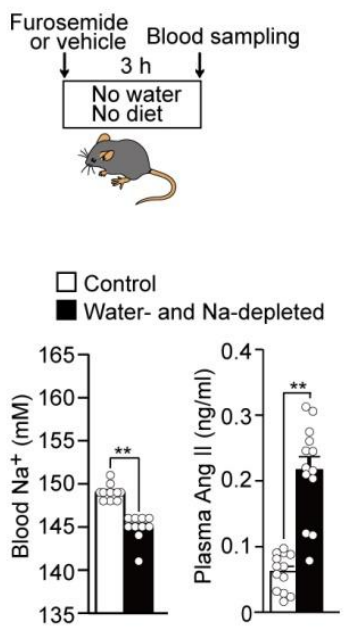

B
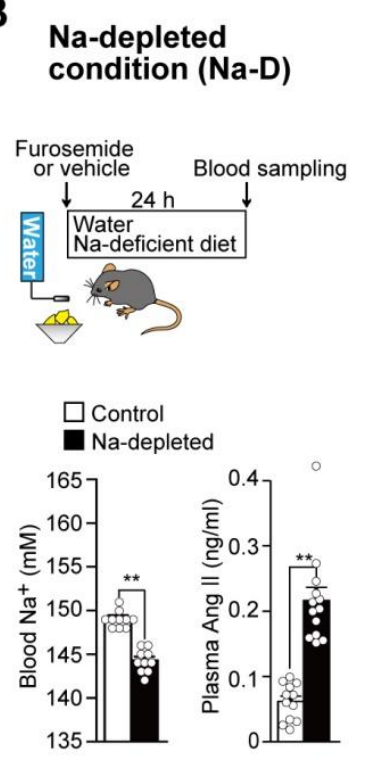

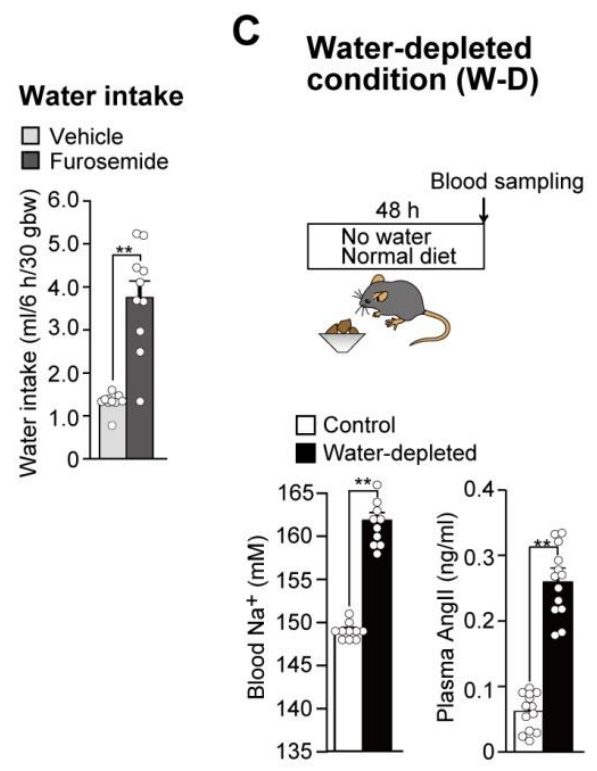

Figure II.1 Blood $\mathrm{Na}^{+}$and plasma Ang II concentrations in WT mice under the water- and/or Na-depleted conditions.

(A) Experimental protocol to induce the water- and Na-depleted condition (W/Na-D). Blood $\mathrm{Na}^{+}$and plasma Ang II concentrations in WT mice under the W/Na-D (left: $n=$ 10 mice each; $U_{(\mathrm{Na})}=100, P=0.0001$; right: $n=13$ mice each; $\left.U_{(\text {Ang II })}=5, P<0.0001\right)$. (B) Experimental protocol to induce the Na-depleted condition (Na-D). Top: water intake during the first $6 \mathrm{~h}$ after furosemide injection $(n=10$ mice each; $U=5.5, P=$ 0.0009). Bottom: blood $\mathrm{Na}^{+}$and plasma Ang II concentrations in WT mice under the Na-D (left: $n=10$ mice each; $U_{(\mathrm{Na})}=100, P=0.0001$; right: $n=13$ mice each; $U_{(\text {Ang II) }}$ $=0, P<0.0001)$. (C) Experimental protocol to induce the water-depleted condition (W-D). Blood $\mathrm{Na}^{+}$and plasma Ang II concentrations in WT mice under the W-D (left: $n$ $=10$ mice each; $U_{(\mathrm{Na})}=0, P=0.0002$; right: $n=13$ mice each; $\left.U_{(\text {Ang II })}=0, P<0.0001\right)$. bw, body weight; $* * P<0.01$; Mann-Whitney $U$-tests. Data show mean \pm s.e.m. 


\section{A Water- and Na-depleted condition (W/Na-D) $_{\text {W }}$}

Two-bottle test
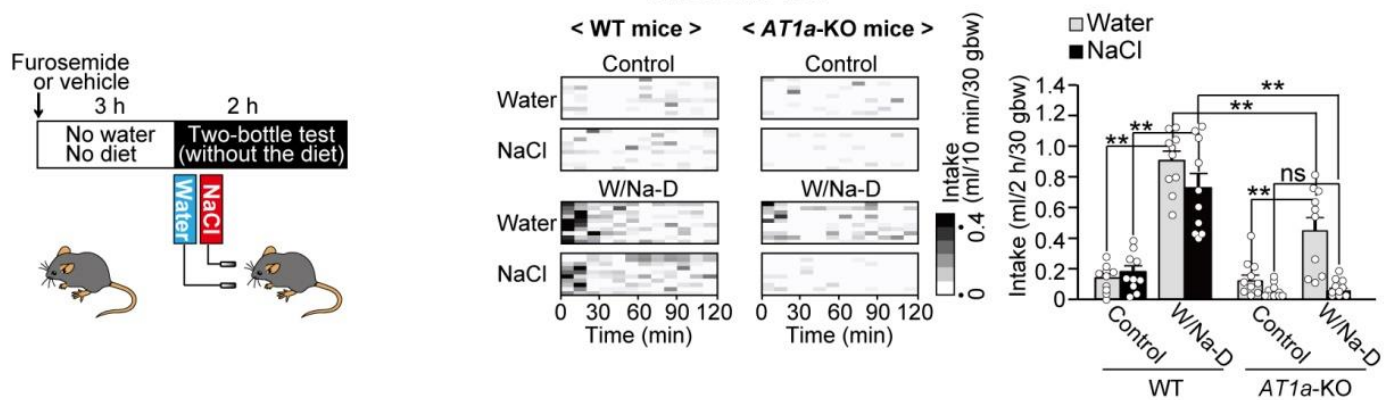

B Na-depleted condition (Na-D)
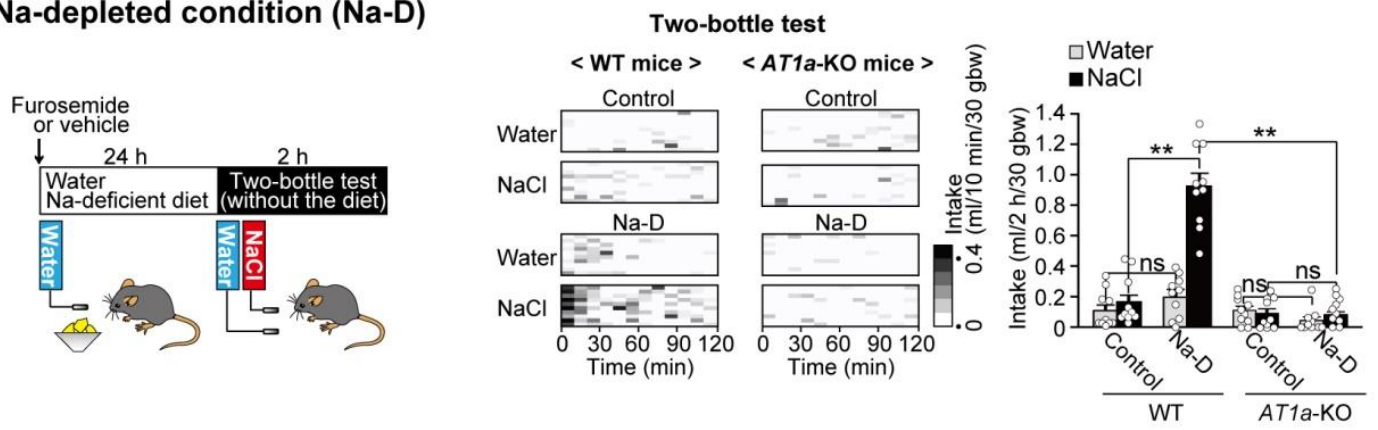

C Water-depleted condition (W-D)

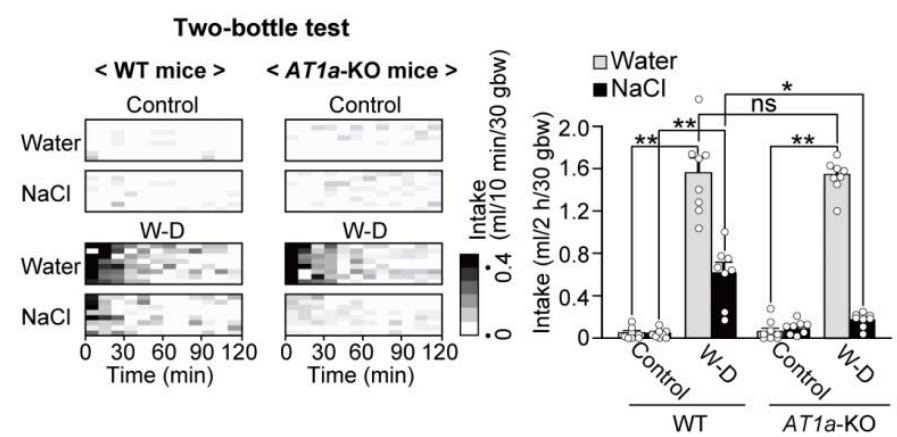

Figure II.2 Water- and salt-intake behaviors of mice under the water- and/or Na-depleted conditions.

(A) Left: experimental protocol to induce the W/Na-D and subsequent two-bottle test. Middle and right: grayscale heat maps and summary of water and $0.3 \mathrm{M} \mathrm{NaCl}$ intakes by WT $\left(n=10\right.$ mice each; $\left.U_{(\text {Water })}=0, P=0.0001 ; U_{(\mathrm{NaCl})}=0, P=0.0001\right)$ and ATla $-\mathrm{KO}\left(n=10\right.$ mice each; $\left.U_{(\text {Water })}=87, P=0.0058 ; U_{(\mathrm{NaCl})}=63.5, P=0.3099\right)$ mice under the W/Na-D (WT vs. $A T 1 a-\mathrm{KO}, U_{(\text {Water })}=91, P=0.0022 ; U_{(\mathrm{NaCl})}=100, P=$ 0.0001). (B) Left: experimental protocol to induce the Na-D condition and subsequent 
two-bottle test. Middle and right: grayscale heat maps and summary of water and $0.3 \mathrm{M}$ $\mathrm{NaCl}$ intakes by WT $\left(n=10\right.$ mice each; $U_{(\text {Water })}=30.5, P=0.1508 ; U_{(\mathrm{NaCl})}=0, P=$ $0.0002)$ and $A T 1 a-\mathrm{KO}\left(n=10\right.$ mice each; $U_{(\text {Water })}=26, P=0.0695 ; U_{(\mathrm{NaCl})}=49, P=$ 0.9696) mice under the Na-D (WT vs. ATla-KO, $U=100, P=0.0001$ ). (C) Left: experimental protocol to induce the W-D and subsequent two-bottle test. Middle and right: grayscale heat maps and summary of water and $0.3 \mathrm{M} \mathrm{NaCl}$ intake by $\mathrm{WT}(n=8$ mice each; $\left.U_{(\text {Water })}=0, P=0.0009 ; U_{(\mathrm{NaCl})}=0, P=0.0009\right)$ and ATla-KO $(n=8$ mice each; $\left.U_{(\text {Water })}=0, P=0.0009 ; U_{(\mathrm{NaCl})}=14, P=0.0661\right)$ mice under the W-D (WT vs. ATla $\left.-\mathrm{KO}, U_{(\text {Water })}=33, P=0.9581 ; U_{(\mathrm{NaCl})}=57, P=0.0100\right)$. bw, body weight; ns, not significant; $* P<0.05$; $* * P<0.01$; Mann-Whitney $U$-tests. Data show mean \pm s.e.m. 

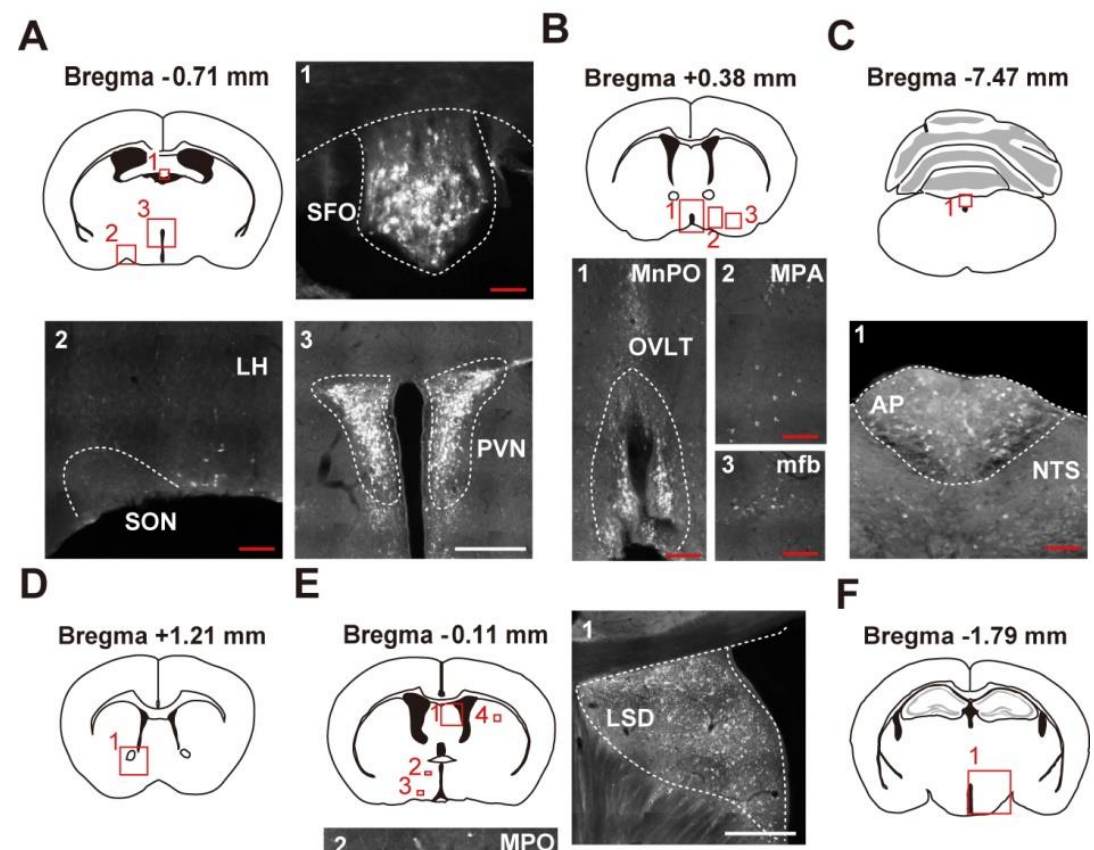

$\mathbf{F}$
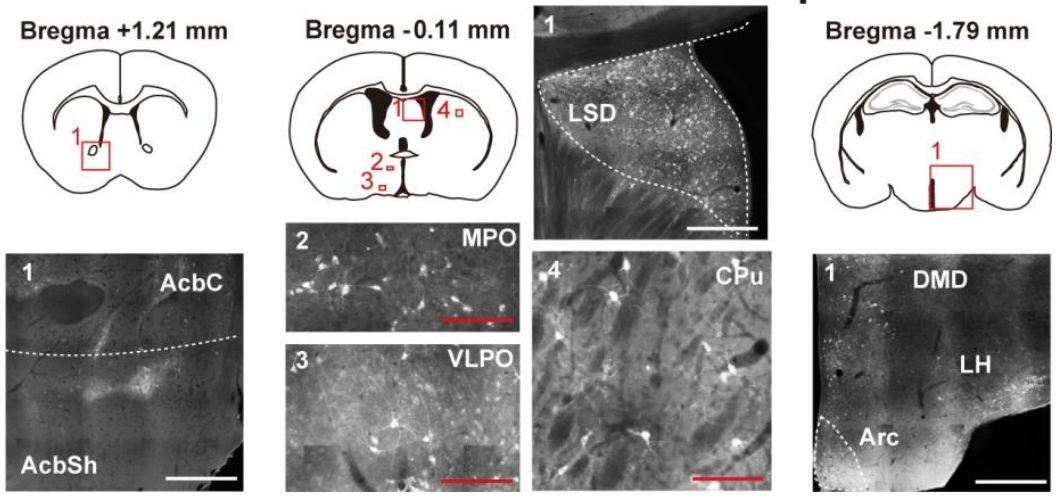

\section{Figure II.3 Visualization of AT1a-positive cells using the $A T 1 a^{\text {lacZ/+ }}$ mouse.}

(A-F) Immunohistochemical detection of $\beta$-gal in the mouse brain. Coronal sections at the respective anteroposterior positions from the bregma, $-0.71(\mathbf{A}),+0.38(\mathbf{B}),-7.47$ $(\mathbf{C}),+1.21(\mathbf{D}),-0.11(\mathbf{E})$, and $-1.79(\mathbf{F}) \mathrm{mm}$ of AT1a ${ }^{\text {lacZ/+ }}$ mice. AcbC, core region of the accumbens nucleus; AcbSh, shell region of the accumbens nucleus; Arc, arcuate hypothalamic nucleus; $\mathrm{CPu}$, caudate putamen; $\mathrm{DMD}$, dorsal part of the dorsomedial hypothalamic nucleus; LH, lateral hypothalamic area; LSD, dorsal part of the lateral septal nucleus; mfb, medial forebrain bundle; MnPO, median preoptic nucleus; MPA, medial preoptic area; MPO, medial preoptic nucleus; NTS, nucleus of the solitary tract; PVN, paraventricular nucleus; SON, supraoptic nucleus; VLPO, ventrolateral preoptic nucleus. Scale bars; $50 \mu \mathrm{m}$ (red), $250 \mu \mathrm{m}$ (white). 
A

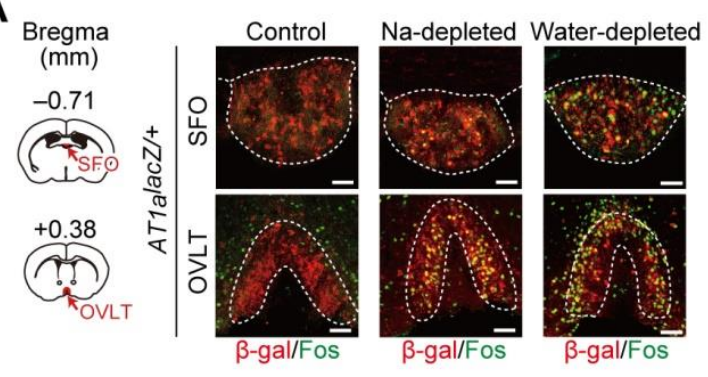

$\square$ Control $\square$ Na-depleted $\square$ Water-depleted

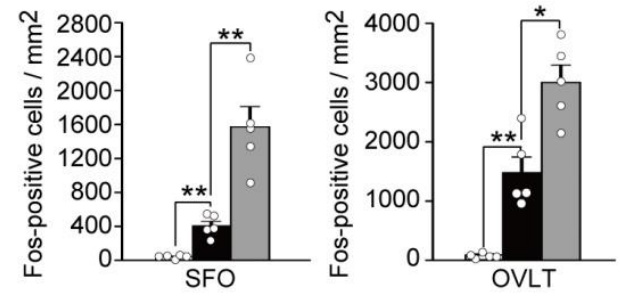

B

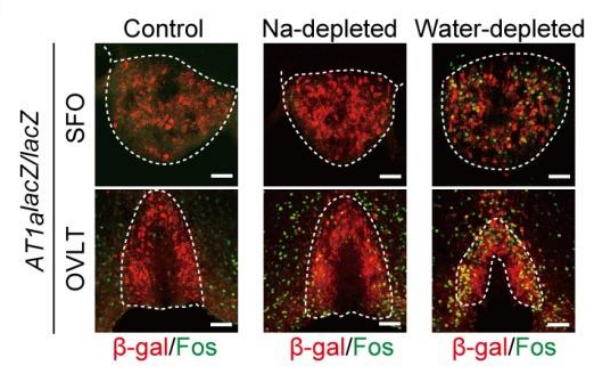

$\square$ Control $\square$ Na-depleted $\square$ Water-depleted

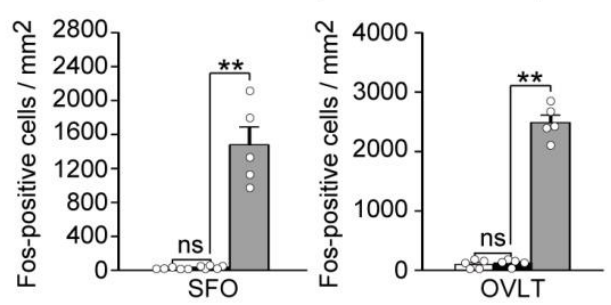

Figure II.4 Fos expression in the AT1a-positive neurons of the SFO and OVLT under the Na-depleted and water-depleted condtions.

(A) Top, left: schematic drawings of mouse coronal brain sections indicating the SFO and OVLT. Top, right: immunohistochemical detection of $\beta$-galactosidase ( $\beta$-gal) and Fos in $A T 1 a^{l a c Z /+}$ mice under the Na-depleted and water-depleted conditions. Bottom: summary of Fos-positive cell counts in the respective brain regions $(n=5$ mice for each; control vs. Na-depleted, $U_{(\mathrm{SFO})}=0, P=0.0090 ; U_{(\mathrm{OVLT})}=0, P=0.0090$; Na-depleted vs. water-depleted, $\left.U_{(\mathrm{SFO})}=0, P=0.0090 ; U_{(\mathrm{OVLT})}=24, P=0.0216\right) .(\mathbf{B})$ Top: immunohistochemical detection of $\beta$-gal and Fos in ATla-KO mice under the Na-depleted and water-depleted conditions. Bottom: summary of Fos-positive cell counts in ATla-KO mice in the respective brain regions ( $n=5$ mice for each; control vs. Na-depleted, $U_{(\mathrm{SFO})}=4, P=0.0946 ; U_{(\mathrm{OVLT})}=10, P=0.6761 ;$ Na-depleted vs. water-depleted, $\left.U_{(\mathrm{SFO})}=0, P=0.0090 ; U_{(\mathrm{OVLT})}=0, P=0.0090\right)$. Scale bars, $50 \mu \mathrm{m}$. ns, not significant; ${ }^{*} P<0.05 ; * * P<0.01$; Mann-Whitney $U$-tests. Data show mean \pm s.e.m. 


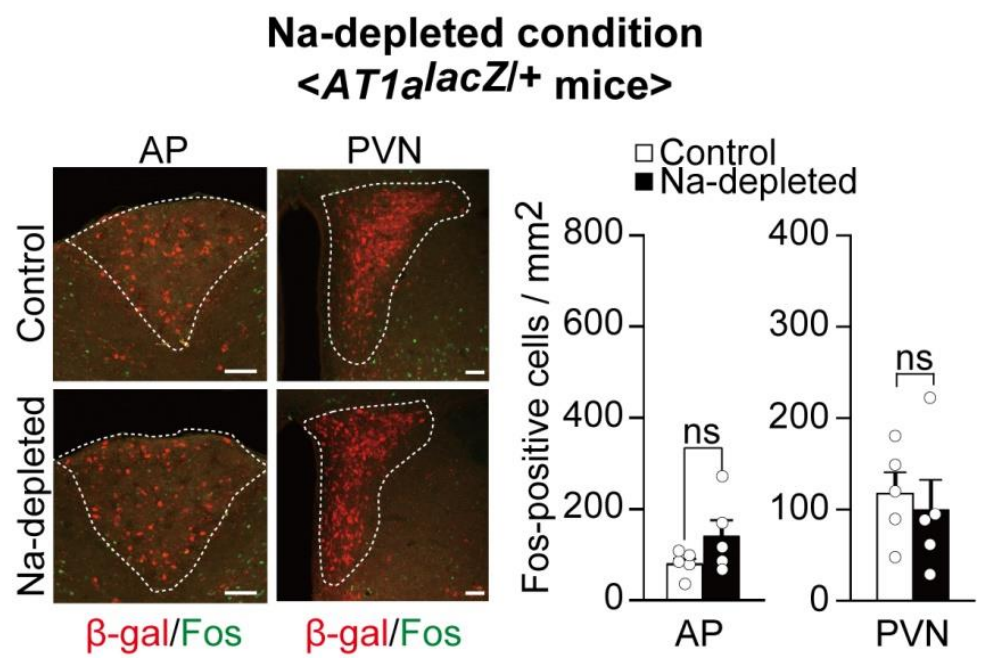

Figure II.5 AT1a-positive neurons in the AP and PVN are not activated under the Na-depleted condition.

Left: immunohistochemical detection of Fos in the AP and PVN of ATla lacZ/+ mice under the Na-depleted condition. Right: summary of Fos-positive cell counts in respective brain regions $\left(n=5\right.$ mice each, $U_{(\mathrm{AP})}=6, P=0.2100 ; U_{(\mathrm{PVN})}=16, P=$ 0.5308). Scale bars, $50 \mu \mathrm{m}$. ns, not significant; Mann-Whitney $U$-tests. Data show mean \pm s.e.m. 
A

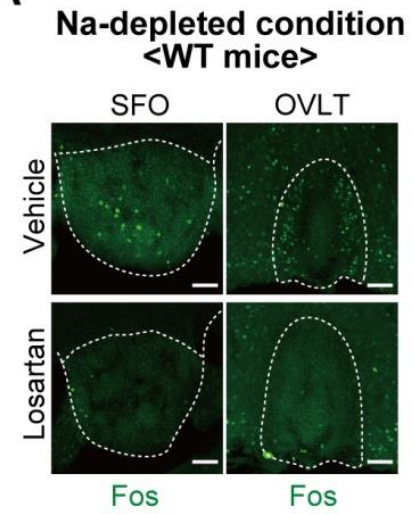

$B$

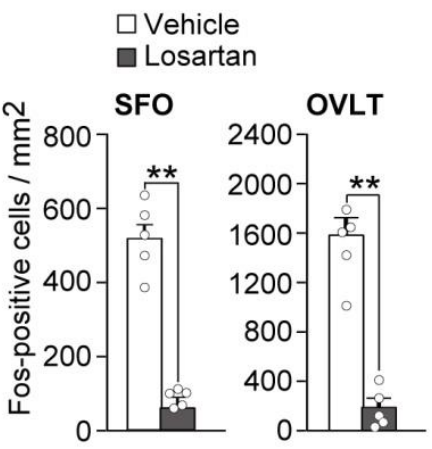

Na-depleted condition $<$ WT mice>

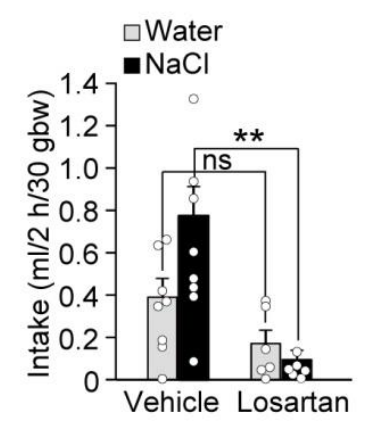

\section{Figure II.6 Inhibition of AT1 signaling in the brain.}

(A) Left: Effects of the continuous intracerebroventricular infusion of losartan $(10 \mu \mathrm{g} / \mathrm{h})$ on immunohistochemical detection of Fos in the SFO and OVLT under the Na-depleted condition. Right: summary of Fos-positive cell counts in these brain loci ( $n=5$ mice each; $\left.U_{(\mathrm{SFO})}=25, P=0.0090 ; U_{(\mathrm{OVLT})}=25, P=0.0090\right)$.

(B) Water and $0.3 \mathrm{M} \mathrm{NaCl}$ intake by WT mice under the Na-depleted condition $(n=6$ mice for vehicle, $n=8$ mice for losartan; $\left.U_{(\text {Water })}=38, P=0.0810 ; U_{(\mathrm{NaCl})}=48, P=0.0024\right)$. Scale bars, $50 \mu \mathrm{m}$. bw, body weight; ns, not significant; ${ }^{* *} P<0.01$; Mann-Whitney $U$-tests. Data show mean \pm s.e.m. 


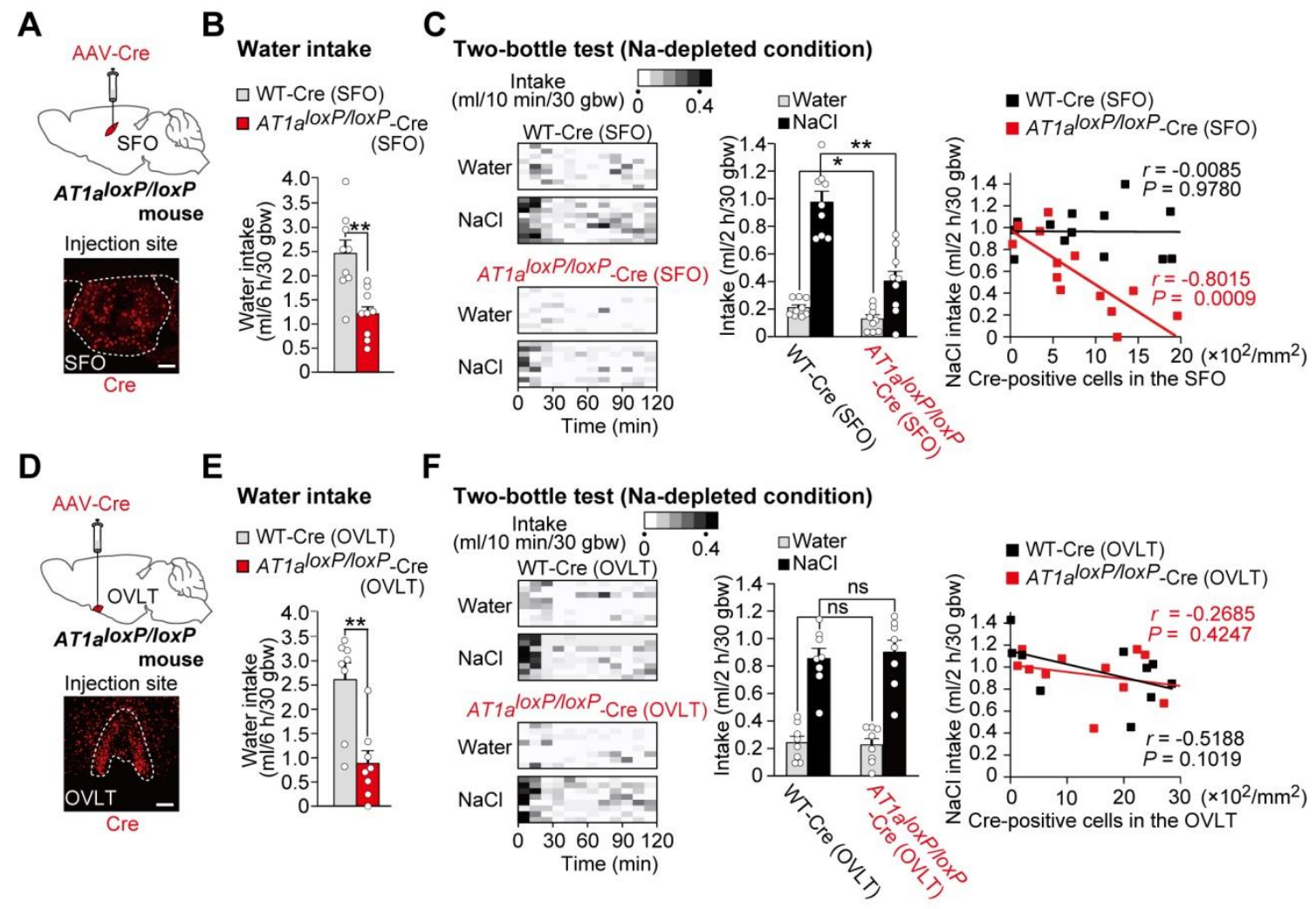

Figure II.7 AT1a in the SFO is involved in thirst and salt appetite, whereas that in the OVLT is only involved in thirst.

(A) Top: injection of AAV-Cre into the SFO of ATla loxP/loxP mice. Bottom: immunohistochemical detection of Cre in the SFO. (B) Water intake during the first 6 h after the furosemide injection $(n=9$ mice each; $U=75, P=0.0027)$. (C) Left: grayscale heat maps of water and $0.3 \mathrm{M} \mathrm{NaCl}$ intakes in the two-bottle test by individual mice under the Na-depleted condition. Middle: summary of intake volumes $\left(n=9\right.$ mice each; $\left.U_{(\text {Water })}=65, P=0.0341 ; U_{(\mathrm{NaCl})}=78, P=0.0011\right)$; data are from the mice used in B. Right: the relationship between the number of Cre-positive cells in the SFO and $0.3 \mathrm{M} \mathrm{NaCl}$ intake $\left(n=13\right.$ mice each; $r_{(\mathrm{WT})}=-0.0085, P=0.9780 ; r_{(l o x P \text {-flanked }}$ Agtrla) $=-0.8015, P=0.0009$; Pearson correlation analysis). Linear regression lines are 
shown in black $(\mathrm{WT})$ and red $\left(A T 1 a^{\text {loxP/loxP }}\right)$. (D) Top: injection of AAV-Cre into the OVLT of ATla $a^{\operatorname{lox} P / l o x P}$ mice. Bottom: immunohistochemical detection of Cre in the OVLT. (E) Water intake during the first $6 \mathrm{~h}$ after the furosemide injection $(n=8$ mice each; $U=59, P=0.0054)$. (F) Left: grayscale heat maps of the two-bottle test under the Na-depleted condition. Middle: summary of intake volumes $(n=8$ mice each; $\left.U_{\text {(Water) }}=34, P=0.8748 ; U_{(\mathrm{NaCl})}=27.5, P=0.6742\right)$; data are from the mice used in $\mathbf{E}$. Right: the relationship between the number of Cre-positive cells in the OVLT and 0.3 M $\mathrm{NaCl}$ intake $\left(n=11\right.$ mice each; $r_{(\mathrm{WT})}=-0.5188, P=0.1019 ; r_{(l o x P \text {-flanked Agtrla })}=-0.2685$, $P=0.4247$; Pearson correlation analysis). Colors of linear regression lines are the same colors as in $\mathbf{C}$. For the statistical analysis in $\mathbf{C}$ and $\mathbf{F}$, mice in which more than 500 Cre-positive cells were detected per $\mathrm{mm}^{2}$ in the SFO, were used. Scale bars, $50 \mu \mathrm{m}$. bw, body weight; ns, not significant; $* P<0.05$; $* * P<0.01$; all tests are Mann-Whitney $U$-test unless otherwise stated. Data show mean \pm s.e.m. 

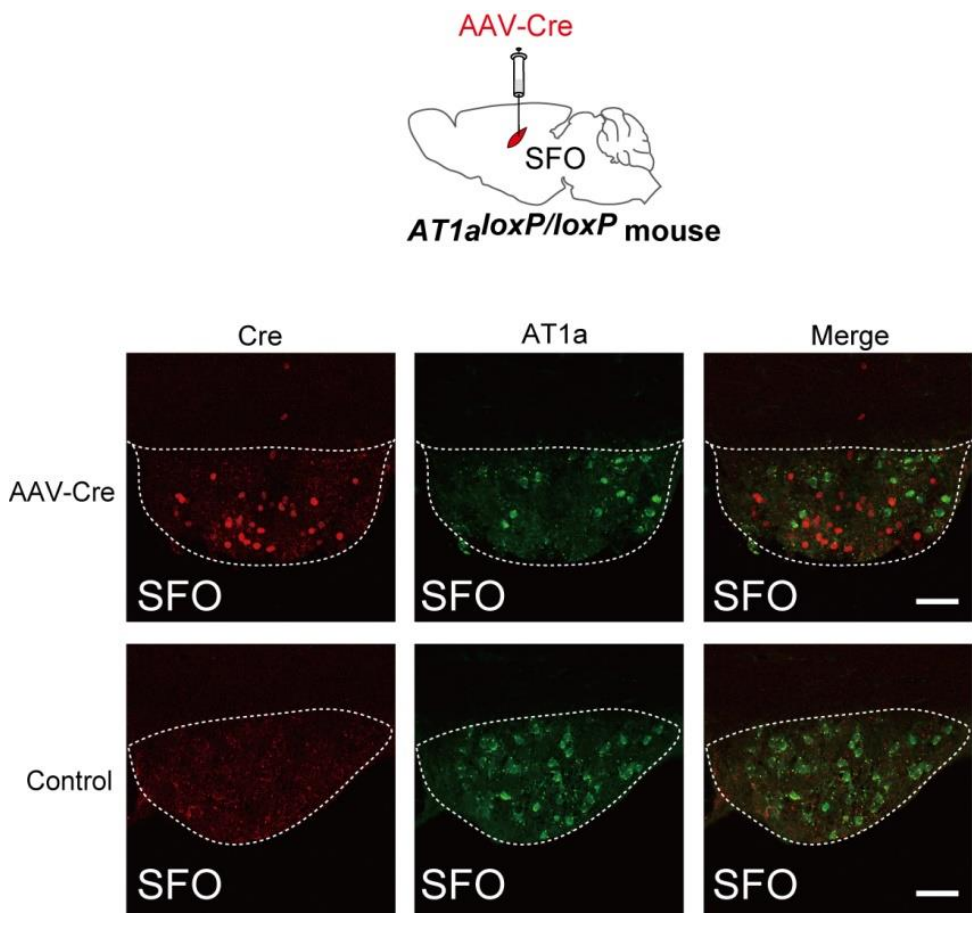

Figure II.8 The local deletion of Agtrla in the SFO of AT1a ${ }^{\text {loxP/loxP }}$ mouse

Immunohistochemical detection of Cre and in situ hybridization of AT1a mRNA in the SFO of $A T 1 a^{\text {loxp } / l o x P}$ mouse with (AAV-Cre) or without (Control) AAV-Cre virus injection. Scale bar, $50 \mu \mathrm{m}$. Expression of AT1a proteins was markedly reduced by Cre recombinase. 


\section{Chapter III}

\section{Distinct neural pathways \\ for the control of thirst and salt appetite in the subfornical organ}




\section{III.1 Introduction}

The SFO has been reported to be involved in water- and salt-intake behaviors by focal electrolytic lesions (Simpson and Routtenberg, 1975; Thunhorst et al, 1999). Recent studies showed that neural nitric oxide synthase (nNOS)-positive neurons in the SFO are overlapped with calcium/calmodulin-dependent protein kinase II (CamKII)-positive excitatory neurons, and optical excitation of these neurons evoked drinking behaviors (Oka et al, 2015). These studies suggest that the excitatory neurons in the SFO include subsets of neurons for the control of thirst and/or salt appetite; however it is not known whether they express AT1a.

Previous studies indicated that the SFO is constituted by multiple neuronal populations projecting to multiple brain nuclei including the OVLT, ventral part of the bed nucleus of the stria terminalis (vBNST), MnPO, SON, and PVN (Mckinley et al, 2003; Johnson 2007). In the OVLT, there exist some neurons that respond to an increase of osmolality (Ciura and Bourque, 2006), suggesting a role of the OVLT in thirst responses. The BNST is a part of the extended amygdala, which is implicated in emotional behaviors such as anxiety and reward (Stamatakis et al, 2014). Electrolytic destructions of the BNST cause reductions in salt appetite (Reilly et al., 1994), and retrogradely labeled SFO neurons from the BNST are activated by the circulating Ang II in rats (Sunn et al., 2003).

In this chapter, I used a retrograde-transporting virus to label specific neuronal projection by the reporter gene expression. I also used optogenetics, techniques to manipulate the excitability of specific neurons, in that light-sensitive channels or pumps are exogenously expressed. Combination of these two approaches enabled me to 
examine the functional roles of the SFO neurons projecting to the OVLT and vBNST in thirst and salt appetite generations. 


\section{III.2 Materials and Methods}

\section{Experimental animals}

In addition to the mice as described in chapter II, Slc17a6-ires-Cre (Vglut2-Cre) (Vong et al., 2011) (Jackson Labs stock 016963), Gadl-GFP (Dneo) (GAD67-GFP) (Tamamaki et al., 2003), and Slc32al-ires-Cre (Vgat-Cre) (Vong et al., 2011) (Jackson Labs stock 016962) mice were used. In some optogenetic experiments, multiple behavioral tests were conducted in the same group of mice.

\section{Reagents}

In addition to the reagents as described in chapter II, tetramethylrhodamine-conjugated dextran (M.W. 3000) (D-3308, Life Technologies), and Alexa555-conjugated cholera toxin subunit b (CTb-555) (C-34776, Life Technologies) were used.

\section{Immunohistochemistry}

In addition to the antibody as described in chapter II, the primary antibodies used in this chapter were as follows: rat anti-GFP (1:1,000, 04404-84, Nacalai Tesque), rabbit anti-RFP (1:500, 600-401-379, Rockland), and goat anti-nNOS (1:1000, ab1376, abcam) antibodies.

\section{In situ hybridization}

Mice were perfused transcardially with PBS followed by fixation with $4 \%$ paraformaldehyde in PBS. After the immunohistochemical staining with anti-Cre antibody as described above, the free-floating sections were rinsed with PBS and then digested with proteinase $\mathrm{K}(0.5 \mathrm{mg} / \mathrm{mL}$ in $0.1 \mathrm{M}$ Tris- $\mathrm{HCl}$ buffer, $\mathrm{pH} 8.0$, containing $0.05 \mathrm{M}$ EDTA) for $10 \mathrm{~min}$ at room temperature $\left(20-25^{\circ} \mathrm{C}\right)$. Digestion was stopped 
with a solution containing $0.25 \%$ acetic anhydride in $0.1 \mathrm{M}$ triethanolamine containing 0.3\% Triton X-100 for 15 min. After a wash with saline sodium citrate (SSC) and prehybridization in a hybridization buffer (5XSSC, $2 \%$ blocking reagent (Roche), $50 \%$ formamide, and $0.1 \% \mathrm{~N}$-lauroylsarcosine) without probe at $60^{\circ} \mathrm{C}$ for $1 \mathrm{~h}$, the sections were hybridized with the digoxigenin-labeled RNA probes for AT1a in the hybridization buffer at $60^{\circ} \mathrm{C}$ for more than $16 \mathrm{~h}$. The template used for the probe preparation was the 757-bp fragment of mouse Agtrla (nucleotide residues 1,485-2,242; GenBank accession number NM_177322). The sections were then washed and incubated with peroxidase-conjugated sheep anti-digoxigenin antibody (1:5000, 11-207-733-910, Roche) at $4^{\circ} \mathrm{C}$ for $16 \mathrm{~h}$. Bound anti-digoxigenin antibodies were detected with TSA-Plus Fluorescein System (NEL741, Perkin Elmer) according to the manufacturer's protocol.

\section{Recombinant Viral Vectors}

In addition to the virus as described in chapter II, a highly efficient retrograde gene-transfer lentivirus (HiRet) (Kato et al., 2011), a pseudotyped lentiviral vectors with the rabies virus glycoprotein, $\left(>1.0 \times 10^{10}\right.$ Genomic Copies $\left./ \mathrm{ml}\right)$ was used for gene transfer in vivo. HiRet-MSCV-NLS-Cre-WPRE was used for the expression of Cre recombinase. AAVDJ-CAGGS-DIO-EGFP and HiRet-MSCV-EGFP-WPRE were used for the expression of EGFP. HiRet-MSCV-mCherry-WPRE was used for the expression of mCherry. AAVDJ-CAGGS-DIO-ChR2(H134R)-EGFP, HiRet-MSCV-ArchT-GFP-WPRE, and HiRet-MSCV-DIO-ChR2(H134R)-EGFP-WPRE were used for the optical manipulation. FCK-ArchT-GFP, which was used to construct the virus vector, was a gift from Dr. Edward Boyden (Cambridge University, USA) 
(Addgene plasmid \# 31177) (Han et al., 2011). DIO, double-floxed inverted orientation; MSCV, murine stem cell virus promoter; WPRE, Woodchuck hepatitis virus response element.

\section{Surgery}

Viruses or tracer dyes were injected with a micro syringe pump (AAV, $0.1 \mu \mathrm{L} / \mathrm{min}$ for 5 min; HiRet, $0.1 \mu \mathrm{L} / \mathrm{min}$ for $10 \mathrm{~min})$ or by iontophoresis $(7 \mu \mathrm{A}$, 7-sec on/off positive pulses for $15 \mathrm{~min}$ ). In addition to the injection sites as described in chapter II, following the coordinates relative to the bregma were used for the viral injection: the vBNST (anteroposterior, $+0.3 \mathrm{~mm}$; lateral, $\pm 1.0 \mathrm{~mm}$; ventral, $+4.6 \mathrm{~mm}$ ), PVN (anteroposterior, $-0.7 \mathrm{~mm}$; lateral, $\pm 0.3 \mathrm{~mm}$; ventral, $+4.9 \mathrm{~mm}$ ), and SON (anteroposterior, $-0.7 \mathrm{~mm}$; lateral, $\pm 1.2 \mathrm{~mm}$; ventral, $+5.5 \mathrm{~mm}$ ).

Immunohistochemical experiments were performed more than 1 week after the virus injection, while behavioral experiments were conducted after more than 4 weeks. Mice used for optogenetic experiments were surgically implanted with stainless steel cannulas (C311G, Plastics One) targeting the SFO or OVLT more than 3 weeks after the virus injection; the cannula was fixed to the skull with two screws and dental acrylic. All stereotaxic injection sites were verified by immunohistochemistry after behavioral tests. When the virus infection or tracer injection to the target site turned out to be unsuccessful, behavioral data obtained from such individuals were excluded from the analyses.

For labeling with dyes, tetramethylrhodamine-conjugated dextran (3000 M.W., 5\% in PBS) or Alexa555-conjugated cholera toxin subunit b (CTb-555, $1.0 \mu \mathrm{g} / \mu \mathrm{L}$ in PBS) was injected into the SFO or vBNST (unilaterally), as described above. The time from 
the injection to fixation was $3 \mathrm{~d}$ for dextran and $7 \mathrm{~d}$ for CTb-555.

To induce electrolytic lesions, a tungsten monopolar electrode $(80-100 \mathrm{kOhm}$ resistance and tip diameter of $\sim 5 \mu \mathrm{m}$; Unique Medical) was inserted into the vBNST. A positive current $(0.5 \mathrm{~mA})$ was passed for $20 \mathrm{~s}$ from a current source (53500, Ugo Basile). After the completion of surgery, animals were allowed to recover for more than $7 \mathrm{~d}$. Brains were sectioned at a thickness of $300 \mu \mathrm{m}$ after the behavioral experiments and images were obtained using a microscope (Biozero, Keyence) with the $2 \times$ objective to validate the lesions.

\section{Behavioral Assays}

For in vivo photoillumination of freely moving mice, laser light was delivered through plastic optic fibers with an optical swivel (COME2-UFC, Lucir), which was connected to a yellow light laser (577 nm, $3000 \mathrm{~mW}$, CW) (Genesis Taipan 577, Coherent) or blue light laser (445 nm, $1000 \mathrm{~mW}, \mathrm{CW})$ (KaLaser). To achieve the optical inhibition with ArchT, the laser output was maintained at $7-10 \mathrm{~mW} / \mathrm{mm}^{2}$ as measured at the tip of the fiber. The laser output ( $20 \mathrm{~Hz} ; 25 \mathrm{msec}$ light $\mathrm{ON}$ duration) for optical activation of ChR2 was maintained at $5-10 \mathrm{~mW} / \mathrm{mm}^{2}$ as measured at the tip of the fiber. The optical power of blue and yellow lights in the SFO and OVLT was estimated using the

online brain tissue light transmission calculator available at http://web.stanford.edu/group/dlab/optogenetics/. In my experiments, the distance from the optical fiber tip to the target tissue was set at 200-500 $\mu \mathrm{m}$, and the expected optical power was $1.20-3.64 \mathrm{~mW} / \mathrm{mm}^{2}$.

In the test under the euhydrated condition, optical stimulation was delivered for 10 min, starting 10 min after the start of the two-bottle test. In each test under the water- 
and/or Na-depleted conditions, the optical stimulation was started 5 min before the start of the two-bottle test. Optical excitation and silencing were observed in cell-attached recordings of action potential firing in ChR2- and ArchT-positive SFO cells. After optical excitation of axon fibers, intensive Fos expression was observed at the target nucleus, indicating that optical excitation successfully evoked synaptic transmission and activated neurons in the target nucleus. I also confirmed that Fos expression was not observed in the ArchT-GFP-expressing neurons after optical silencing, though Fos expression was observed in GFP-expressing neurons under the Na-depleted condition. 


\section{III.3 Results}

\section{SFO $\rightarrow$ OVLT pathway controls water intake}

To identify the neuronal types of AT1a-expressing cells in the SFO, I generated Vglut2-Cre;AT1alacZ/+ (Fig. III.1A) and GAD67-GFP;ATla lacZ/+ (Fig. III.1B) mice by crossing the ATla $a^{\text {lacZ/+ }}$ mouse with the vesicular glutamate transporter 2 (Vglut2, its gene is Slc17a6)-Cre mouse or with glutamic acid decarboxylase 67 (GAD67; Gad1)-green fluorescent protein $(G F P)$ mouse $\left(G A D 67^{G F P /+}\right)$, respectively. In Vglut2-Cre;ATIalacZ/+ mice that received an injection of the AAV carrying the double-loxP-flanked inverted orientation (DIO)-EGFP into the SFO ( $n=4$ mice), $\beta$-galactosidase signals largely overlapped with EGFP in glutamatergic neurons (Fig. III.1A): over $80 \%$ of neurons showed EGFP- $\beta$-galactosidase overlap, depending on the infection rate. Notably, most though not all AT1a-positive neurons expressed nNOS, a marker of excitatory neurons in the SFO (Oka et al., 2015): $75.7 \pm 2.9 \%$ ( $n=5$ mice) of the AT1a neurons were nNOS-positive (Fig. III.2). On the other hand, AT1a-positive neurons did not overlap with GFP in GAD67-GFP;AT1alacZ/+ mice (Fig. III.1B). These results indicate that AT1a neurons in the SFO are glutamatergic (excitatory) but not GABAergic (inhibitory) neurons.

I then examined the projection targets of glutamatergic SFO neurons by injecting the AAV carrying DIO-EGFP into the SFO of Vglut2-Cre mice (Fig. III.3A). This revealed that glutamatergic SFO neurons had projections to the OVLT, MnPO, vBNST, PVN, and SON (Fig. III.3A). I confirmed these results by using the highly efficient retrograde gene transfer lentiviral vector (HiRet; Kato et al., 2011) carrying the EGFP (Fig. III.3B-E). The OVLT received intensive neural connections from AT1a-positive SFO neurons: $56.8 \pm 3.9 \%$ ( $n=4$ mice) of the SFO neurons projecting to the OVLT 
[hereafter referred to as SFO $\rightarrow$ OVLT) neurons] were AT1a-positive (Fig. III.4A). On the other hand, when the targets of GABAergic neurons were examined using vesicular GABA transporter (Vgat; Slc32al)-Cre mice as the recipient, a small number of fibers were detected in the OVLT and MnPO; however, no fibers were observed in the vBNST, PVN, or SON (Fig. III.3F). These results were reproduced by injecting the anterograde tracer, tetramethylrhodamine-conjugated dextran (TRITC-Dextran), into the SFO (Fig. III.3G).

Fos-positive neurons under the water-depleted condition overlapped well with the SFO neurons that were retrogradely labeled from the OVLT: $52.0 \pm 4.6 \%(n=4$ mice) of the SFO $(\rightarrow \mathrm{OVLT})$ neurons were Fos-positive (Fig. III.4B). Therefore, I presumed that the SFO $\rightarrow$ OVLT neural pathway controlled thirst responses under dehydration. I optically silenced the $\mathrm{SFO}(\rightarrow$ OVLT) neurons using archearhodopsin 3 (ArchT), a yellow-light drivable proton pump (Fig. III.5). The HiRet lentiviral vector carrying ArchT-GFP was injected into the OVLT of WT mice, and the cell bodies of SFO neurons with ArchT-GFP was exposed to yellow light under awake and free-moving conditions (Fig. III.6A). In the absence of the light, mice typically showed enhanced water intake under the water-depleted condition (Fig. III.6B). However, the optical silencing of SFO neurons significantly reduced water intake (Fig. III.6B). I confirmed that furosemide-induced water intake was AT1a-dependent (Fig. III.7A) and that this water intake was also reduced by the specific deletion of the Agtrla (Fig. III.7B) and the optical silencing of the SFO $\rightarrow$ OVLT pathway (Fig. III.7C). In contrast to water intake, salt intake under the Na-depleted condition was not affected by the optical silencing of the same pathway (Fig. III.8).

I next investigated the effects of the optical excitation of the SFO $\rightarrow$ OVLT pathway 
on the water- and salt-intake behaviors using channelrhodopsin 2 (ChR2), a blue-light gated cation channel. In these experiments, an AAV carrying DIO-ChR2-EGFP was injected into the SFO of Vglut2-Cre mice, and the axon fibers innervating the OVLT were optically stimulated (Fig. III.5, III.9A, and III.10). Here the optical stimulation induced rapid water-intake behavior in mice in the two-bottle test under the normal water-satiated condition (Fig. III.9B). The termination of water intake within several minutes is presumably due to feedback neural suppression from the oropharynx and/or hepatic portal vein (Stricker and Sved, 2000). When light stimulation was terminated shortly after the initiation of drinking, most mice immediately stopped drinking and left the spout (data not shown), indicating that the neural stimulation is directly related to the drinking behavior (or drives the recognition of thirst). In contrast, $0.3 \mathrm{M} \mathrm{NaCl}$ intake was not affected by the optical excitation of the SFO $\rightarrow$ OVLT pathway (Fig. III.9B). Together, these data indicate that the SFO $\rightarrow$ OVLT pathway mediates thirst control but not salt-appetite control.

\section{SFO $\rightarrow$ vBNST pathway controls salt appetite}

Some glutamatergic SFO neurons projected to the vBNST as described above (Fig. III.3A). They specifically projected to the ventral but not dorsal part of the BNST (Fig. III.11). Dual injection of HiRet-EGFP and HiRet-mCherry to the OVLT and vBNST, respectively, revealed that the two neuronal populations projecting to the vBNST (hereafter refered to as $\mathrm{SFO}(\rightarrow \mathrm{VBNST})$ neurons $)$ and OVLT $(\mathrm{SFO}(\rightarrow \mathrm{OVLT})$ neurons $)$ had an intermingled distribution in the SFO (Fig. III.12). When I injected a retrograde tracer, Alexa555-conjugated cholera toxin subunit b (CTb-555), into the vBNST of the $A T 1 a^{\text {lacZ/+ }}$ mouse (Fig. III.13), most of the CTb-555-positive neurons in the SFO were 
positive for $\beta$-galactosidase and, accordingly, were AT1a neurons $(92.6 \pm 0.3 \% ; n=3$ mice). These neurons overlapped with Fos-positive neurons under the Na-depleted condition: $52.2 \pm 6.0 \%$ ( $n=3$ mice $)$ of the $\mathrm{SFO}(\rightarrow \mathrm{vBNST})$ neurons were Fos-positive. Of note, the Fos expression in the vBNST increased $\sim 2$ fold as a result of Na depletion (Fig. III.14A).

Therefore, I investigated the importance of the vBNST in salt-intake behavior by generating focal, bilateral electrolytic lesion in the vBNST of WT mice (Fig. III.14B). This procedure drastically reduced $0.3 \mathrm{M} \mathrm{NaCl}$ intake under the Na-depleted condition (Fig. III.14C). To confirm the notion that the SFO $\rightarrow$ vBNST pathway is involved in salt-intake control, I deleted the Agtrla from the $\mathrm{SFO}(\rightarrow$ vBNST) neurons by injecting an HiRet carrying Cre into the bilateral vBNST of $A T 1 a^{\text {loxP/loxP }}$ mice (Fig. III.15A). When AT1a was ablated from the $\mathrm{SFO}(\rightarrow$ vBNST) neurons, $0.3 \mathrm{M} \mathrm{NaCl}$ intake got smaller compared to that of the control (WT) group in the two-bottle test (Fig. III.15B). Notably, the reductions in $0.3 \mathrm{M} \mathrm{NaCl}$ intake were proportional to increases in the number of Cre-positive cells in the SFO (Fig. III.15B). On the other hand, no reductions in $0.3 \mathrm{M} \mathrm{NaCl}$ intake occurred when the other sites (OVLT, PVN, and SON) were individually injected with the same vector (Fig. III.16).

Subsequently, I also examined the effects of the optical silencing of the SFO $\rightarrow$ vBNST pathway on salt-intake behavior using ArchT (Fig. III.17). HiRet-ArchT-GFP was bilaterally injected into the vBNST of WT mice (Fig. III.18A), and the SFO was exposed to yellow light under the Na-depleted condition (Fig. III.18B). In the absence of light exposure, mice injected with HiRet-ArchT-GFP showed normal enhancement of $0.3 \mathrm{M} \mathrm{NaCl}$ intake under the Na-depleted condition (Fig. III.18B). However, optical silencing significantly reduced salt intake (Fig. III.18B) in a manner 
that depended on the number of cells expressing ArchT-GFP in the SFO (Fig. III.18B). In contrast, water intake was not affected by light exposure (Fig. III.18B). These results again indicate that the activity of the SFO $\rightarrow$ vBNST pathway is involved in the control of salt intake but not water intake. In support of this, water intake was not affected by the optical silencing of the same pathway under either the water-depleted (Fig. III.18C and III.19A) or water- and Na-depleted conditions (Fig. III.18D and III.19B).

I further investigated the effects of the optical excitation of the SFO $\rightarrow$ vBNST pathway on salt preference and avoidance by two-bottle tests; the HiRet-DIO-ChR2-EGFP was injected bilaterally into the vBNST of Vglut2-Cre mice (Fig. III.20A). Optical excitation of the $\mathrm{SFO}(\rightarrow$ vBNST) neurons significantly increased salt intake (bottles containing 0.15 and $0.3 \mathrm{M} \mathrm{NaCl}$, respectively) under the water-depleted condition, but did not affect water intake (Fig. III.20B). When the amounts of $\mathrm{NaCl}$ consumed were calculated, no significant differences were noted between 0.15 and $0.30 \mathrm{M} \mathrm{NaCl}$ (Fig. III.20C). Under the water-depleted condition, mice showed a slight preference for $0.15 \mathrm{M} \mathrm{NaCl}$ solution, but avoided the $0.3 \mathrm{M} \mathrm{NaCl}$ solution (Fig. III.20D); however, the optical stimulation enhanced the salt preference for the $0.15 \mathrm{M} \mathrm{NaCl}$ solution and reduced salt avoidance for the $0.3 \mathrm{M} \mathrm{NaCl}$ solution (Fig. III.20D). When I replaced $0.3 \mathrm{M} \mathrm{NaCl}$ with $0.3 \mathrm{M} \mathrm{KCl}$ in the two-bottle test, the amount of $\mathrm{KCl}$ consumed by mice was not affected by the optical stimulation (Fig. III.20E). Taken together, I conclude that the SFO $\rightarrow$ vBNST pathway specifically controls $\mathrm{NaCl}$-intake behavior. 


\section{III.4 Discussion}

To investigate neuronal population of the SFO, I characterized the AT1a-positive SFO neurons as glutamatergic (excitatory) neurons by using combination of transgenic mice with viral transduction. Moreover, these excitatory SFO neurons were revealed to have efferent projections to several brain loci. Among them, the SFO $\rightarrow$ OVLT pathway was identified by optogenetic manipulation as an initiator of thirst-induced drinking behavior, whereas the $\mathrm{SFO} \rightarrow$ vBNST pathway as that of salt-appetite-induced salt intake. These results indicate that distinct neuronal populations in the SFO control thirst and salt appetite, respectively.

The optical excitation of the SFO $\rightarrow$ OVLT pathway induced water intake under the water-satiated condition (Fig. III.9) and the optical silencing of the same pathway significantly reduced water intake induced by dehydration (Fig. III.6). The neural fibers from the SFO to the OVLT pass along the midline of the anterior wall of the 3rd ventricle, where the MnPO is located. The MnPO also receives neural inputs from the SFO, and has been suggested to have functions to control water intake (Fitzsmons, 1998). In my optogenetical experiments, I carefully placed the tip of the optical fiber just above the OVLT and confirmed that optical excitation induced Fos expression in a small area within the OVLT (Fig. III.10). However, we can not completely exclude the possibility that the SFO $\rightarrow \mathrm{MnPO}$ pathway was also involved in the control of water intake (Abbott et al., 2016).

Regarding downstream neural pathways, the OVLT reportedly has direct or indirect neural connections to the insular cortex and anterior cingulate cortex in rats, which are shown to be activated during the systemic infusion of hypertonic saline (Hollis et al., 
2008). Consistently, activation of these loci under thirst conditions is demonstrated in human subjects by PET and functional MRI (Egan et al., 2003). Functional roles of these areas are plausible targets for future studies.

I demonstrated that the optical excitation of the SFO $\rightarrow$ vBNST pathway enhanced salt intake even under the dehydrated condition (Fig. III.20). I also demonstrated that the optical silencing of the SFO $\rightarrow$ vBNST pathway reduced salt intake even under the Na-depleted condition (Fig. III.18). My results are consistent with the previous finding that the ablation of the BNST, including both of the dorsal and ventral parts, reduced salt intake (Reilly et al., 1994; Zardetto-Smith et al., 1994). In rats, the vBNST is functionally divided into subnuclei, and the ventrolateral BNST has been reported to have neural connections with some brain regions related to salt appetite (Shin et al., 2008). It would be a future task to investigate whether such subregions also exist in the vBNST of mice.

The vBNST harbors two types of projection neurons to the ventral tegmental area (VTA): Glutamatergic neurons promote aversion and anxiety, whereas GABAergic neurons promote rewarding and anxiolytic phenotypes (Jennings J. H. et al., 2013). The depletion of $\mathrm{Na}$ is known to induce anhedonia, a symptom of anxiety disorders, defined as a reduction or loss of pleasure (Hurley and Johnson, 2015). Neural inputs from the SFO $\rightarrow$ vBNST pathway may activate rewarding signals or inhibit aversion signals via the vBNST $\rightarrow$ VTA circuit to promote the motivation for salt intake. These interactions between salt appetite and anxiety may be derived from signal cross-talk in the vBNST.

Aldosterone, another natriorexigenic hormone, is known to be detected by 11ß-hydroxysteroid dehydrogenase type 2 (HSD2)-positive neurons in the nucleus of 
the solitary tract (NTS) and to induce salt appetite (Geerling and Loewy, 2009). Recently, chemogenetic activation of HSD2-positive neurons in the NTS was reported to drive salt intake, but inhibition of these neurons resulted in a small reduction of salt intake under physiological Na-depleted conditions (Jarvie and Palmiter, 2016). On the other hand, in my SFO-specific Agtrla deletion experiments using ATla $a^{\text {loxP/loxP }}$ mice (Fig. II.7), salt appetite under the Na-depleted condition completely disappeared in the most effective cases. Therefore, it is reasonable to consider that Ang II signalling but not aldosterone is the main pathway for the control of salt appetite. Because HSD2-positive neurons have projections to the vBNST, there is the possibility that the aldosterone signal may modify the neural signals of the $\mathrm{SFO}(\rightarrow \mathrm{vBNST})$ neurons. 


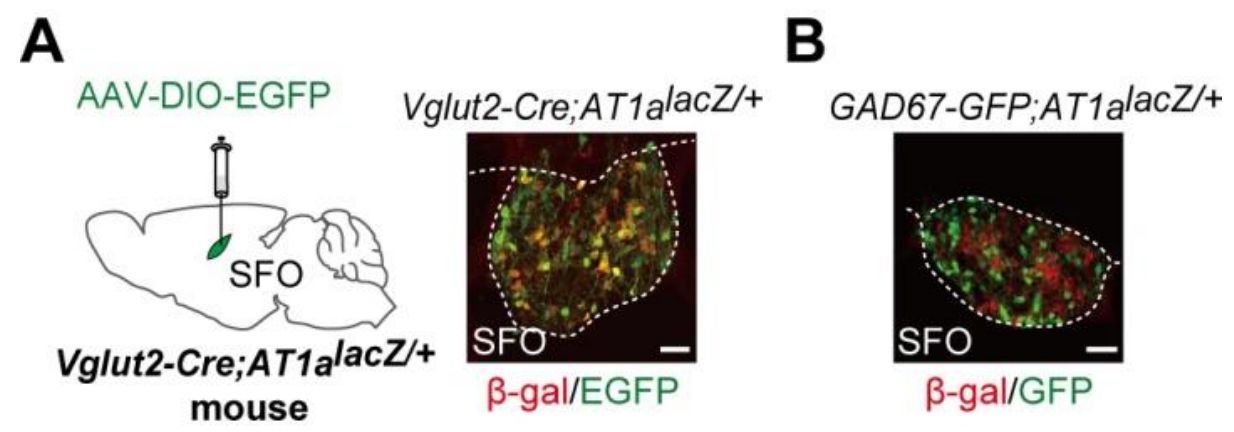

Figure III.1 The AT1a-positive neurons in the SFO are glutamatergic but not GABAergic neurons.

(A) Left: injection of AAV-DIO-EGFP into the SFO of Vglut2-Cre;ATla ${ }^{\text {lacZ/+ }}$ mice. Right: immunohistochemical detection of EGFP and $\beta$-gal in the injection site. Immunohistochemical detection of GFP and $\beta$-gal in the SFO of GAD67-GFP;AT1 ${ }^{\text {lacZ/+ }}$ mice. Scale bars, $50 \mu \mathrm{m}$. 

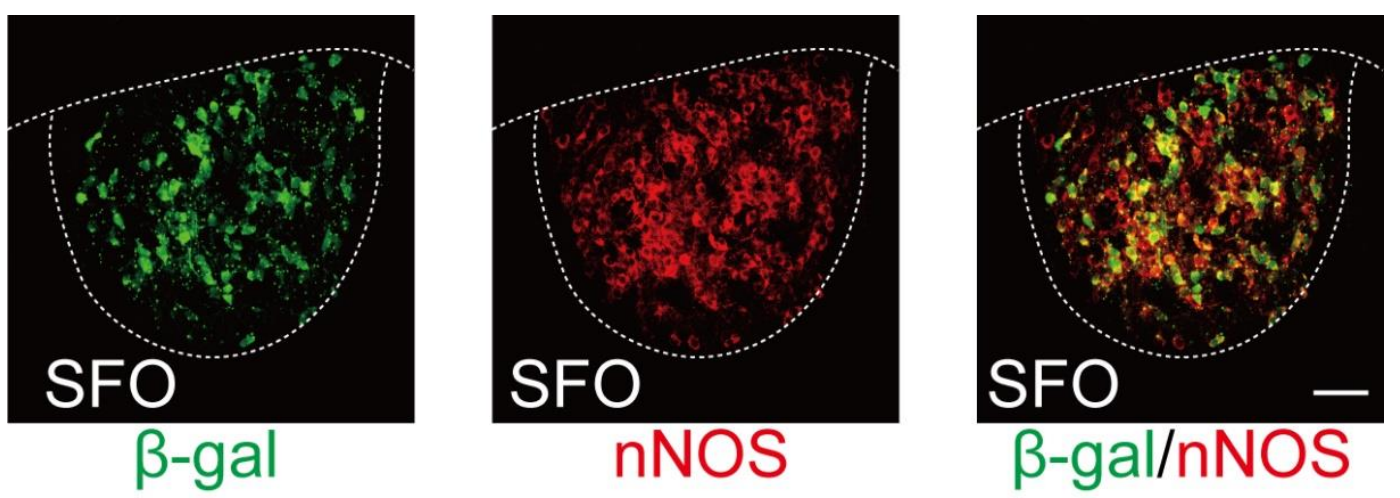

Figure III.2 Most though not all AT1a-positive neurons express neuronal nitric oxide synthase in the SFO.

Immunohistochemical detection of $\beta$-gal and neuronal nitric oxide synthase (nNOS) proteins in the SFO of $A T 1 a^{\text {lacZ/+ }}$ mouse. Scale bar, $50 \mu \mathrm{m}$. 
A

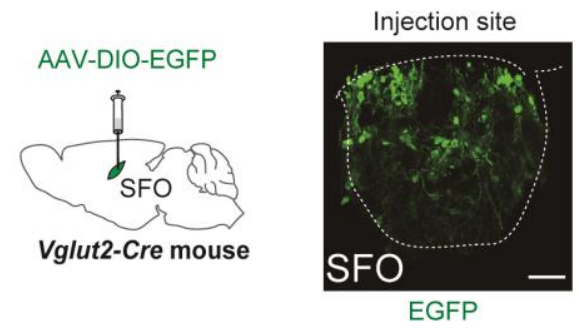

Projection sites

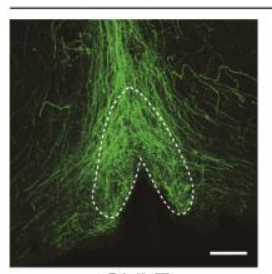

OVLT

B

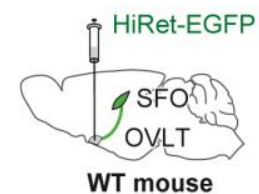

WT mouse

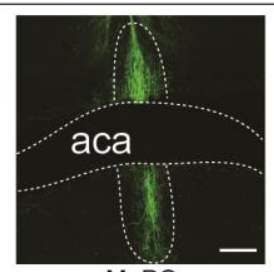

C

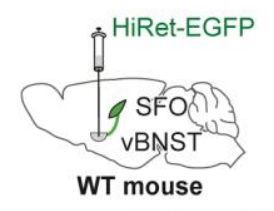

labeled cells

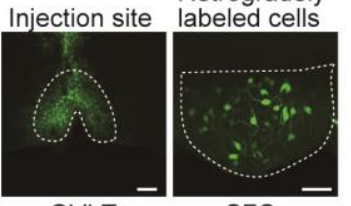

OVLT

SFO

F

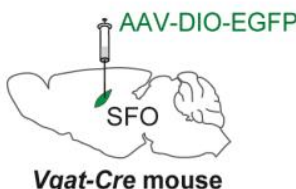

G

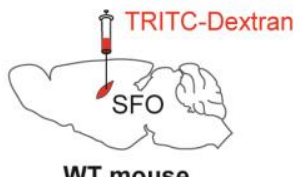

WT mouse

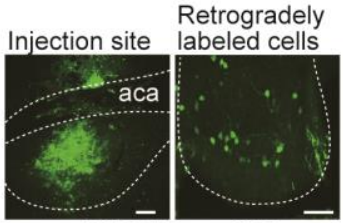

vBNST

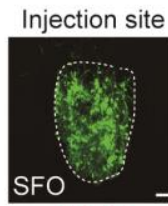

EGFP

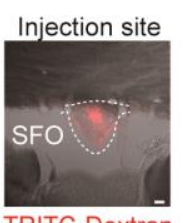

TRITC-Dextran

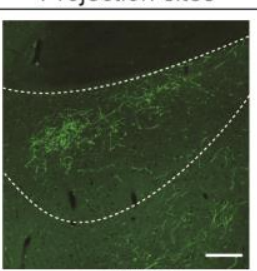

vBNST

D

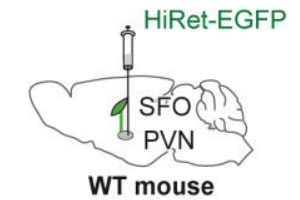

Retrogradely

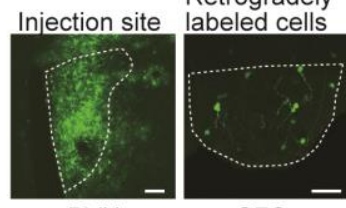

PVN

SFO

Projection sites

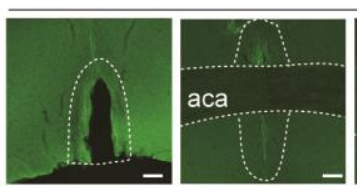

$\mathrm{MnPO}$

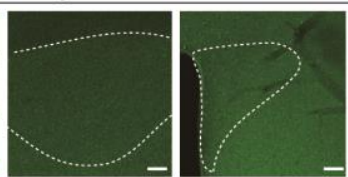

vBNST

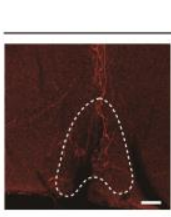

OVLT

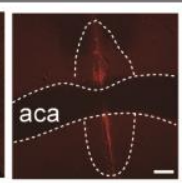

$\mathrm{MnPO}$
Projection sites

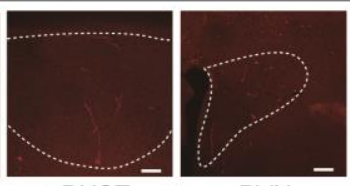

vBNST
PVN

SON

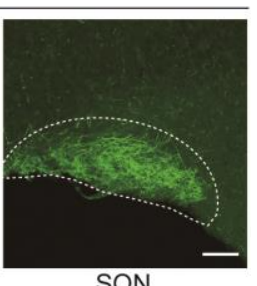

SON

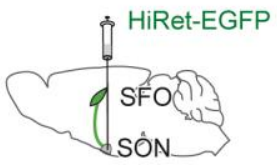

WT mouse

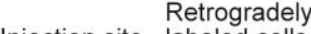

Injection site labeled cells

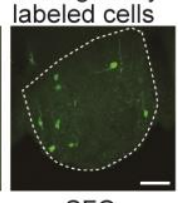

SFO
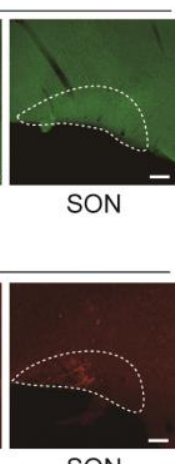
Figure III.3 Projection targets of glutamatergic and GABAergic neurons in the SFO.

(A) Injection of AAV-DIO-EGFP into the SFO of the Vglut2-Cre mouse. Top: immunohistochemical detection of EGFP in the injection site. Bottom: projection sites. (B-E) Top: injections of HiRet-EGFP into the OVLT (B), vBNST(C), PVN (D), and SON (E). Bottom: immunohistochemical detection of EGFP in the injection sites and retrogradely labeled cells (SFO). (F) Left: injection of AAV-DIO-EGFP into the SFO of the Vgat-Cre mouse. Middle and right: immunohistochemical detection of EGFP in the injection site and projection sites. (G) Left: injection of tetramethylrhodamine-conjugated dextran (TRITC-Dextran) into the SFO of the WT mouse. Middle and right: fluorescence images of tetramethylrhodamine in the injection site and projection sites. Scale bars; $50 \mu \mathrm{m}$ (SFO), $100 \mu \mathrm{m}$ (OVLT, MnPO, vBNST, PVN, and SON). 
A

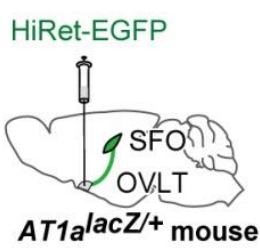

Retrogradely labeled cells

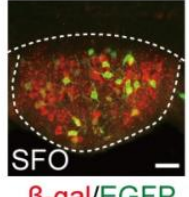

$\beta$-gal/EGFP
B

Water-depleted condition Retrogradely

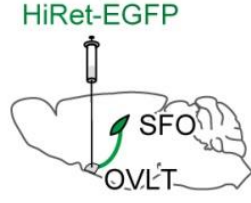

WT mouse labeled cells Magnified view

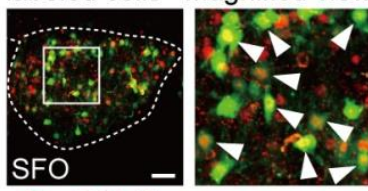

Fos/EGFP

Figure III.4 The SFO neurons projecting to the OVLT are expressed AT1a receptors and activated under the water-depleted condition.

(A) Left: injection of HiRet-EGFP into the OVLT of ATlalacZ/+ mice. Right: immunohistochemical detection of EGFP and $\beta$-gal in the SFO. (B) Left: injection of HiRet-EGFP into the OVLT of WT mice. Right: immunohistochemical detection of EGFP and Fos in the SFO under the water-depleted condition. Arrowheads indicate double-positive cells. Scale bars, $50 \mu \mathrm{m}$. 


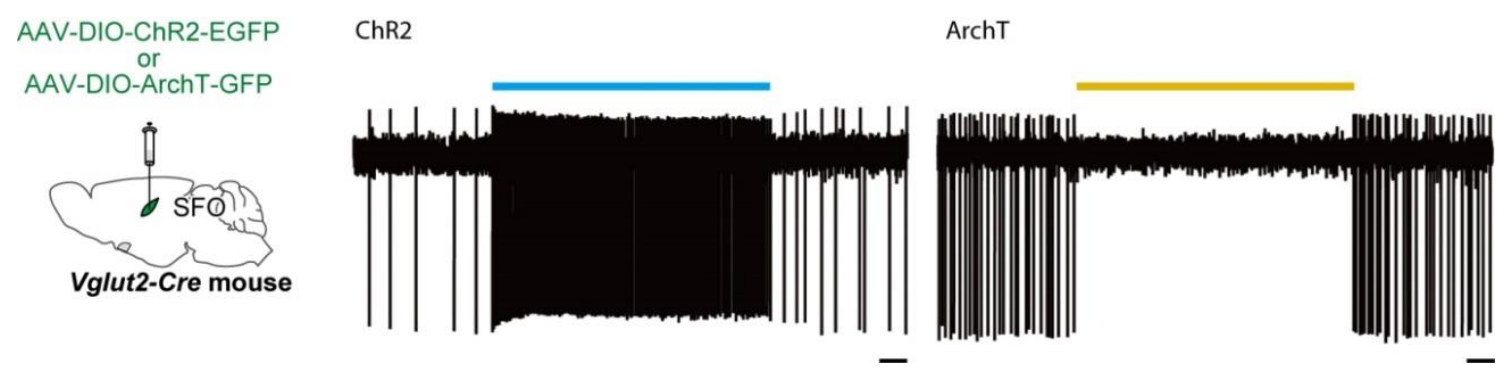

Figure III.5 Manipulation of neuronal activity by optical excitation and silencing. Left: injection of AAV-DIO-ChR2-EGFP or AAV-DIO-ArchT-GFP into the SFO of the Vglut2-Cre mouse. Right: cell-attached recordings of the action potential firing in ChR2- and ArchT-positive SFO cells in the slice prepared from the mice with respective virus infection. Regarding ArchT-positive neurons, the experiments were performed in the presence of Ang II $(0.1 \mu \mathrm{M})$. Blue and yellow lines indicate the period of the respective light exposure. Blue or yellow light caused excitation or suppression of the firing activity, respectively. Scale bars, $1 \mathrm{~s}$. 


\section{A Optical silencing of the SFO $\rightarrow$ OVLT pathway}

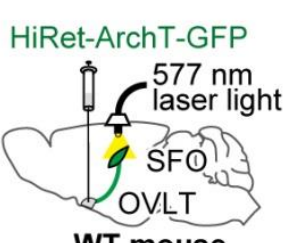

WT mouse

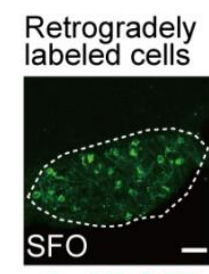

ArchT-GFP
B

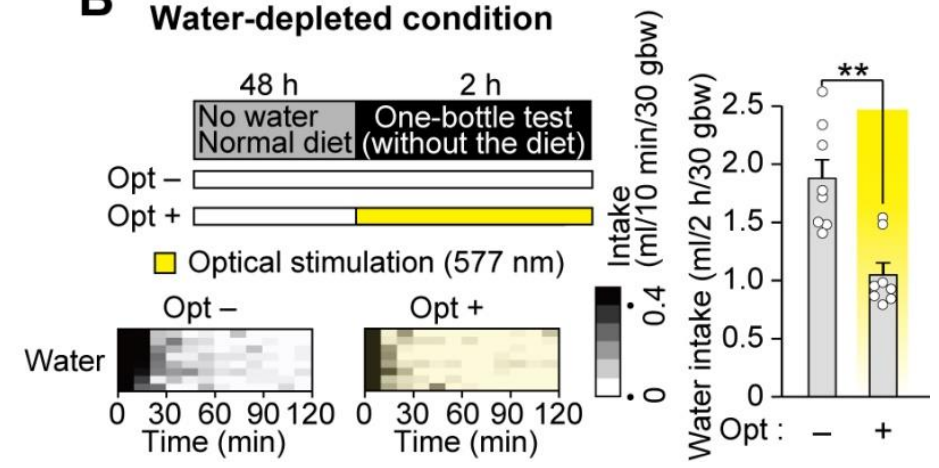

Figure III.6 Optical silencing of the SFO $\rightarrow$ OVLT pathway reduces water intake under the water-depleted condition.

(A) Left: injection of HiRet-ArchT-GFP into the OVLT of WT mice. Right: immunohistochemical detection of ArchT-GFP in the SFO. (B) Experimental protocols for the water-depleted condition and subsequent one-bottle test with (Opt+) or without (Opt-) optical stimulation. Effects of optically silencing of the SFO $\rightarrow$ OVLT pathway on water intake under the water-depleted condition $(n=8$ mice each; $U=59, P=$ 0.0054). Scale bars, $50 \mu \mathrm{m}$. bw, body weight; ns, not significant; ** $P<0.01$; Mann-Whitney $U$-tests. Data show mean \pm s.e.m. 
A

Water- and Na-depleted condition (W/Na-D)

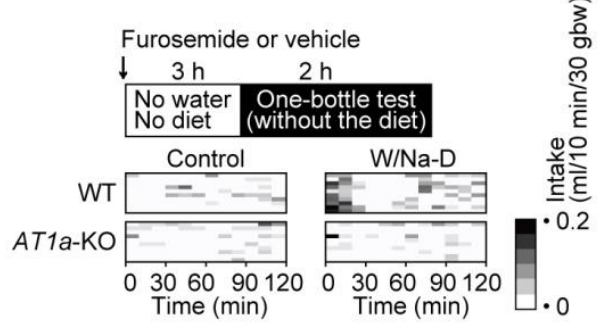

$\square$ Control

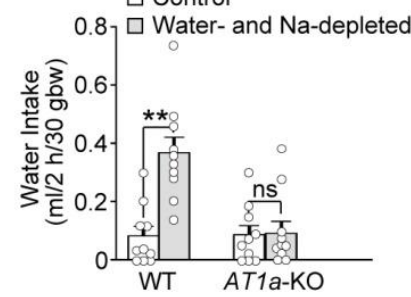

C

Water- and Na-depleted condition (W/Na-D)

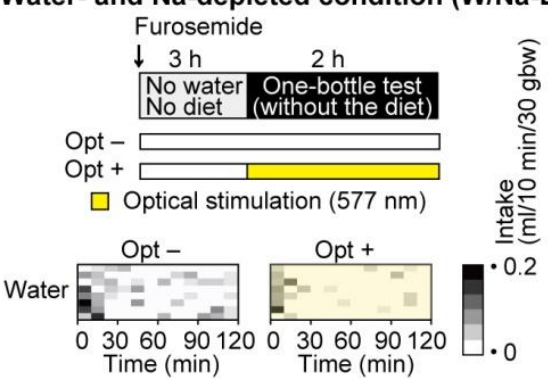

B

Water- and Na-depleted condition (W/Na-D)

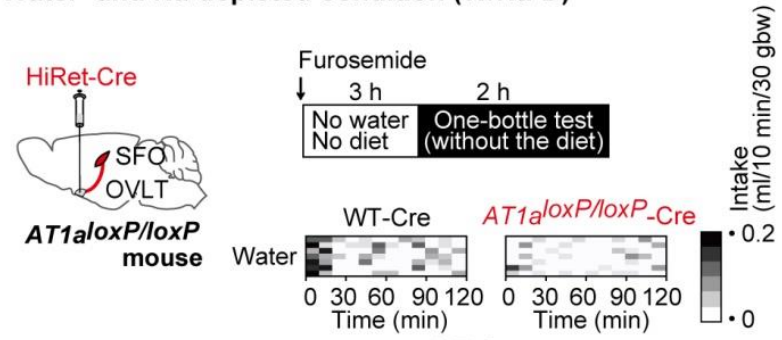

-WT-Cre

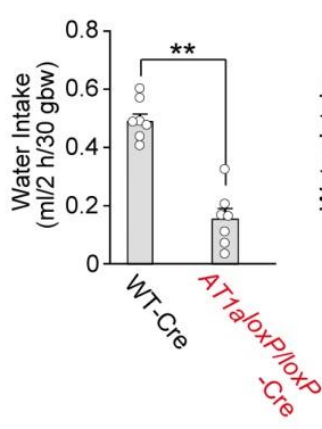

AT1aloxP/loxP-Cre

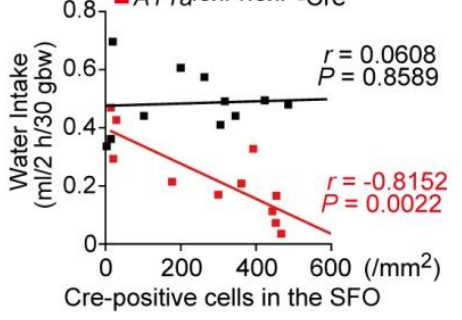

Figure III.7 Optical silencing of the SFO $\rightarrow$ OVLT pathway reduces water intake under the water- and Na-depleted condition.

(A) Top: experimental protocol to observe water intake induced by the furosemide injection and gray scale heat maps of water intake by WT and ATla-KO mice under the water- and Na-depleted condition (W/Na-D). Bottom: summary of the one-bottle test ( $n$ $=10$ mice each; $\left.U_{(\mathrm{WT})}=4.5, P=0.0007 ; U_{(\mathrm{ATla}-\mathrm{KO})}=52.5, P=0.8789\right) . \quad$ (B) Top, left: injection of HiRet-Cre into the OVLT of the ATla $a^{\text {loxPlloxP }}$ mouse. Top, right: experimental protocol of the one-bottle test under the W/Na-D, and gray scale heat maps of water intake under the W/Na-D. Bottom, left: summary of the one-bottle test 
( $n=7$ mice each; $U=49, P=0.0022$ ). For the summary, mice, in which more than $200\left(/ \mathrm{mm}^{2}\right)$ Cre-positive cells were detected in the SFO, were used. Bottom, right: the relationship between the number of Cre-positive cells in the SFO and water intake in the one-bottle test $\left(n=11\right.$ mice each; $r_{(\mathrm{WT})}=0.0608, P=0.8589 ; r_{(\text {loxP-flanked Agtrla })}=-0.8152$, $P=0.0022$; Pearson correlation analysis). Linear regression lines for WT-Cre and AT1 $a^{\text {loxP/loxP }}-$ Cre are shown in black and red, respectively. (C) Left: experimental protocols of one-bottle test by WT mice injected HiRet-ArchT-GFP into the OVLT with the optical stimulation of the SFO under the W/Na-D, and gray scale heat maps of water intake. Right: summary of water intake $(n=8$ mice each; $U=58, P=0.0074)$. bw, body weight; ns, not significant; ${ }^{* *} P<0.01$; all tests are Mann-Whitney $U$-tests unless otherwise stated. Data show mean \pm s.e.m. 
Two-bottle test (Na-depleted condition)

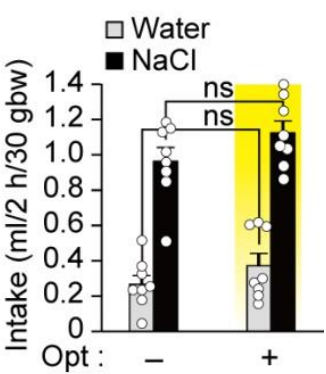

Figure III.8 Optical silencing of the SFO $\rightarrow$ OVLT pathway does not affect the salt intake under the Na-depleted condition.

Experimental protocols for the Na-depleted condition and subsequent two-bottle test with $(\mathrm{Opt}+)$ or without (Opt-) optical stimulation. Effects of optically silencing of the $\mathrm{SFO} \rightarrow$ OVLT pathway on water and $0.3 \mathrm{M} \mathrm{NaCl}$ intakes under the Na-depleted condition $\left(n=8\right.$ mice each; $\left.U_{(\text {Water })}=24, P=0.4306 ; U_{(\mathrm{NaCl})}=20, P=0.2271\right) . \quad n$ n, not significant; Mann-Whitney $U$-tests. Data show mean \pm s.e.m. 

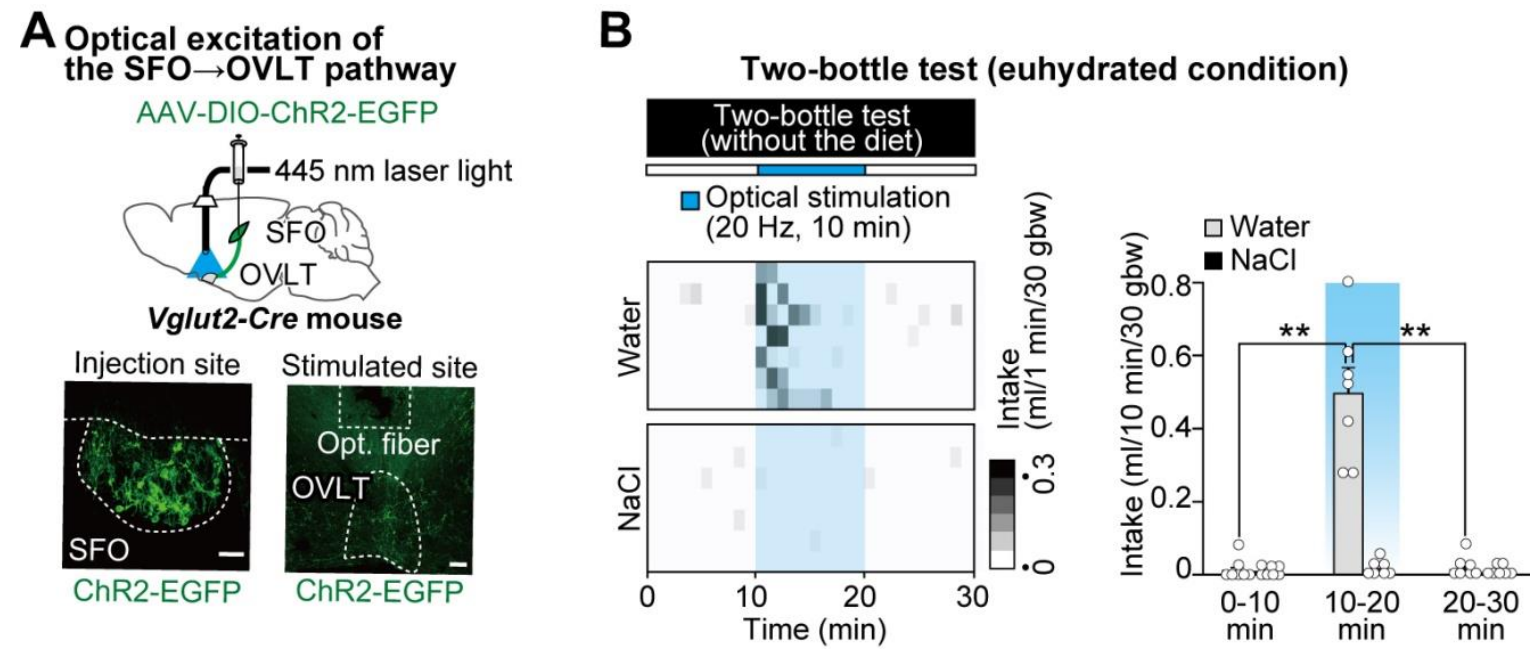

Figure III.9 Optical excitation of the SFO $\rightarrow$ OVLT pathway induces appetitive behavior for water, but not for salt.

(A) Top: injection of AAV-DIO-ChR2-EGFP into the SFO of Vglut2-Cre mice. Bottom, left: immunohistochemical detection of ChR2-EGFP in the SFO. Bottom, right: immunohistochemical detection of EGFP in the OVLT after the optical stimulation. (B) Top: experimental protocol of the two-bottle test with optical stimulation. Optical stimulation started at $10 \mathrm{~min}$ and ended at $20 \mathrm{~min}$. Bottom, left: grayscale heat map of water and $0.3 \mathrm{M} \mathrm{NaCl}$ intakes by individual euhydrated mice. Bottom, right: Summary of intake volumes in the two-bottle test. ( $n=7$ mice each; $U_{(0-10 \mathrm{~min} \text { vs. } 10-20 \mathrm{~min})}$ $\left.=0, P=0.0017 ; U_{(10-20 \min \text { vs. } 20-30 \min )}=49, P=0.0019\right)$. Scale bars, $50 \mu \mathrm{m}$. bw, body weight; ${ }^{* *} P<0.01$; Mann-Whitney $U$-tests. Data show mean \pm s.e.m. 


\section{Optical excitation of the SFO $\rightarrow$ OVLT pathway}

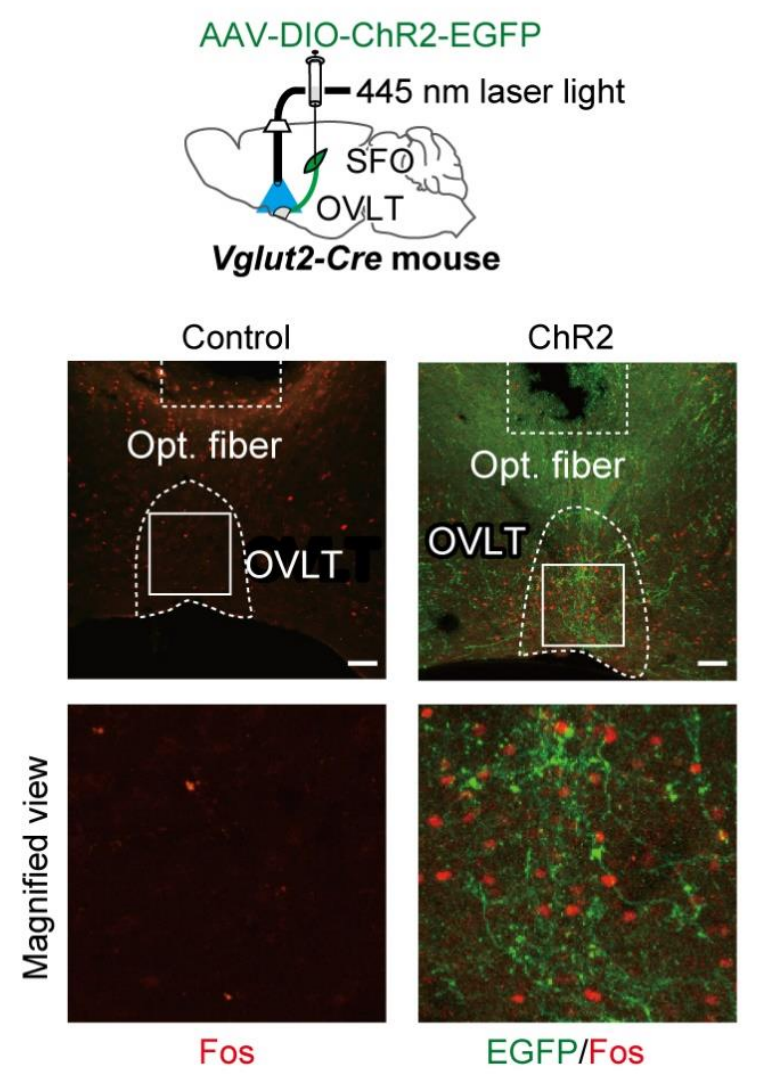

Figure III.10 Optical excitation of the SFO $\rightarrow$ OVLT pathway induces Fos expression in the OVLT.

Top: injection of AAV-DIO-ChR2-EGFP into the SFO of the Vglut2-Cre mouse. Bottom: immunohistochemical detection of Fos and EGFP after the optical excitation of the OVLT of mice with (ChR2) or without (Control) infection of AAV-DIO-ChR2-EGFP. After the optical exposure, the number of Fos-positive cells was drastically elevated in the OVLT with ChR2-EGFP expression. The position of the tip of optic fiber (Opt. fiber) was set just above the OVLT. Scale bars, $50 \mu \mathrm{m}$. 

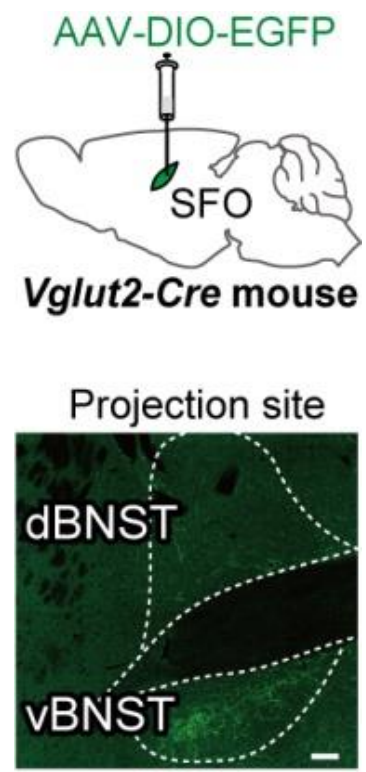

EGFP

Figure III.11 The SFO neurons project to the ventoral BNST, but not dorsal BNST.

Top: injection of AAV-DIO-EGFP into the SFO of Vglut2-Cre mice. Bottom: immunohistochemical detection of EGFP in the BNST. Scale bar, $100 \mu \mathrm{m}$. Part of this micrograph is also shown in Figure III.3A. 


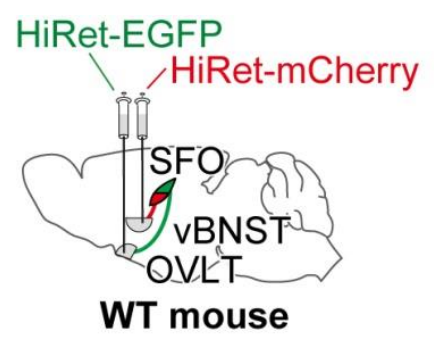

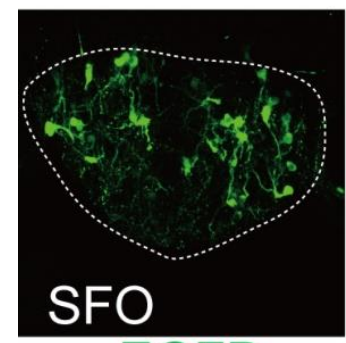

EGFP

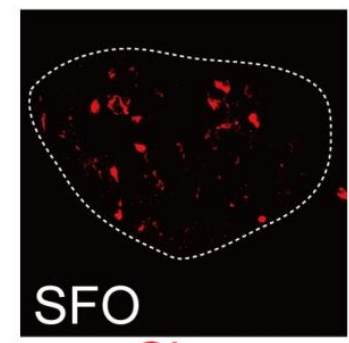

mCherry

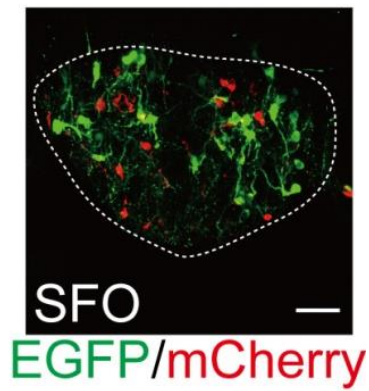

Figure III.12 Two separate SFO neurons projecting to the vBNST and OVLT.

Top: HiRet-EGFP and HiRet-mCherry were injected into the OVLT and vBNST of the WT mouse, respectively. Bottom: immunohistochemical detections of EGFP (left panel) and mCherry (middle panel) in the retrogradely labeled cells in the SFO. Scale bar, $50 \mu \mathrm{m}$. 

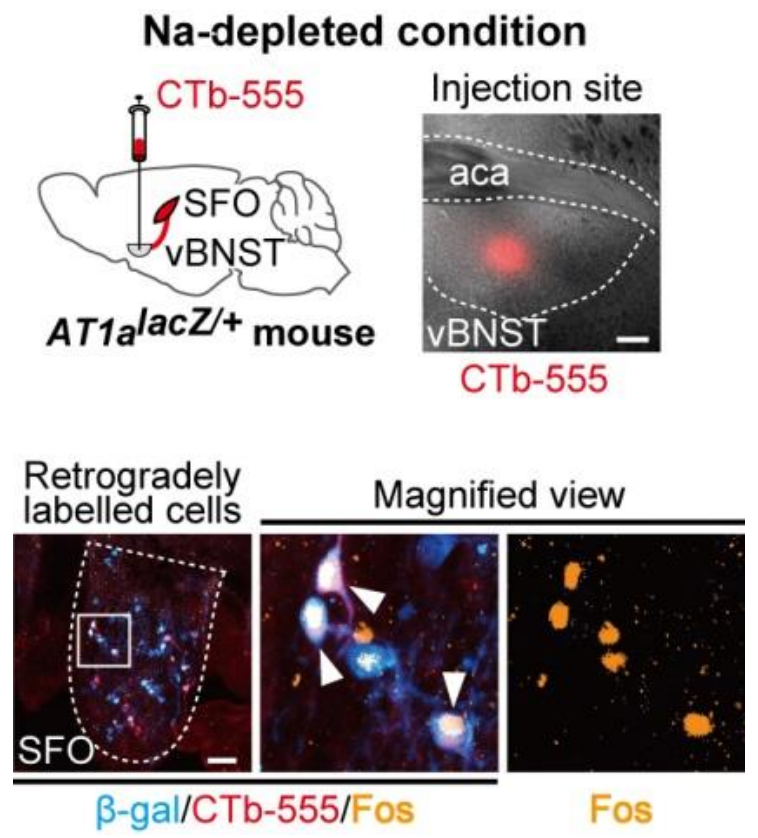

Figure III.13 The SFO neurons projecting to the vBNST are activated under the Na-depleted condtion.

Top, left: injection of CTb-555 into the vBNST of ATla lacZ/+ mice. Top, right: representative injection site. Scale bar, $100 \mu \mathrm{m}$. Bottom: immunohistochemical detection of $\beta$-gal and Fos, and CTb-555 fluorescence in the SFO under the Na-depleted condition. Arrowheads indicate triple-positive cells. Scale bar, $50 \mu \mathrm{m}$. 


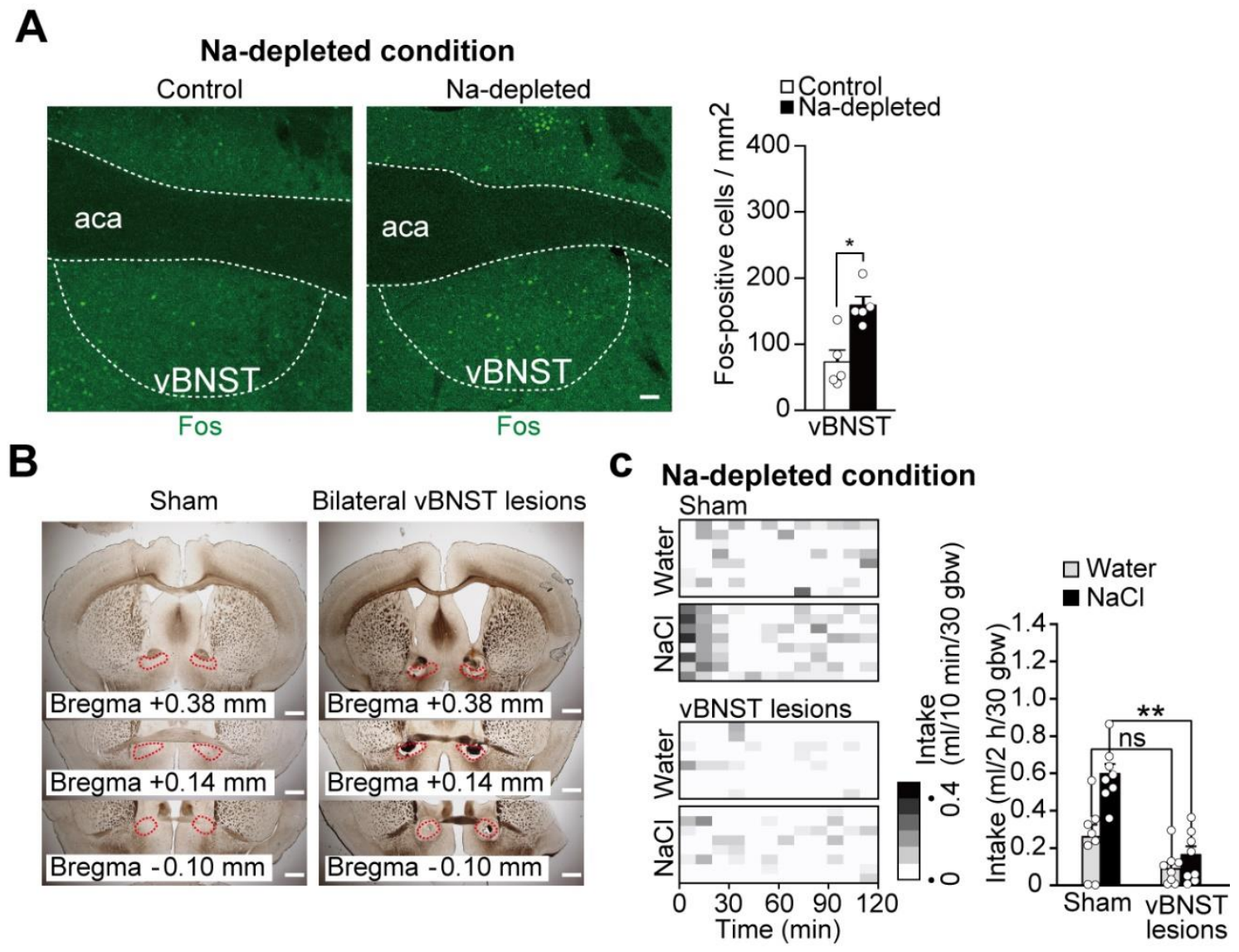

Figure III.14 The vBNST is involved in salt-intake, but not water-intake behavior.

(A) Left: immunohistochemical detection of Fos in the vBNST under the Na-depleted condition. Right: summary of Fos-positive cell counts $(n=5$ mice each; $U=1, P=$ 0.0216). Scale bar, $50 \mu \mathrm{m}$. (B) Electrolytic lesions in bilateral vBNST. Representative coronal sections show the lesioned areas. Scale bar, $600 \mu \mathrm{m}$. Left: gray scale heat maps of water and $0.3 \mathrm{M} \mathrm{NaCl}$ intakes showing the effects of lesions on their intakes under the Na-depleted condition. Right: summary of intake volumes $\left(n=8\right.$ mice each; $\left.U_{(\text {Water })}=50, P=0.0658 ; U_{(\mathrm{NaCl})}=63, P=0.0013\right) . \quad$ ns, not significant; $* P<0.05$; $* * P<0.01$; Mann-Whitney $U$-tests. Data show mean \pm s.e.m. 
A
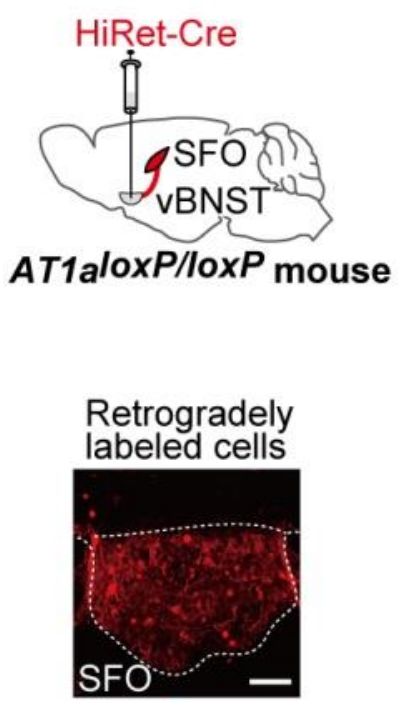

Cre
B

Two-bottle test (Na-depleted condition)
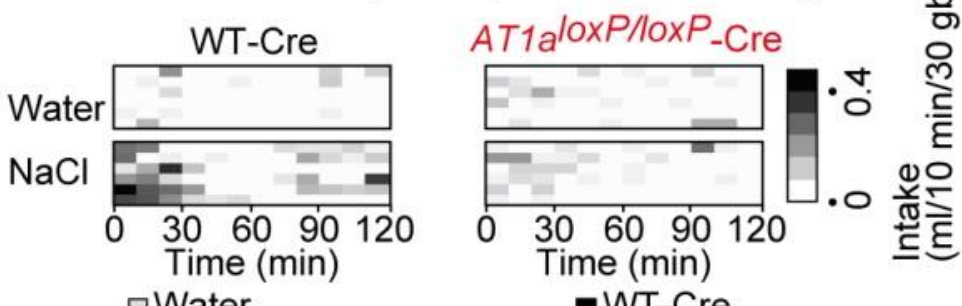

-WT-Cre

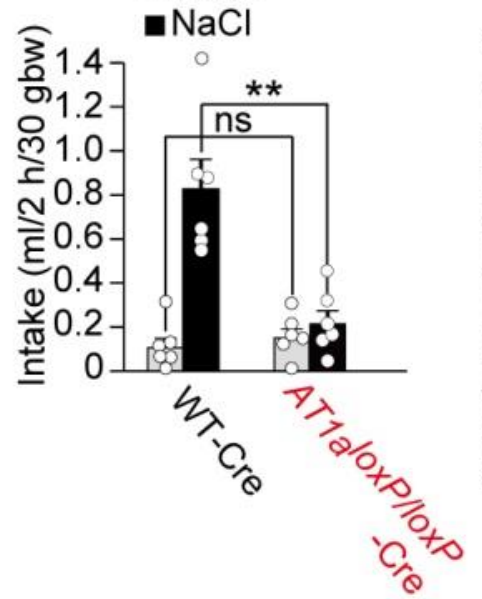

-AT1aloxP/loxP-Cre

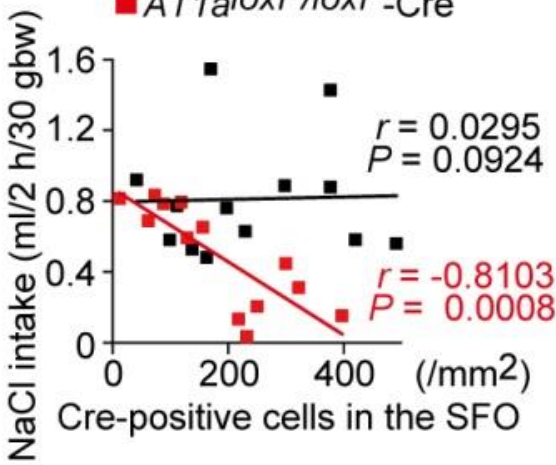

Figure III.15 Deletion of AT1a receptors in the SFO neurons projecting to the vBNST reduces salt intake under the Na-depleted condition.

(A) Top: injection of HiRet-Cre into bilateral vBNST of ATla $a^{\text {loxP/loxP }}$ mice. Bottom: immunohistochemical detection of Cre in the SFO. Scale bar, $50 \mu \mathrm{m}$. (B) Top: grayscale heat maps of water and $0.3 \mathrm{M} \mathrm{NaCl}$ intakes under the $\mathrm{Na}$-depleted condition. Bottom, left: a summary of the two-bottle test. Only data from highly infected mice, in which more than 200 Cre-positive cells were detected per $\mathrm{mm}^{2}$ in the SFO, were used in the analysis $\left(n=6\right.$ mice each; $\left.U_{(\text {Water })}=10.5, P=0.2615 ; U_{(\mathrm{NaCl})}=36, P=0.0051\right)$. Bottom, right: the relationship between the number of Cre-positive cells in the SFO and $0.3 \mathrm{M} \mathrm{NaCl}$ intake in the two-bottle test $\left(n=13\right.$ mice each; $r_{(\mathrm{WT})}=0.0295, P=0.0924$; $r_{(l o x P \text {-flanked Agtrla })}=-0.8103, P=0.0008$; Pearson correlation analysis). Linear regression lines are shown in black (WT-Cre) and red $\left(A T 1 a^{\text {loxP/loxP }}-C r e\right)$. bw, body weight; ns, not significant; $* * P<0.01$; Mann-Whitney $U$-tests. Data show mean \pm s.e.m. 
A Na-depleted condition

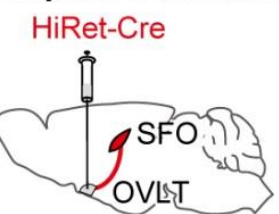

AT1aloxP/loxP mouse

aWT-Cre

AT1aloxP/loxP-Cre

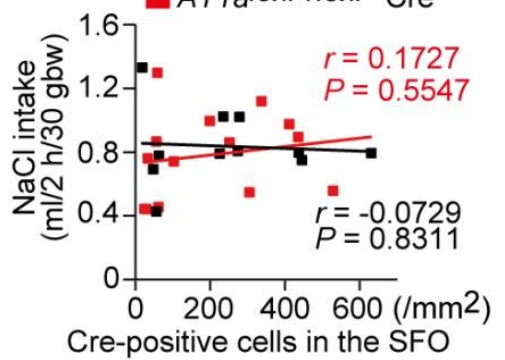

$\mathrm{B}$

Na-depleted condition

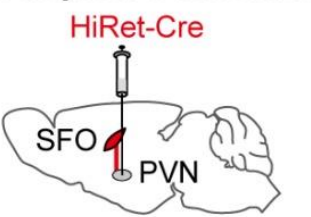

AT1aloxP/loxP mouse

WT-Cre

AT1aloxP/loxP-Cre

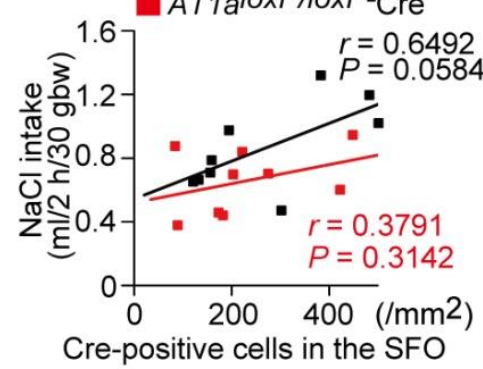

C Na-depleted condition

HiRet-Cre

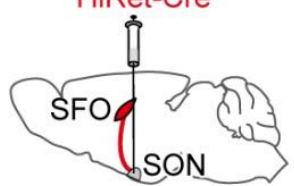

AT1aloxP/loxP mouse

WT-Cre

AT1aloxP/loxP-Cre

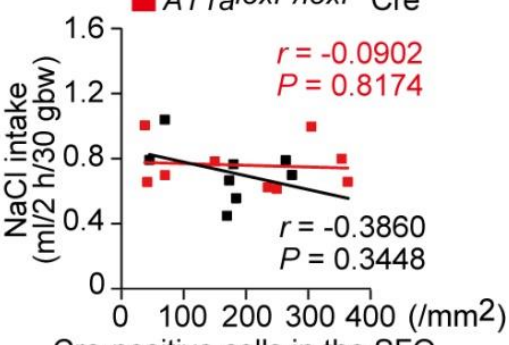

Figure III.16 The SFO neurons projecting to the OVLT, PVN, and SON are not involved in salt-intake behavior under the Na-depleted condtion. (A-C) Top: injection of HiRet-Cre into the OVLT (A), PVN (B), and SON (C) of the AT1a $a^{\text {loxPlloxP }}$ mouse. Bottom: the relationship between the number of Cre-positive cells in the SFO and $0.3 \mathrm{M} \mathrm{NaCl}$ intake in the two-bottle test under the Na-depleted condition $(n=11$ mice for WT and $n=14$ mice for $A T 1 a^{\text {loxP/loxP }}$ in $\mathbf{A} ; r_{(\mathrm{WT})}=-0.0729, P=0.8311$; $r_{(\text {loxP-flanked Agtrla })}=0.1727, P=0.5547: n=9$ mice each in $\mathbf{B} ; r_{(\mathrm{WT})}=0.6492, P=0.0584$; $r_{(\text {loxP-flanked Agtrla })}=0.3791, P=0.3142: n=8$ mice for WT and $n=9$ mice for $A T 1 a^{\text {loxPlloxP }}$ in $\mathbf{C} ; r_{(\mathrm{WT})}=-0.3860, P=0.3448 ; r_{(\text {loxP-flanked Agtrla })}=-0.0902, P=0.8174$; Pearson correlation analysis). Linear regression lines are shown in black (WT-Cre) and $\operatorname{red}\left(A T 1 a^{\text {loxP/loxP }}-\mathrm{Cre}\right)$. 


\section{Optical silencing of the SFO $\rightarrow$ VBNST pathway (Na-depleted condition)}

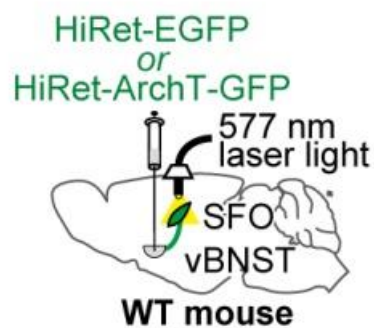

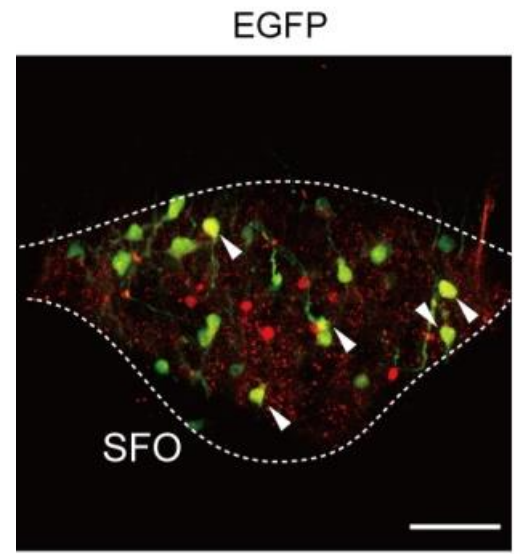

EGFP/Fos

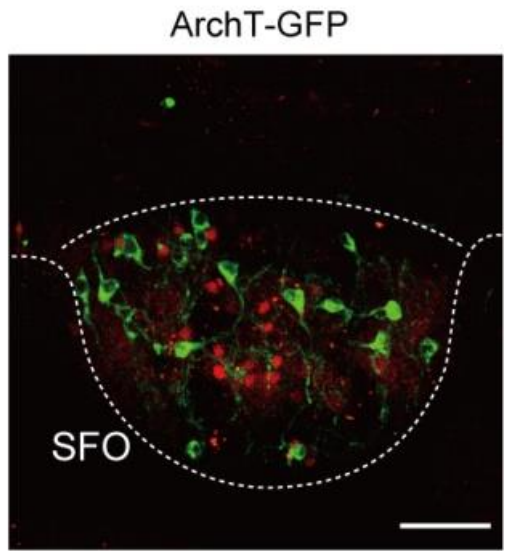

ArchT-GFP/Fos

Figure III.17 Optical silencing of the SFO $\rightarrow$ vBNST pathway reduces Fos expression in the SFO under the Na-depleted condition.

Top: injection of HiRet-EGFP or HiRet-ArchT-EGFP into the vBNST of WT mouse. Bottom: immunohistochemical detection of Fos and EGFP after the optical silencing of the SFO under the Na-depleted condition. Arrow heads indicate double-positive cells (left panel). After the optical silencing, Fos expression was not observed in the ArchT-GFP expressing neurons (right panel), and no double-positive cells were detected. Scale bars, $50 \mu \mathrm{m}$. 


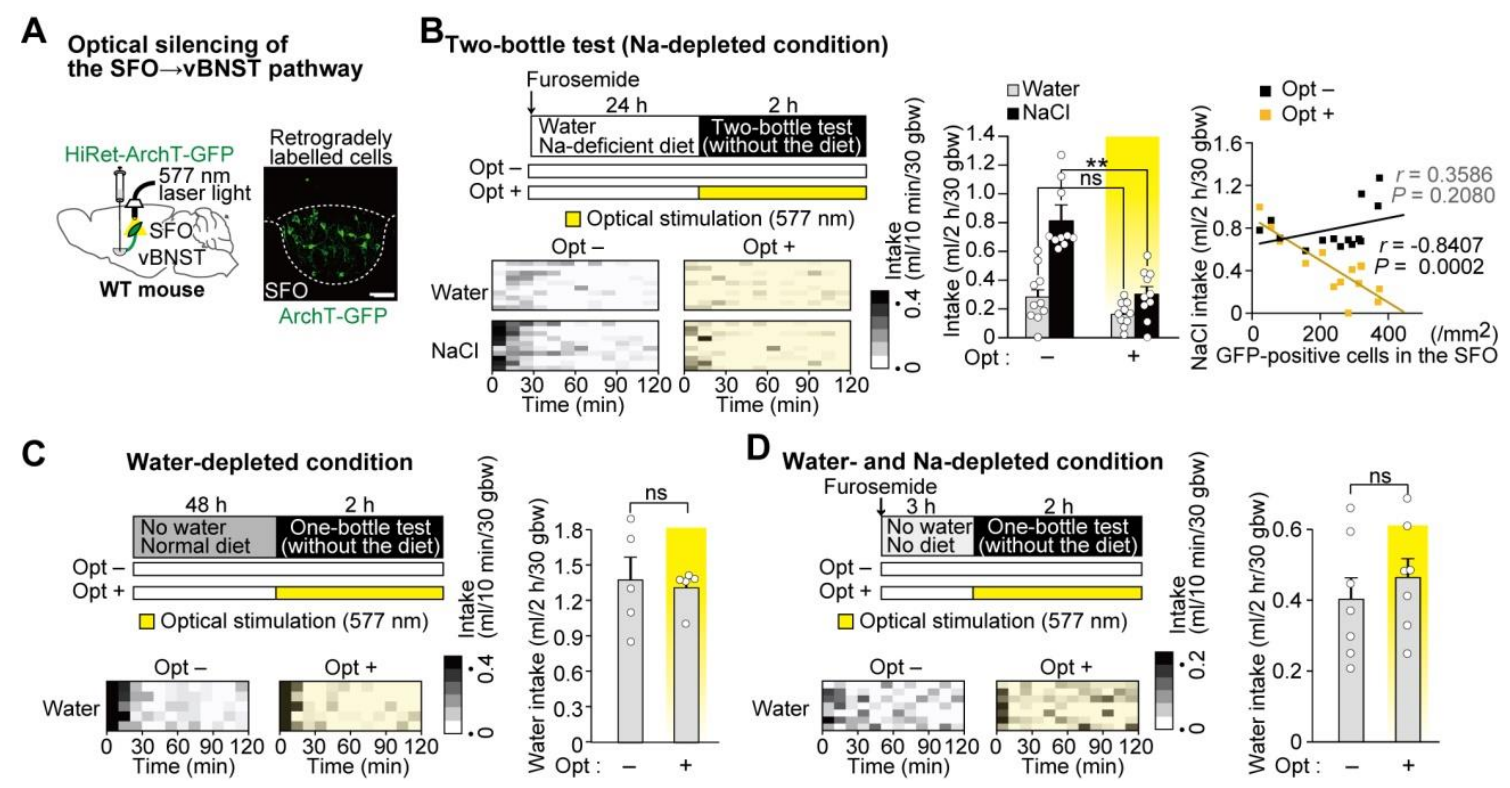

Figure III.18 Optical silencing of the SFO $\rightarrow$ vBNST pathway reduces appetitive behavior for salt, but not for water.

(A) Left: injection of HiRet-ArchT-GFP into the bilateral vBNST of WT mice. Right: immunohistochemical detection of ArchT-GFP in the SFO. Scale bar, $50 \mu \mathrm{m} . \quad$ (B) Left. top: experimental protocol of Na-depletion and subsequent two-bottle test with optical silencing of the SFO $\rightarrow$ vBNST pathway. Left, bottom: grayscale heat maps of water and $0.3 \mathrm{M} \mathrm{NaCl}$ intakes by individual mice, in which more than 200 ArchT-GFP-positive cells were detected per $\mathrm{mm}^{2}$ in the SFO. Middle: summary of intake volumes in the two-bottle test ( $n=10$ mice each; $\left.U_{(\text {Water })}=68, P=0.1859 ; U_{(\mathrm{NaCl})}=100, P=0.0002\right)$. Right: the relationship between the number of GFP-positive cells in the SFO and $0.3 \mathrm{M}$ $\mathrm{NaCl}$ intake with $(\mathrm{Opt}+)$ or without $(\mathrm{Opt}-)$ optical stimulation $\left(n=14\right.$ mice each; $r_{(\mathrm{Opt}-)}$ $=0.3586, P=0.2080 ; r_{(\mathrm{Opt}+)}=-0.8407, P=0.0002 ;$ Pearson correlation analysis $)$.

D) Effects of optically silencing the SFO $\rightarrow$ vBNST pathway on water intake under the 
water-depleted $(\mathbf{C})$ or water- and Na-depleted (D) conditions. The relationships between the number of GFP-positive cells in the SFO and water intake with the optical stimulation are shown in Figure III.19 (C: $n=5$ mice each; $U=12, P=1.0000 ; \mathbf{D}: n=$ 7 mice each; $U=18, P=0.4432$ ). bw, body weight; ns, not significant; ** $P<0.01$; all tests are Mann-Whitney $U$-test unless otherwise stated. Data show mean \pm s.e.m. 


\section{A Water-depleted condition}

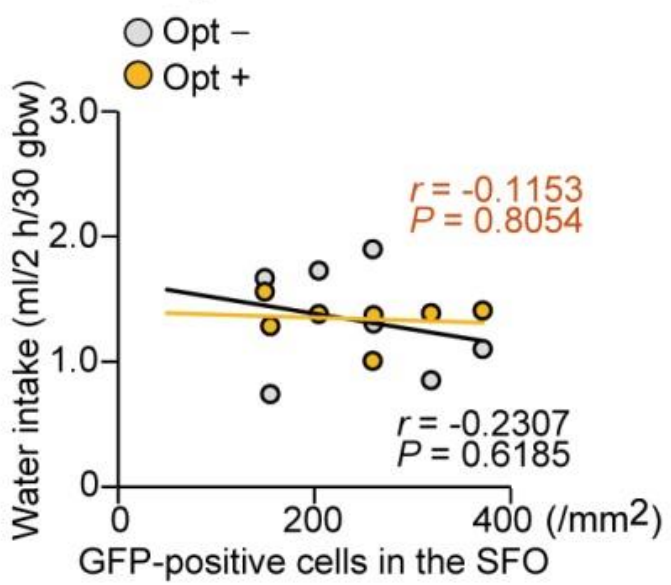

B Water- and Na-depleted condition

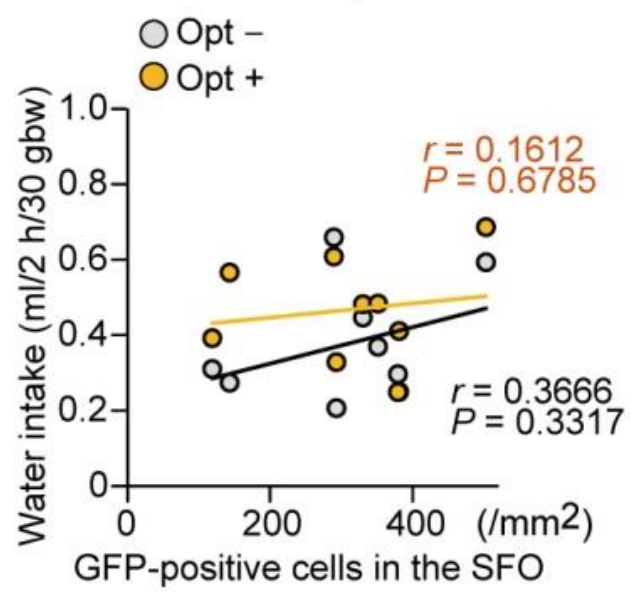

Figure III.19 Optical silencing of the SFO $\rightarrow$ vBNST pathway does not reduce appetitive behavior for water.

(A, B) Optical silencing of the SFO $\rightarrow$ vBNST pathway on water intake under the water-depleted $(\mathbf{A})$ or water- and Na-depleted $(\mathbf{B})$ condition. The relationship between the number of ArchT-GFP-positive cells in the SFO and water intake with or without the optical stimulation $\left(n=7\right.$ mice for $\mathbf{A} ; r_{(\mathrm{Opt}-)}=-0.2307, P=0.6185 ; r_{(\mathrm{Opt}+)}=-0.1153, P=$ 0.8054: $n=9$ mice for $\mathbf{B} ; r_{(\mathrm{Opt}-)}=0.3666, P=0.3317 ; r_{(\mathrm{Opt}+)}=0.1612, P=0.6785$; Pearson correlation analysis). bw, body weight. 


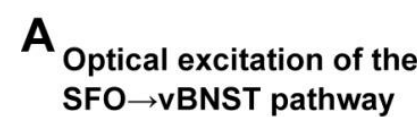

B Two-bottle test (water-depleted condition) SFO $\rightarrow$ VBNST pathway

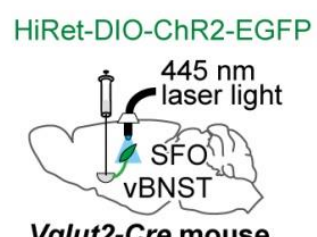

Vglut2-Cre mouse
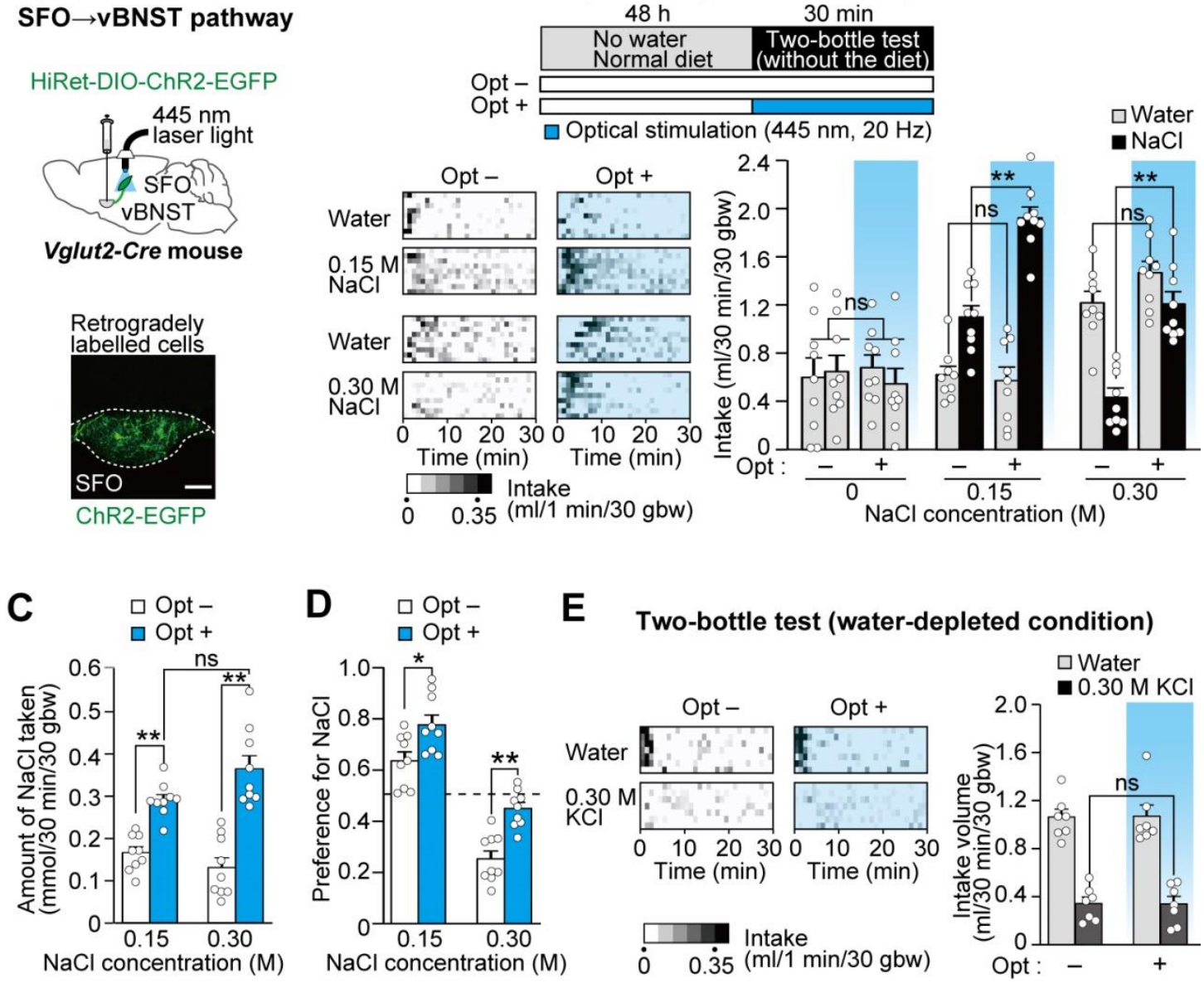

Figure III.20 Optical excitation of the SFO $\rightarrow$ vBNST pathway reverses salt avoidance and increases salt appetite in dehydrated mice.

(A) Top: injection of HiRet-DIO-ChR2-EGFP into bilateral vBNST of Vglut2-Cre mice. Bottom: immunohistochemical detection of ChR2-EGFP in the SFO. Scale bar, $50 \mu \mathrm{m}$. (B) Experimental protocol for optical excitation of the SFO $\rightarrow$ vBNST pathway under the water-depleted condition. Bottom, left: grayscale heat maps of water and salt $(0.15$ or $0.30 \mathrm{M} \mathrm{NaCl})$ intakes by individual mice with $(\mathrm{Opt}+)$ or without $(\mathrm{Opt}-)$ optical excitation of the SFO $\rightarrow$ vBNST pathway under the water-depleted condition. Bottom, right: effects of optical stimulation on the intakes of water and salt $(0,0.15$ and $0.30 \mathrm{M}$ 
$\mathrm{NaCl})\left(n=9\right.$ mice each; $U=46, P=0.6588$ in $0 \mathrm{M} ; U_{(\text {Water })}=44, P=0.7911 ; U_{(\mathrm{NaCl})}=1$, $P=0.0006$ in $0.15 \mathrm{M} ; U_{\text {(Water) }}=20, P=0.0774 ; U_{(\mathrm{NaCl})}=0, P=0.0004$ in $\left.0.30 \mathrm{M}\right)$. (C) Amounts of $\mathrm{NaCl}$ consumed by mice as calculated from the data in $\mathbf{B}$ ( $n=9$ mice each; $U_{(0.15 \mathrm{M})}=1, P=0.0006 ; U_{(0.30 \mathrm{M})}=0, P=0.0004 ; U_{(0.15 \mathrm{M} \text { vs. } 0.30 \mathrm{M})}=18, P=$ 0.0520). (D) Preference ratio for $\mathrm{NaCl}$ as calculated from the data in $\mathbf{B}$ ( $n=9$ mice each; $\left.U_{(0.15 \mathrm{M})}=15, P=0.0273 ; U_{(0.30 \mathrm{M})}=3, P=0.0011\right)$. The broken line indicates 0.5 , which represents no preference. The broken line indicates 0.5 , which represents no preference. (E) Grayscale heat maps and summary of water and $0.3 \mathrm{M} \mathrm{KCl}$ intakes under the water-depleted condition with or without optical stimulation $(n=7$ mice each; $U=26, P=0.8983$ ). bw, body weight; ns, not significant; $* P<0.05$; $* * P<0.01$; Mann-Whitney $U$-tests. Data show mean \pm s.e.m. 


\section{Chapter IV}

\section{Modulation of the neuronal activity of the water and salt neurons in the SFO}




\section{IV.1 Introduction}

Previous studies on $N a_{x}-\mathrm{KO}$ mice by my laboratory revealed that $\mathrm{Na}_{\mathrm{x}}$ channels expressed in specific glial cells sense an increase in $\left[\mathrm{Na}^{+}\right]$in body fluids to generate salt-avoidance behavior in dehydrated animals (Hiyama et al., 2004). In the SFO, activation of $\mathrm{Na}_{\mathrm{x}}$ leads to release of lactate from $\mathrm{Na}_{\mathrm{x}}$-positive glial cells, which functions as a gliotransmitter for the activation of the GABAergic inhibitory neurons (Shimizu, et al., 2007). The GABAergic neurons were postulated to suppress putative neurons that activate salt appetite; however, the target neurons of the GABAergic neurons have not been identified yet. In this chapter, I tested the possibility that the putative neurons for salt appetite are the $\mathrm{SFO}(\rightarrow \mathrm{vBNST})$ neurons.

A recent study showed that optical excitation of GABAergic neurons in the SFO reduced the drinking amount of water (Oka et al., 2015), suggesting that there exist some inhibitory mechanisms to suppress thirst in the SFO. Because receptors of several peptide hormones are known to be highly expressed in the SFO (Orskov, et al., 1996; Pulman et al., 2006; Smith, et al., 2009), neural modulations by these peptides are plausible mechanisms for the thirst regulation. Among the peptides that are known to modulate the excitability of the SFO neurons, cholecystokinin (CCK) has been reported to inhibit water intake when injected into the cerebroventricle (Willis et al., 1984). Expressions of the CCK receptors (CCKAR and CCKBR) are detected in the SFO by reverse transcription PCR (Ahmed et al., 2014). Moreover, CCKBR-KO mice show enhanced water consumption compared to WT mice (Noble and Roques, 1999). Based on these studies, I speculated that CCK may be involved in the control of driving neurons for thirst in the SFO. 


\section{IV.2 Materials and Methods}

Immunohistochemistry, virus infection, surgery, and behavioral assays were performed as described in chapter II and III.

\section{Experimental animals}

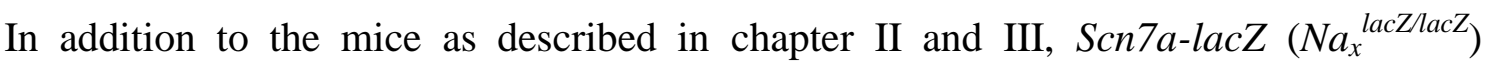
(Watanabe et al., 2000) mice were used.

\section{Reagents}

In addition to the reagents as described in chapter II and III, CCK (4100-V, Peptide institute) was used. All other reagents were obtained from Sigma-Aldrich.

\section{Quantification of CCK levels in the SFO}

For the measurement of CCK, the SFO tissues dissected from WT mice were homogenized in the modified Ringer solution. These tissues collected from 3 mice were used as one sample. CCK was extracted from the homogenized samples with acetone and diethyl ether. These samples were dried in a vacuum chamber, and then dissolved in RIA buffer supplied with the RIA kit. Measurements were performed as described in chapter II.

\section{Electrophysiology with SFO Slices}

Electrophysiological experiments with $G A D 67-G F P$ mice and $G A D 67-G F P ; N a_{x}-\mathrm{KO}$ mice were performed as reported (Shimizu et al., 2007) with minor modifications. CTb-555 was injected bilaterally into vBNST at least 1 week before the recordings. The brains were quickly removed and submerged for 5-10 min in ice-cold sucrose Ringer 
solution containing (in $\mathrm{mM}$ ): 260 sucrose, $2.5 \mathrm{KCl}, 10 \mathrm{MgSO}_{4}, 0.5 \mathrm{CaCl}_{2}, 5 \mathrm{HEPES}, 10$ glucose and $5 \mathrm{NaOH}$, bubbled with $100 \% \mathrm{O}_{2}(\mathrm{pH} 7.3$ with $\mathrm{HCl})$. Slices were cut with a microslicer (Pro 7, Dosaka EM) at a thickness of $350 \mu \mathrm{m}$ and at an angle of $45^{\circ}$ to the coronal plane and then preincubated at room temperature for more than $1 \mathrm{~h}$.

Slices were mounted in a recording chamber on an upright microscope (BX61WI, Olympus) and continuously perfused with modified Ringer solution. Recordings were made in modified Ringer solution (see "Surgery" section in chapter III). In experiments performed under the $160 \mathrm{mM} \mathrm{Na}$ condition, $\mathrm{NaCl}$ was added to modified Ringer solution. To record evoked IPSCs, CTb-555-labeled neurons were selected using fluorescent optics, and a whole-cell configuration was then obtained. In analyses of firing frequencies, cell-attached configurations were obtained in $\mathrm{CTb}$-555-labeled and GFP-positive neurons. All recordings were made at $33-36{ }^{\circ} \mathrm{C}$. Inhibitors were applied to the slices more than 10 min before the start of the experiments and the concentrations of the inhibitors were kept constant until the experiments finished.

Patch pipettes were prepared from borosilicate glass capillaries and filled with pipette solution containing (in $\mathrm{mM}$ ): $140 \mathrm{~K}$ gluconate, $10 \mathrm{KCl}, 2 \mathrm{MgCl}_{2}, 0.2 \mathrm{EGTA}, 2$ $\mathrm{Na}_{2} \mathrm{ATP}, 10$ HEPES and 0.1 spermine $(\mathrm{pH} 7.3$ with $\mathrm{HCl})$. The resistance of the electrodes was 3-7 M $\Omega$ in Ringer solution. Data were acquired using Axopatch 200B and Axopatch 1D patch-clamp amplifiers (Axon Instruments) with the software pCLAMP and analyzed with the software Clampfit (Axon Instruments). 


\section{IV.3 Results}

\section{$\mathrm{Na}_{\mathrm{x}}$ is involved in the control of $\mathrm{SFO} \rightarrow \mathrm{vBNST}$ pathway}

Prof. Noda's laboratory previously revealed that $N a_{x}-\mathrm{KO}\left(N a_{x}^{\text {lacZlacZ }}\right)$ mice did not show salt aversion under the water-depleted condition (Watanabe et al., 2000; Hiyama et al., 2004). To examine the relationship between $\mathrm{Na}_{\mathrm{x}}$ signals and the ATla-dependent control of salt appetite, I examined $0.3 \mathrm{M} \mathrm{NaCl}$ intake by WT, $N a_{x}-\mathrm{KO}, A T l a-\mathrm{KO}$, and $N a_{x}-A T l a$-double KO (DKO) mice in the two-bottle test before and after $48 \mathrm{~h}$ of water depletion (Fig. IV.1A). When dehydrated, salt intake by WT mice was significantly less than water intake reflecting salt avoidance due to high $\left[\mathrm{Na}^{+}\right]$in body fluids as a result of dehydration (Fig. IV.1B). Consistent with previous results (Watanabe et al., 2000; Hiyama et al., 2004), $N a_{x}$-KO mice consumed pure water and $0.3 \mathrm{M} \mathrm{NaCl}$ equally; as the result, the preference ratio for $0.3 \mathrm{M} \mathrm{NaCl}$ was larger than that for WT mice (Fig. IV.1B). In contrast, notably, $0.3 \mathrm{M} \mathrm{NaCl}$ intake was almost negligible by $A T l a-\mathrm{KO}$ and $N a_{x}-A T l a-\mathrm{DKO}$ mice (Fig. IV.1A,B; see also Fig. II.2C), indicating that salt appetite in WT and $N a_{x}-\mathrm{KO}$ mice under the water-depleted condition was completely abolished by knocking out Agtrla. Thus, $\mathrm{Na}_{\mathrm{x}}$ signals appear to be upstream of the AT1a-dependent control of salt intake.

To investigate this possibility at the cellular level, I examined the activity levels of the $\mathrm{SFO}(\rightarrow \mathrm{vBNST})$ neurons in $\mathrm{WT}, N a_{x}-\mathrm{KO}$ and $A T l a-\mathrm{KO}$ mice, in which HiRet-EGFP was injected into the vBNST (Fig. IV.1C). Under the water-depleted condition, Fos expression was increased in the SFO neurons of all genotypes. The number of Fos-positive cells among EGFP-positive neurons was significantly higher in $N a_{x}$-KO mice than in WT mice (Fig. IV.1C; $P=0.0009$ ), suggesting that the activity of $\mathrm{SFO}(\rightarrow \mathrm{vBNST})$ neurons is negatively regulated by $\mathrm{Na}_{\mathrm{x}}$ signals. Furthermore, the 
value of the ratio was smaller in ATla-KO mice than in WT mice (Fig. IV.1C), indicating that the neural activity of the SFO $\rightarrow$ vBNST pathway is stimulated in an AT1a-dependent manner in dehydrated animals.

\section{$\left[\mathrm{Na}^{+}\right]$-dependent modulation of the neuronal activity of the $\mathrm{SFO}(\rightarrow \mathrm{vBNST})$} neurons

Since the activation of $\mathrm{Na}_{\mathrm{x}}$ by an increase in $\left[\mathrm{Na}^{+}\right]$in body fluids causes the activation of GABAergic neurons in the SFO (Shimizu et al., 2007), I conducted electrophysiological experiments using acute brain slices containing the SFO to examine whether the activity of the SFO $\rightarrow$ vBNST pathway is regulated by GABAergic neurons. Brain slices were prepared from GAD67-GFP $\left(G A D 67^{G F P /+}\right)$ and GAD67-GFP;N $a_{x}-\mathrm{KO}$ mice that received $\mathrm{CTb}-555$ injections bilaterally to the vBNST beforehand (Fig. IV.2A). In these slices, GABAergic and SFO $(\rightarrow \mathrm{vBNST})$ neurons were identified by green (GFP) and red fluorescence (CTb-555), respectively.

I stimulated GABAergic neurons and recorded inhibitory postsynaptic currents from the neighbouring CTb-labeled $\mathrm{SFO}(\rightarrow$ vBNST) neurons (Fig. IV.2B). I then recorded the firing activities of sets of the $\mathrm{SFO}(\rightarrow \mathrm{vBNST})$ neurons and GABAergic neurons connected synaptically (Fig. IV.2C). Under normal $145 \mathrm{mM}\left[\mathrm{Na}^{+}\right]$, the $\mathrm{SFO}(\rightarrow \mathrm{vBNST})$ neurons were silent in GAD67-GFP mice and GAD67-GFP;N $a_{x}-\mathrm{KO}$ mice; however, firing activity was stimulated upon the application of Ang II (Fig. IV.2C). On the other hand, the firing frequency of the GABAergic neurons was not affected by Ang II (Fig. IV.2C). When the perfusing solution was changed to a hypertonic $\mathrm{Na}$ solution $\left(160 \mathrm{mM} \mathrm{Na}{ }^{+}\right)$, the firing rate of the GABAergic neurons was upregulated (Fig. IV.2C-E), as prof. Noda's laboratory reported previously (Shimizu et 
al., 2007). These responses were absent in slices prepared from $N a_{x}$ - $\mathrm{KO}$ mice (Fig. IV.2D, E), indicating that the GABAergic activity is regulated by $\mathrm{Na}_{\mathrm{x}}$ signals.

In line with elevations in the activity of the GABAergic neurons by the hypertonic $\mathrm{Na}$ solution, the Ang II-induced firing activity of the $\mathrm{SFO}(\rightarrow \mathrm{vBNST})$ neurons was suppressed in WT mice (Fig. IV.2D, E). This effect by GABAergic neurons on the $\mathrm{SFO}(\rightarrow \mathrm{vBNST})$ neurons in WT mice disappeared when $\left[\mathrm{Na}^{+}\right]$was returned to normal levels (Fig. IV.2D, E). Notably, the $\left[\mathrm{Na}^{+}\right]$-dependent control of the $\mathrm{SFO}(\rightarrow \mathrm{vBNST})$ neurons was absent in $N a_{x}-\mathrm{KO}$ mice (Fig. IV.2D, E). These findings supported the activity of the SFO $\rightarrow$ vBNST pathway being under the regulation of GABAergic neurons, the activity of which is controlled by the $\left[\mathrm{Na}^{+}\right]$signals sensed by $\mathrm{Na}_{\mathrm{x}}$. Since the regulation of GABAergic activities by $\mathrm{Na}_{\mathrm{x}}$ is known to be mediated by lactate signaling from $\mathrm{Na}_{\mathrm{x}}$-positive glial cells to GABAergic neurons (Shimizu et al., 2007), I examined the effects of $\alpha$-cyano-4-hydroxycinnamic acid ( $\alpha$-CHCA), an inhibitor of monocarboxylate transporters, which mediate the intercellular transport of lactate (Gladden, 2004). The $\left[\mathrm{Na}^{+}\right]$-dependent modulation of the GABAergic neurons and the $\mathrm{SFO}(\rightarrow \mathrm{vBNST})$ neurons was abolished by $5 \mathrm{mM} \alpha$-CHCA (Fig. IV.2F).

I then tested whether the activation of GABAergic neurons in the SFO reduced salt intake, using optogenetics in animals. As expected, the optical excitation of GABAergic neurons in the SFO significantly reduced salt intake under the Na-depleted condition (Fig. IV.3). Optical stimulation also reduced water intake slightly but significantly (Fig. IV.3), suggesting that there may exist a population of GABAergic neurons that control the SFO $(\rightarrow$ OVLT) neurons. 
Cholecystokinin-dependent modulation of the neuronal activity of the SFO $(\rightarrow$ OVLT $)$ neurons

I then explored inhibitory signals that suppress the activity of the $\mathrm{SFO}(\rightarrow$ OVLT $)$ neurons. Brain slices containing the SFO were prepared from GAD67-GFP mice that had received CTb-555 injections to the OVLT beforehand, and the firing activity of the set of CTb-labelled $\mathrm{SFO}(\rightarrow \mathrm{OVLT})$ neurons and their synaptically connected GABAergic neurons was examined (Fig. IV.4A-C). Under normal $145 \mathrm{mM}\left[\mathrm{Na}^{+}\right]$, the $\mathrm{SFO}(\rightarrow \mathrm{OVLT})$ neurons were silent in WT mice; the firing activity of a half of these neurons (8/13 cells) was stimulated upon the application of Ang II (Fig. IV.4B, C). I then applied CCK to the perfusate, because it has been reported as inhibiting water intake when injected to the brain (Willis et al., 1984). CCK upregulated the GABAergic activities along with suppression of the Ang II-induced firing activity of the $\mathrm{SFO}(\rightarrow \mathrm{OVLT})$ neurons (Fig. IV.4B, C). On the other hand, the hypertonic Na solution (160 mM) did not change the activities of these neurons (Fig. IV.4D).

Notably, CCK did not affect the activity of the GABAergic neurons that are connected to the SFO $(\rightarrow$ vBNST) neurons (Fig. IV.5). These findings indicate that there exist distinct populations of GABAergic neurons in the SFO that selectively regulate the $\mathrm{SFO}(\rightarrow$ VBNST $)$ neurons or $\mathrm{SFO}(\rightarrow$ OVLT $)$ neurons. Finally, I corroborated the possibility that the CCK is increased in the SFO under the Na-depleted condition to suppress water intake despite the high Ang II. As was expected, the CCK levels in the SFO were increased approximately nine-fold under the Na-depleted (water-satiated) condition (Fig. IV.6). 


\section{IV.4 Discussion}

In this chapter, I investigated whether the AT1a signals for salt appetite are modulated by $\mathrm{Na}_{\mathrm{x}}$ signals based on body-fluid conditions. I performed electrophysiological experiments with acute brain slice containing the SFO in which the $\mathrm{SFO}(\rightarrow \mathrm{vBNST})$ neurons and $\mathrm{SFO}(\rightarrow \mathrm{OVLT})$ neurons were labelled by retrograde tracer. The results of these experiments indicate that the $\mathrm{SFO}(\rightarrow \mathrm{vBNST})$ neurons for salt appetite are modulated by $\mathrm{Na}_{\mathrm{x}}$ signals through GABAergic neurons in the SFO. On the other hand, I also demonstrated that the increase in CCK levels in the SFO activates the another population of GABAergic neurons along with inactivation of the $\mathrm{SFO}(\rightarrow$ OVLT $)$ neurons.

Prof. Noda's laboratory previously reported that the activation of $\mathrm{Na}_{\mathrm{x}}$ leads to elevation in the firing rate of GABAergic neurons in the SFO (Shimizu et al., 2007; Noda and Sakuta, 2013), and I postulated that the GABAergic neurons lead to suppression of the hypothetical SFO neurons driving salt appetite. In present study, electrophysiological experiments using acute brain slices revealed that the hypothetical salt-appetite driving neurons are the $\mathrm{SFO}(\rightarrow$ vBNST) neurons (Fig. IV.2). Salt intake disappeared under the water-depleted condition, even when that the plasma Ang II level was high (Fig. II.1C and II.2C). Taken together, these results indicate that the activity of the $\mathrm{SFO}(\rightarrow \mathrm{vBNST})$ neurons in the $\mathrm{SFO}$ is suppressed by $\mathrm{Na}_{\mathrm{x}}$ signals through GABAergic neurons even in the presence of Ang II.

Water intake disappeared under the Na-depleted condition in WT mice, even when the plasma Ang II level was high (Fig. II.2B). This indicated that the activities of the $\mathrm{SFO}(\rightarrow \mathrm{OVLT})$ neurons were suppressed, even in the presence of Ang II. In the 
present study, I revealed that the Ang II-dependent neural activities of the $\mathrm{SFO}(\rightarrow \mathrm{OVLT})$ neurons were suppressed by CCK (Fig. IV.4). Consistently, CCK contents in the SFO tissue were markedly enhanced under the Na-depleted (namely water-satiated) condition, as compared with control (water- and Na-satiated) and water-depleted conditions (Fig. IV.6). This may explain why mice under the Na-depleted condition did not drink water despite the high Ang II levels.

Here I should note that CCK levels in plasma were constantly $\sim 60 \mathrm{pM}$ irrespective of body-fluid conditions in my experiments. Considering it together with the affinity of CCK receptors (600 pM for CCKAR; $300 \mathrm{pM}$ for CCKBR) (Weiland et al., 2004), circulating CCK is unlikely to activate CCK receptors in the SFO. The CCK-expressing neurons were reportedly located in the parabrachial nucleus (Garfield et al., 2014) and nucleus tractus solitaries (D'Agostino et al., 2016), both of which were also known to be related to body fluid homeostasis (Johnson, 2007). Because neurons in these nuclei have projections to the SFO (McKinley et al., 2003), CCK originated from these neurons may contribute to the suppression of water neurons. Identification of CCK-producing cells in the brain and regulatory mechanisms of the production are important subjects in the future. 
A
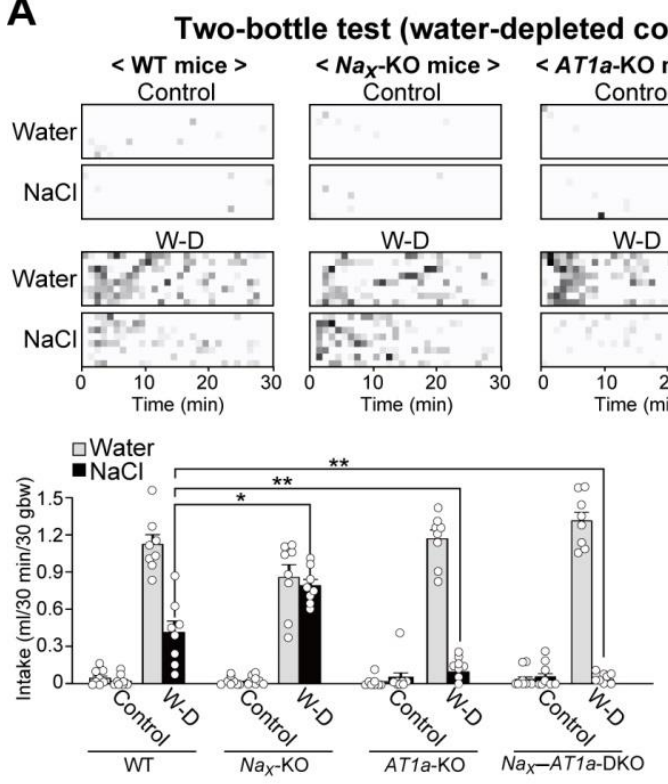

B

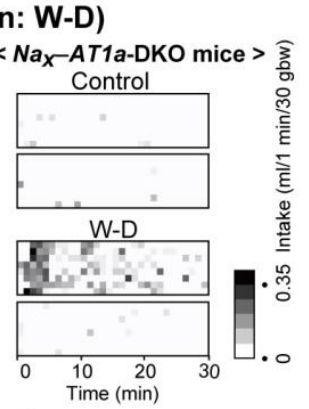

C Water-depleted condition

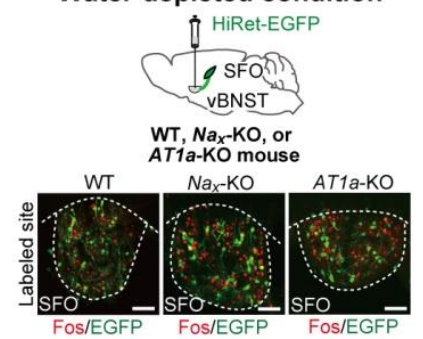

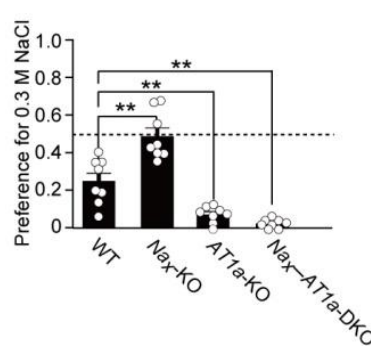

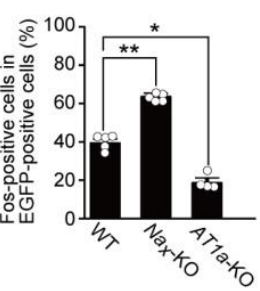

Figure IV.1 Salt appetite in $N a_{x}$-KO mice under the water-depleted condition is abolished by Agtr1a deletion.

(A) Top: grayscale heat maps of individuals. Bottom: summary of water and $0.3 \mathrm{M}$ $\mathrm{NaCl}$ intakes by WT, $N a_{x}-\mathrm{KO}, A T l a-\mathrm{KO}$ and $N a_{x}-A T l a-\mathrm{DKO}$ mice under the water-satiated (control) and water-depleted (W-D) conditions $\left(n=8\right.$ mice each; $U_{(\text {Nax }-\mathrm{KO})}$ $\left.=7, P=0.0100 ; U_{(\text {ATla-KO })}=57, P=0.0086 ; U_{(\text {Nax-ATIa-DKO })}=60, P=0.0036\right)$.

Preference ratios for $\mathrm{NaCl}$ under the $\mathrm{W}-\mathrm{D}$ as calculated from the data in $\mathbf{A}$ ( $n=8$ mice each; $U_{(\text {Nax }-\mathrm{KO})}=3, P=0.0028 ; U_{(\text {ATla-KO })}=58, P=0.0074 ; U_{(\text {Nax }- \text { ATla }-\mathrm{DKO})}=63, P=$ 0.0013). (C) Left, top: injection of HiRet-EGFP into bilateral vBNST of WT, $N a_{x}$-KO and ATla-KO mice. Left, bottom: immunohistochemical detection of Fos and EGFP in the SFO under the W-D. Scale bars, $50 \mu \mathrm{m}$. Right: summary of Fos-positive cell counts in EGFP-positive cells of mice under the W-D ( $n=5$ mice each for WT and $N a_{x}-\mathrm{KO}, n$ $=4$ mice for ATla-KO; $\left.U_{(\text {Nax }-\mathrm{KO})}=25, P=0.0009 ; \mathrm{U}_{(\text {ATla-KO })}=20, P=0.0199\right) . \mathrm{bw}$, body weight; $* P<0.05 ; * * P<0.01$; Mann-Whitney $U$-tests. Data show mean \pm s.e.m. 


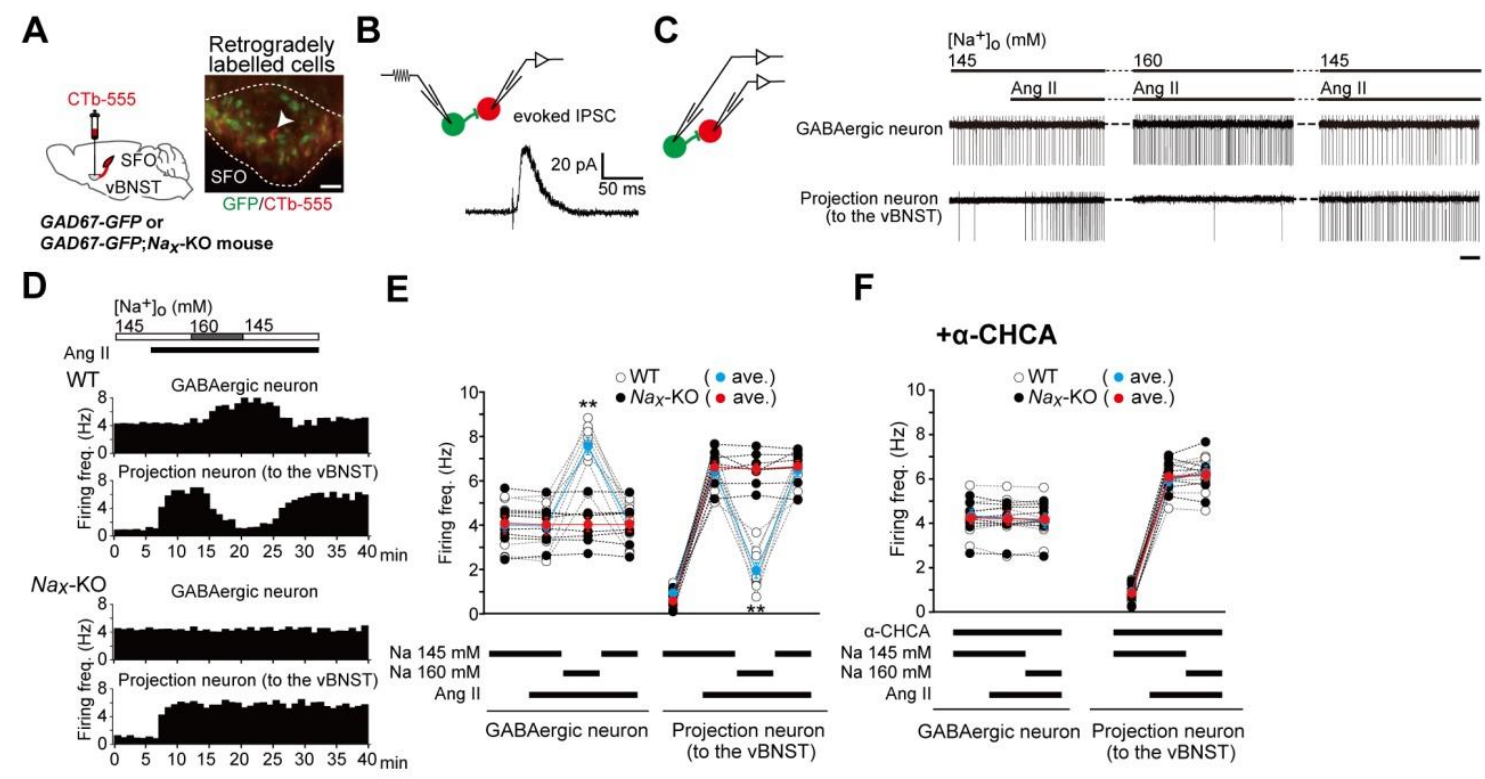

Figure IV.2 Activity of the SFO $\rightarrow$ vBNST pathway for salt appetite is suppressed by $\mathrm{Na}_{\mathrm{x}}$ signal.

(A) Left: injection of CTb-555 into bilateral vBNST of GAD67-GFP and GAD67-GFP;N $a_{x}-\mathrm{KO}$ mice. Right: representative image of the SFO. Arrowhead, CTb-555-labeled neuron; scale bar, $50 \mu \mathrm{m}$. (B) Schematic drawing of the electrical stimulation of a GABAergic neuron (green) and whole-cell patch-clamp recording from a CTb-555-labeled neuron (red). Representative inhibitory postsynaptic currents (IPSC) recorded from the $\mathrm{CTb}$-555-labeled neuron evoked by stimulation of the GABAergic neuron (right). The holding potential of the CTb-555-labeled neuron was set at $-20 \mathrm{mV}$. Of the GABAergic neurons around the CTb-555-labeled neuron, 50\% had synaptic outputs to the CTb-555-labeled neuron. (C) Left: schematic drawing of recordings from GABAergic and CTb-555-labeled neurons. Right: representative firing activities of GABAergic and CTb-555-labeled neurons recorded with the patch-clamp method in 
cell-attached configurations. Ang II $(0.1 \mu \mathrm{M})$ was added to the perfusate during the time indicated with the horizontal bar. Scale bar, 1 s. (D, E) Effects of hypertonic Na on firing activities of GABAergic neurons. Representative time courses of firing frequencies recorded from GAD67-GFP (WT) and GAD67-GFP; $N a_{x}-\mathrm{KO}\left(N a_{x}-\mathrm{KO}\right)(\mathbf{D})$. Application of Ang II started at the 7 min mark. Summary data in $\mathbf{E}$ were obtained at 5$6 \mathrm{~min}, 10-11 \mathrm{~min}, 20-21 \mathrm{~min}$ and 30-31 $\min (n=8$ slices each; GABAergic neuron: $U_{(\mathrm{WT})}=0, P=0.0009 ; U_{(\mathrm{Nax}-\mathrm{KO})}=32, P=1.0419$; projection neuron: $U_{(\mathrm{WT})}=64, P=$ $\left.0.0009 ; U_{(\mathrm{Nax}-\mathrm{KO})}=36, P=0.7128\right)$. Blue and red values are means \pm s.e.m. of $\mathrm{WT}$ and $N a_{x}$-KO mice, respectively. ${ }^{*} P P<0.01$, significantly different from control solution (145 $\mathrm{mM} \mathrm{Na}{ }^{+}$) with Ang II by Mann-Whitney $U$-tests. (F) Effects of lactate transporter inhibition on firing frequencies. Data from 5-6 min, 10-11 min and 20-21 $\min \left(n=8\right.$ slices each; GABAergic neuron: $U_{(\mathrm{WT})}=36.5, P=0.6742 ; U_{(\mathrm{Nax}-\mathrm{KO})}=30, P$ $=0.8748$; projection neuron: $\left.U_{(\mathrm{WT})}=22.5, P=0.9459 ; U_{(\mathrm{Nax}-\mathrm{KO})}=33.5, P=0.9163\right)$. Blue and red values are means \pm s.e.m. of WT and $N a_{x}$-KO mice, respectively: the two almost overlap. $\quad * * P<0.01$; Mann-Whitney $U$-test. $\quad$ Data show mean \pm s.e.m. 
Two-bottle test (Na-depleted condition)
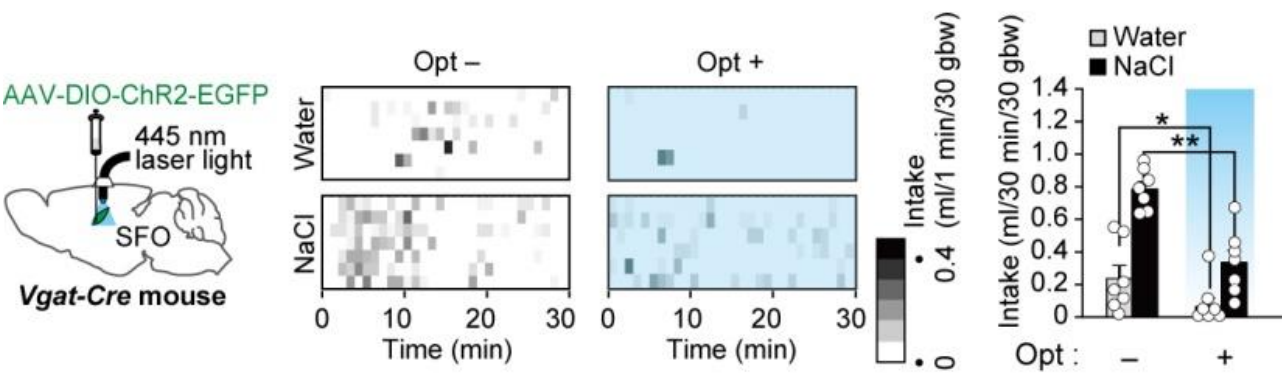

Figure IV.3 Optical excitation of GABAergic neurons in the SFO reduces water and salt intake under the Na-depleted condition.

Left: injection of AAV-DIO-ChR2-EGFP into SFO of Vgat-Cre mice. Middle: gray scale heat maps of water and $0.3 \mathrm{M} \mathrm{NaCl}$ intakes by individual mice under the Na-depleted condition with $(\mathrm{Opt}+)$ or without $(\mathrm{Opt}-)$ the optical excitation of GABAergic neurons in the SFO. Right: effects of optical excitation of GABAergic neurons in the $\mathrm{SFO}$ on water and $0.3 \mathrm{M} \mathrm{NaCl}$ intakes under the Na-depleted condition $\left(n=7\right.$ mice each; $\left.U_{(\text {Water })}=43, P_{(\text {Water })}=0.0208 ; U_{(\mathrm{NaCl})}=47, P=0.0049\right) . \quad$ bw, body weight. $\quad * P<0.05$; $* * P 0.01$; Mann-Whitney $U$-tests. Data show mean \pm s.e.m. 

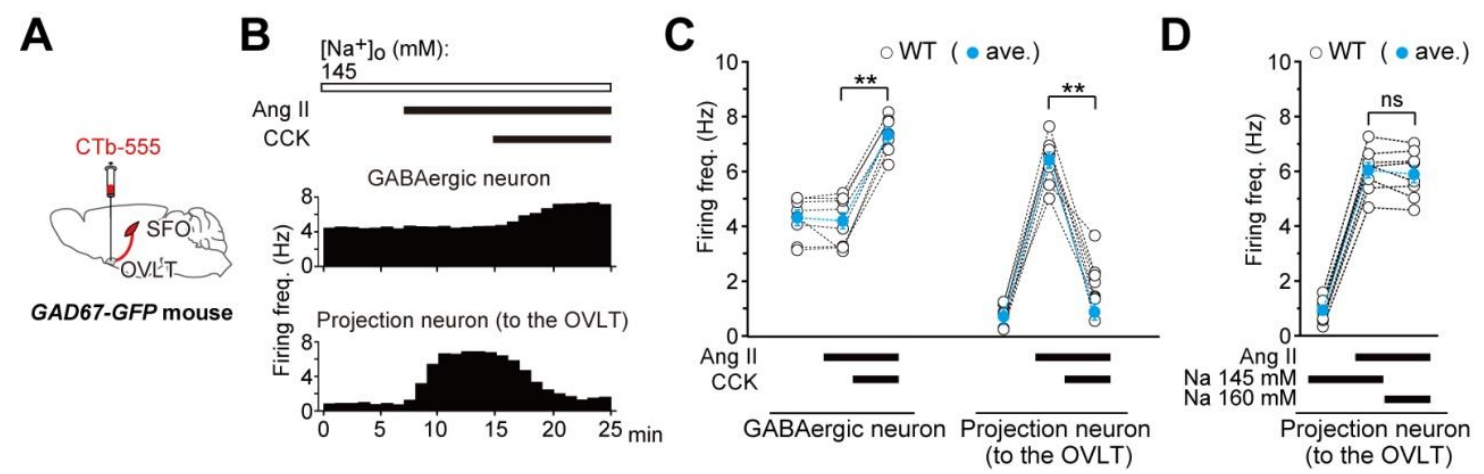

Figure IV.4 Activity of the SFO $\rightarrow$ OVLT pathway for thirst is suppressed by CCK.

(A) Injection of CTb-555 into the OVLT of GAD67-GFP mice. (B, C) Effects of CCK on firing activities of $\mathrm{SFO}(\rightarrow \mathrm{OVLT})$ neurons and synaptically connected GABAergic neurons. Representative time courses of the firing frequencies (B). Ang II application started at the 7 min mark. Summary data in $\mathbf{C}$ were from 4-5 min, 14-15 min and 24$25 \min \left(n=8\right.$ slices each; $U_{(\mathrm{GABAergic} \text { neuron })}=0, P=0.0009 ; U_{(\text {projection neuron })}=64, P=$ 0.0009). Blue values show mean \pm s.e.m. (D) Effects of the hypertonic Na solution on firing activities of $\mathrm{SFO}(\rightarrow$ OVLT $)$ neurons and synaptically connected GABAergic neurons $(n=8$ slices each; $\mathrm{U}=33.5, P=0.9163)$. Blue values show mean \pm s.e.m. $n s$, not significant; ** $P<0.01$; Mann-Whitney $U$-tests. 
A

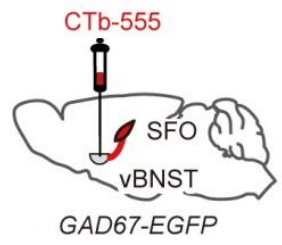

B

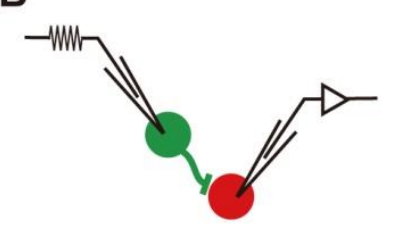

C

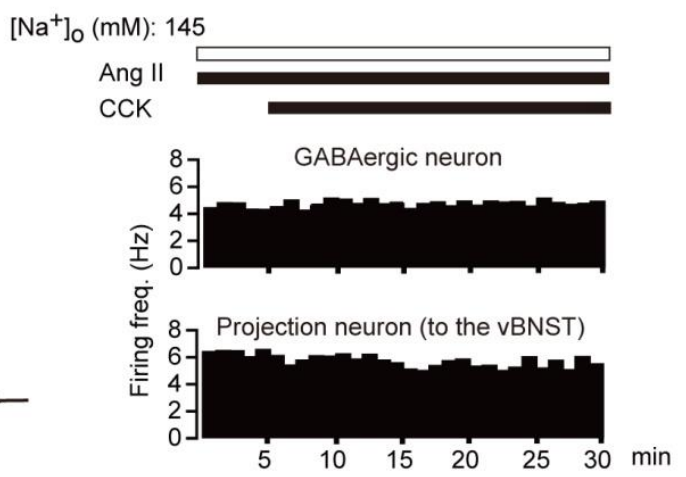

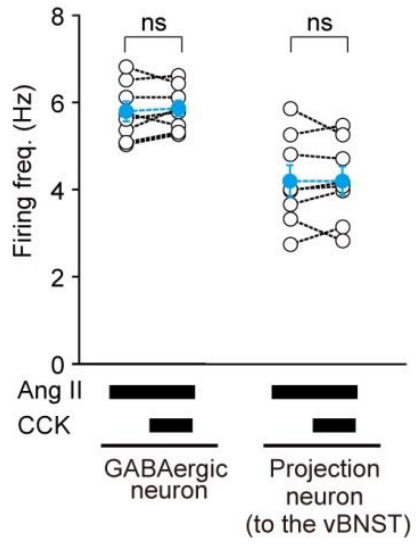

Figure IV.5 Neural activities of the SFO $(\rightarrow$ vBNST) neurons and GABAergic neurons in the presence of $\mathrm{CCK}$.

(A) Schematic drawing of the retrograde labeling of the SFO $\rightarrow$ vBNST) neurons in GAD67-EGFP mice by using CTb-555. (B) Schematic drawing of electrical stimulation of a GABAergic neuron (green) and electrophysiological recording from a CTb-labelled neuron synaptically connected in the SFO (red).

(C) Representative spike frequency histogram and summary showing the effects of CCK (10 nM) and Ang II $(0.1 \mu \mathrm{M})$ on the firing activities of the GABAergic neuron and the $\mathrm{SFO}(\rightarrow \mathrm{vBNST})$ neuron in the SFO of WT mice $\left(n=8\right.$ slices each; $U_{(\mathrm{GABA} A e r g i c}$ neuron $)=30, P=0.8746$; $\left.U_{\text {(Projection neuron) }}=28.5, P=0.7525\right)$. Blue values are the mean \pm s.e.m. of mice, respectively. ns, not significant; Mann-Whitney $U$-tests. 


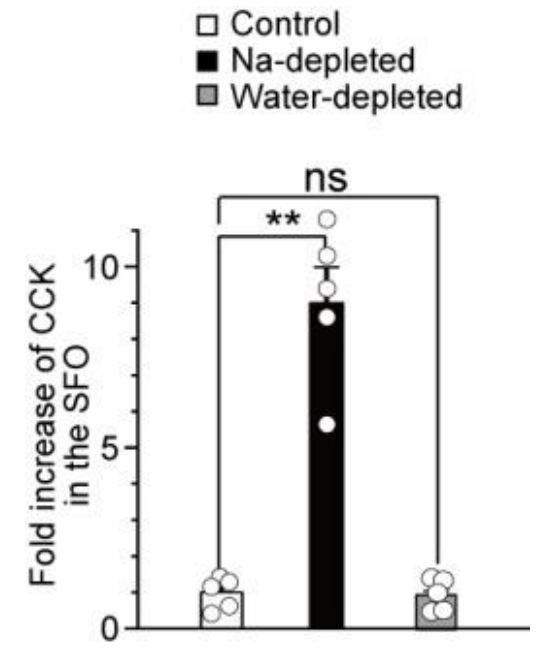

Figure IV.6 CCK levels in the SFO are increased under the Na-depleted condition.

CCK levels in SFO tissues of mice under control, Na-depleted and water-depleted conditions $\left(n=5\right.$ samples in 15 mice each; $U_{\text {(Na-depleted })}=0, P=0.0090 ; U_{\text {(Water-depleted })}=$ $15, P=0.6761)$. The mean value of the control was set at 1 . bw, body weight; ns, not significant; $* * P<0.01$; Mann-Whitney $U$-tests. Data show mean \pm s.e.m. 


\section{Chapter V}

\section{Summary and conclusion}


Since Buggy and Fisher have reported the dual central roles of Ang II in thirst and salt appetite (Buggy and Fisher, 1974), the dipsogenic and natriorexigenic functions of Ang II have been important targets in the research field of body fluid homeostasis. sCVOs in the brain have been suggested as the major sites for the signal transduction of circulating Ang II to neural signals, because they lack a blood-brain barrier and strongly express Ang II receptors (Premer et al., 2013). In addition, Prof. Noda's studies previously reported that the glial cells in the SFO expressed $\mathrm{Na}_{\mathrm{x}}$ which sensed increases of $\left[\mathrm{Na}^{+}\right]$in body fluids to upregulate the firing rate of GABAergic neurons, and suggested that this GABAergic activation leads to suppression of the hypothetical SFO neurons encoding salt appetite (Noda and Hiyama, 2015b). However, the detailed neural mechanisms for the control of thirst and salt appetite according to the body-fluid conditions remain unknown.

In this thesis, I identified different groups of AT1a-positive SFO neurons separately driving thirst and salt appetite based on body-fluid conditions. I referred to them as "water neurons" and "salt neurons", respectively. Water neurons are AT1a-positive excitatory neurons innervating the OVLT, and salt neurons are those innervating the vBNST. CCK, which is increased in the SFO under the Na-depleted condition, controlled the activity of water neurons via inhibitory GABAergic neurons. On the other hand, signals of $\mathrm{Na}_{x}$ channels sensing $\left[\mathrm{Na}^{+}\right]$in body fluids controlled the activity of salt neurons through another population of GABAergic neurons in the SFO. The balance between the dipsogenic and natriorexigenic effects of Ang II thus appears to be controlled based on the $\left[\mathrm{Na}^{+}\right]$in body fluids. The neural mechanisms by which waterand salt-intake behaviors were separately controlled by two distinct GABAergic neuron populations based on body-fluid conditions are summarized in Figure V.1. 
It is important to understand the central mechanisms for body fluid homeostasis, because disorders in brain mechanisms for water intake may induce adipsia or polydipsia, and high salt intake is relevant to some systemic diseases including salt-sensitive hypertension. My doctor thesis thus provides insights into the central mechanisms by which body-fluid conditions regulate thirst and salt appetite, and into the preventive care for several diseases attributed to deficits of water and salt. 


\section{$<$ Water-depleted condition $>\quad<$ Na-depleted condition $>$}

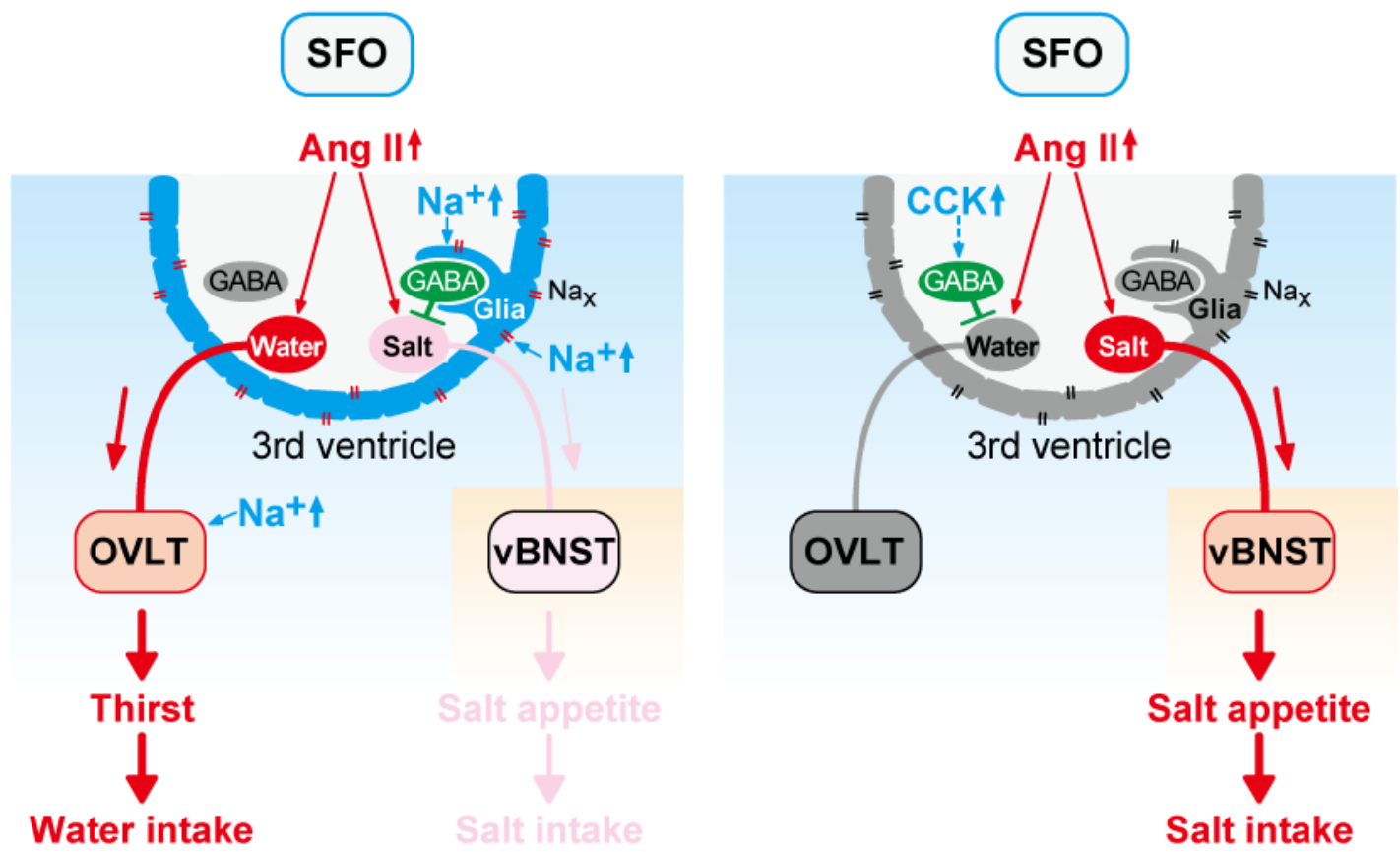

Figure V.1 A schematic overview of controls for thirst and salt appetite from the SFO.

SFO is characterized by the presence of neuronal cell bodies and extensive networks of fenestrated capillaries that allow circulating Ang II to be released into the intercellular space. Their ventricular side is partitioned by an ependymal cell layer facing the third ventricle. $\mathrm{Na}_{\mathrm{x}}$ channels populate the perineural processes of astrocytes and ependymal cells, enveloping a population of GABAergic neurons. Salt neurons innervating the vBNST receive inhibitory synaptic inputs from GABAergic neurons.

Under the water-depleted condition (left), Ang II and $\left[\mathrm{Na}^{+}\right]$both increase in the SFO. $\mathrm{Na}_{\mathrm{x}}$ in glial cells is activated, which stimulates anaerobic glycolysis in glial cells, and eventually promotes the release of lactate, the end product of anaerobic glycolysis 
(Shimizu et al., 2007). Lactate is metabolized to ATP in GABAergic neurons, leading to depolarization through a $\mathrm{K}_{\mathrm{ATP}}$ channel-dependent mechanism and the up-regulation of the firing activity (Shimizu et al., 2007). The GABAergic neurons thus activated by the $\mathrm{Na}_{\mathrm{x}}$ signal suppress salt neurons, but not water neurons. Water neurons innervate the OVLT, and the selective activation of water neurons results in water intake under the water-depleted condition. However, some experimental data suggest that AT2 receptor-positive neurons may be also involved in water-intake control, and that some other water neurons are also present in the SFO and OVLT, which are activated by signals of $\mathrm{Na}^{+}$, osmolality, or other dipsogenic hormones (Fitzsmons, 1998; Li et al., 2003; Sakuta et al., 2016). Under the Na-depleted condition (right), salt neurons which innervate the vBNST are activated by Ang II and enhance salt appetite. Under the Na-depleted condition, CCK is upregulated in the SFO, and the secreted CCK suppresses the Ang II-dependent neural activities of water neurons via GABAergic neurons. This is a mechanism for the suppression of water intake under the Na-depleted condition. Under the water- and Na-depleted condition, both water and $\mathrm{Na}$ intakes are stimulated, because neither the $\mathrm{Na}_{\mathrm{x}}$ signal nor $\mathrm{CCK}$ signal is induced. 


\section{Chapter VI}

\section{References}


Abbott, S. B., Machado, N. L., Geerling, J. C. \& Saper, C. B. Reciprocal Control of Drinking Behavior by Median Preoptic Neurons in Mice. J. Neurosci. 36, 8228-8237 (2016).

Ahmed, A. S., Dai, L., Ho, W., Ferguson, A. V. \& Sharkey, K. A. The subfornical organ: a novel site of action of cholecystokinin. Am. J. Physiol. Regul. Integr. Comp. Physiol. 306, R363-R373 (2014).

Avrith, D. B. \& Fitzsimons, J. T. Increased sodium appetite in the rat induced by intracranial administration of components of the renin-angiotensin system. J. Physiol. 301, 349-364 (1980).

Beresford, M. J. \& Fitzsimons, J. T. Intracerebroventricular angiotensin II-induced thirst and sodium appetite in rat are blocked by the AT1 receptor antagonist, Losartan (DuP 753), but not by the AT2 antagonist, CGP 42112B. Exp Physiol. 77, 761-764 (1992).

Buggy, J. \& Fisher, A. E. Evidence for a dual central role for angiotensin in water and sodium intake. Nature 250, 733-735 (1974).

Ciura, S. \& Bourque, C. W. Transient receptor potential vanilloid 1 is required for intrinsic osmoreception in organum vasculosum lamina terminalis neurons and for normal thirst responses to systemic hyperosmolality. J. Neurosci. 26, 9069-9075 (2006).

D'Agostino, G., Lyons, D. J., Cristiano, C., Burke, L. K., Madara, J. C., Campbell, J. N., Garcia, A. P., Land, B. B., Lowell, B. B., Dileone, R. J. \& Heisler, L. K. Appetite controlled by a cholecystokinin nucleus of the solitary tract to hypothalamus neurocircuit. eLIFE. eLife. 2016;5:e12225. (2016).

Egan, G., Silk, T., Zamarripa, F., Williams, J., Federico, P., Cunnington, R., Carabott, L., Blair-West, J., Shade, R., McKinley, M., Farrell, M., Lancaster, J., Jackson, G., Fox, P. \& Denton, D. Neural correlates of the emergence of consciousness of thirst. Proc. Natl. Acad. Sci. U S A. 100, 15241-15246 (2003).

Fitzsimons, J. T. The effects of slow infusions of hypertonic solutions on drinking and drinking thresholds in rats. $J$ Physiol. 167, 344-354 (1963). 
Fitzsimons, J. T. Angiotensin, thirst, and sodium appetite. Physiol. Rev. 78, 583-686 (1998).

Gabor, A. \& Leenen, F. H. Central neuromodulatory pathways regulating sympathetic activity in hypertension. J. Appl. Physiol. (1985). 113, 1294-1303 (2012).

Garfield, A. S., Shah, B. P., Madara, J. C., Burke, L. K., Patterson, C. M., Flak, J., Neve, R. L., Evans, M. L., Lowell, B. B., Myers, M. G. Jr \& Heisler, L. K. A parabrachial-hypothalamic cholecystokinin neurocircuit controls counterregulatory responses to hypoglycemia. Cell Metab. 20, 1030-1037 (2014).

Geerling, J. C. \& Loewy, A. D. Central regulation of sodium appetite. Exp. Physiol. 93, 177-209 (2008).

Geerling, J. C. \& Loewy, A. D. Aldosterone in the brain. Am. J. Physiol. Renal. Physiol. 297, 559-576 (2009).

Gizowski, C., Zaelzer, C. \& Bourque, C. W. Clock-driven vasopressin neurotransmission mediates anticipatory thirst prior to sleep. Nature. 537, 685-688 (2016).

Gladden, L. B. Lactate metabolism: a new paradigm for the third millennium. J. Physiol. 558, 5-30 (2004).

Goldin, A. L., Barchi, R. L., Caldwell, J. H., Hofmann, F., Howe, J. R., Hunter, J. C., Kallen, R. G., Mandel, G., Meisler, M. H., Netter, Y. B., Noda, M., Tamkun, M. M., Waxman, S. G., Wood, J. N. \& Catterall, W. A. Nomenclature of voltage-gated sodium channels. Neuron 28, 365-368 (2000).

Han, X., Chow, B. Y., Zhou, H., Klapoetke, N. C., Chuong, A., Rajimehr, R., Yang, A., Baratta, M. V., Winkle, J., Desimone, R. \& Boyden, E. S. A high-light sensitivity optical neural silencer: development and application to optogenetic control of non-human primate cortex. Front. Syst. Neurosci. doi: 10.3389/fnsys.2011.00018. (2011). 
Hiyama, T. Y., Watanabe, E., Ono, K., Inenaga, K., Tamkun, M. M., Yoshida, S. \& Noda, M. $\mathrm{Na}_{\mathrm{x}}$ channel involved in CNS sodium-level sensing. Nat. Neurosci. 5, 511-512 (2002).

Hiyama, T. Y., Watanabe, E., Okado, H. \& Noda, M. The subfornical organ is the primary locus of sodium-level sensing by $\mathrm{Na}_{\mathrm{x}}$ sodium channels for the control of salt-intake behavior. J. Neurosci. 24, 9276-9281 (2004).

Hiyama, T. Y., Matsuda, S., Fujikawa, A., Matsumoto, M., Watanabe, E., Kajiwara, H., Niimura, F. \& Noda, M. Autoimmunity to the sodium-level sensor in the brain causes essential hypernatremia. Neuron 66, 508-522 (2010).

Hiyama, T. Y., Yoshida, M., Matsumoto, M., Suzuki, R., Matsuda, T., Watanabe, E. \& Noda, M. Endothelin-3 expression in the subfornical organ enhances the sensitivity of $\mathrm{Na}_{\mathrm{x}}$, the brain sodium-level sensor, to suppress salt intake. Cell Metab. 17, 507-519 (2013).

Hollis, J. H., McKinley, M. J., D'Souza, M., Kampe, J. \& Oldfield, B. J. The trajectory of sensory pathways from the lamina terminalis to the insular and cingulate cortex: a neuroanatomical framework for the generation of thirst. Am. J. Physiol. Regul. Integr. Comp. Physiol. 294, R1390-R1401 (2008).

Holmes, J. H. \& Gregersen, M. I. Observations on drinking induced by hypertonic solutions. Am. J. Physiol. 162, 326-327 (1950).

Hurley, S. W. \& Johnson, A. K. The biopsychology of salt hunger and sodium deficiency. Pflügers Arch. - Eur. J. Physiol. 467, 445-456 (2015).

Jarvie, B. C. \& Palmiter, R. D. HSD2 neurons in the hindbrain drive sodium appetite. Nat. Neurosci. doi: 10.1038/nn.4451. (Epub ahead of print) (2016).

Jennings, J. H., Sparta, D. R., Stamatakis, A. M., Ung, R. L., Pleil, K. E., Kash, T. L. \& Stuber, G. D. Distinct extended amygdala circuits for divergent motivational states. Nature 496, 224-228 (2013). 
Johnson, A. K. The sensory psychobiology of thirst and salt appetite. Med. Sci. Sports Exerc. 39, 1388-1400 (2007).

Johnson, A.K. \& Gross, P. M. Sensory circumventricular organs and brain homeostatic pathways. FASEB J. 7, 678-686 (1993).

Kato, S., Kobayashi, K., Inoue, K., Kuramochi, M., Okada, T., Yaginuma, H., Morimoto, K., Shimada, T., Takada, M. \& Kobayashi, K. A lentiviral strategy for highly efficient retrograde gene transfer by pseudotyping with fusion envelope glycoprotein. Hum. Gene Ther. 22, 197-206 (2011).

Kenney, W. L. \& Chiu, P. Influence of age on thirst and fluid intake. Med. Sci. Sports Exerc. 33, 1524-1532 (2001).

Lazartigues, E., Sinnayah, P., Augoyard, G., Gharib, C., Johnson, A. K. \& Davisson, R. L. Enhanced water and salt intake in transgenic mice with brain-restricted overexpression of angiotensin (AT1) receptors. Am. J. Physiol. Regul. Integr. Comp. Physiol. 295, R1539-R1545 (2008).

Li, Z., Iwai, M., Wu, L., Shiuchi, T., Jinno, T., Cui, T. X. \& Horiuchi, M. Role of AT2 receptor in the brain in regulation of blood pressure and water intake. Am. J. Physiol. Heart Circ. Physiol. 284, 116-121 (2003).

Lind, R. W. \& Johnson, A. K. A further characterization of the effects of AV3V lesions on ingestive behavior. Am. J. Physiol. 245, 83-90 (1983).

Matsusaka, T., Asano, T., Niimura, F., Kinomura, M., Shimizu, A., Shintani, A., Pastan, I., Fogo, A. B. \& Ichikawa, I. Angiotensin receptor blocker protection against podocyte-induced sclerosis is podocyte angiotensin II type 1 receptor-independent. Hypertension 55, 967-973 (2010).

McKinley, M. J., Denton, D. A., Nelson, J. F. \& Weisinger, R. S. Dehydration induces sodium depletion in rats, rabbits, and sheep. Am. J. Physiol. 245, R287-292 (1983). 
McKinley, M. J., Badoer, E. \& Oldfield, B. J. Intravenous angiotensin II induces Fos-immunoreactivity in circumventricular organs of the lamina terminalis. Brain Res. 594, 295-300 (1992).

McKinley, M. J., McAllen, R. M., Davern, P., Giles, M. E., Penschow, J., Sunn, N., Uschakov, A. \& Oldfield, B. J. The sensory circumventricular organs of the mammalian brain. Adv. Anat. Embryol. Cell Biol. 172, 1-122 (2003).

McKinley, M. J. \& Johnson, A. K. The Physiological Regulation of Thirst and Fluid Intake. Physiology. 19, 1-6 (2004).

Nation, H. L., Nicoleau, M., Kinsman, B. J., Browning, K. N. \& Stocker, S. D. DREADD-induced activation of subfornical organ neurons stimulates thirst and salt appetite. J Neurophysiol. jn.00149.2016. doi: 10.1152/jn.00149.2016 (Epub ahead of print) (2016).

Noble, F. \& Roques, B. P. CCK-B receptor: chemistry, molecular biology, biochemistry and pharmacology. Prog. Neurobiol. 58, 349-379 (1999).

Noda, M. \& Hiyama, T. Y. Sodium-level-sensitive sodium channel and salt-intake behavior. Chem. Senses 30, Suppl. 1, i44-i45 (2005).

Noda, M. The subfornical organ, a specialized sodium channel, and the sensing of sodium levels in the brain. Neuroscientist 12, 80-91 (2006).

Noda, M. \& Sakuta, H. Central regulation of body-fluid homeostasis. Trends Neurosci. 36, 661-673 (2013).

Noda, M. \& Hiyama, T. Y. Sodium sensing in the brain. Pflügers Arch. - Eur. J. Physiol. 467, 465-474 (2015a).

Noda, M. \& Hiyama, T. Y. The $\mathrm{Na}_{\mathrm{x}}$ channel: What it is and what it does. Neuroscientist 21, 399-412 (2015b).

Oka, Y., Ye, M. \& Zuker, C. S. Thirst driving and suppressing signals encoded by distinct neural populations in the brain. Nature 520, 349-352 (2015). 
Orskov, C., Poulsen, S. S., Møller, M. \& Holst, J. J. Glucagon-like peptide I receptors in the subfornical organ and the area postrema are accessible to circulating glucagon-like peptide I. Diabetes. 45, 832-835 (1996).

Paul, M., Poyan, Mehr, A. \& Kreutz, R. Physiology of local renin-angiotensin systems. Physiol Rev. 86,747-803 (2006).

Premer, C., Lamondin, C., Mitzey, A., Speth, R. C. \& Brownfield, M. S. Immunohistochemical localization of AT1a, AT1b, and AT2 angiotensin II receptor subtypes in the rat adrenal, pituitary, and brain with a perspective commentary. Int. J. Hypertens. doi: 10.1155/2013/175428. (2013).

Pulman, K. J., Fry, W. M., Cottrell, G. T. \& Ferguson, A. V. The subfornical organ: a central target for circulating feeding signals. J. Neurosci. 26, 2022-30 (2006).

Reilly, J. J., Maki, R., Nardozzi, J. \& Schulkin, J. The effects of lesions of the bed nucleus of the stria terminalis on sodium appetite. Acta. Neurobiol. Exp. (Wars). 54, 253-257 (1994).

Rowland, N. E., Fregly, M. J., Li, B. H. \& Han, L. Angiotensin-related induction of immediate early genes in rat brain. Regul. Pept. 66, 25-29. (1996).

Rowland, N. E., Farnbauch, L. J. \& Crews, E. C. Sodium deficiency and salt appetite in ICR: CD1 mice. Physiol. Behav. 80, 629-635 (2004).

Sakuta, H., Nishihara, E., Hiyama, T. Y., Lin, C. H. \& Noda, M. Na $a_{x}$ signaling evoked by an increase in $\left[\mathrm{Na}^{+}\right]$in CSF induces water intake via EET-mediated TRPV4 activation. Am. J. Physiol. Regul. Integr. Comp. Physiol. doi: 10.1152/ajpregu.00352.2015. (Epub ahead of print) (2016).

Sasamura, H., Hein, L., Krieger, J. E., Pratt, R. E., Kobilka, B. K. \& Dzau, V. J. Cloning, characterization, and expression of two angiotensin receptor (AT-1) isoforms from the mouse genome. Biochem. Biophys. Res. Commun. 185, 253-259 (1992).

Sealey, J. E., Glorioso, N., Itskovitz, J. \& Laragh, J. H. Prorenin as a reproductive hormone. New form of the renin system. Am. J. Med. 81, 1041-1046 (1986). 
Shimizu, H., Watanabe, E., Hiyama, T. Y., Nagakura, A., Fujikawa, A., Okado, H., Yanagawa, Y., Obata, K. \& Noda, M. Glial $\mathrm{Na}_{\mathrm{x}}$ channels control lactate signaling to neurons for brain $\left[\mathrm{Na}^{+}\right]$sensing. Neuron 54, 59-72 (2007).

Shin, J. W., Geerling, J. C. \& Loewy, A. D. Inputs to the ventrolateral bed nucleus of the stria terminalis. J. Comp. Neurol. 511, 628-657 (2008).

Simpson, J. B. \& Routtenberg, A. Subfornical organ: site of drinking elicitation by angiotensin II. Science 181, 1172-1175 (1973).

Simpson, J. B. \& Routtenberg, A. Subfornical organ lesions reduce intravenous angiotensin-induced drinking. Brain Res. 88, 154-161 (1975).

Smith, P. M., Chambers, A. P., Price, C. J., Ho, W., Hopf, C., Sharkey, K. A. \& Ferguson, A. V. The subfornical organ: a central nervous system site for actions of circulating leptin. Am. J. Physiol. Regul. Integr. Comp. Physiol. 296, R512-520 (2009).

Stamatakis, A. M., Sparta, D. R., Jennings, J. H., McElligott, Z. A., Decot, H. \& Stuber, G. D. Amygdala and bed nucleus of the stria terminalis circuitry: Implications for addiction-related behaviors. Neuropharmacology 76, Pt B, 320-328 (2014).

Stricker, E. M. \& Sved, A. F. Thirst. Nutrition 16, 821-826 (2000).

Sugaya, T., Nishimatsu, S., Tanimoto, K., Takimoto, E., Yamagishi, T., Imamura, K., Goto, S., Imaizumi, K., Hisada, Y., Otsuka, A., Uchida, H., Sugiura, M., Fukuta, K., Fukamizu, A. \& Murakami, K. Angiotensin II type 1a receptor-deficient mice with hypotension and hyperreninemia. J. Biol. Chem. 270, 18719-18722 (1995).

Sunn, N., McKinley, M. J. \& Oldfield, B. J. Circulating angiotensin II activates neurones in circumventricular organs of the lamina terminalis that project to the bed nucleus of the stria terminalis. J. Neuroendocrinol. 15, 725-731 (2003).

Tamamaki, N., Yanagawa, Y., Tomioka, R., Miyazaki, J., Obata, K. \& Kaneko, T. Green fluorescent protein expression and colocalization with calretinin, parvalbumin, and somatostatin in the GAD67-GFP knock-in mouse. J. Comp. Neurol. 467, 60-79 (2003). 
Thrasher, T. N., Keil, L. C. \& Ramsay, D. J. Lesions of the organum vasculosum of the lamina terminalis (OVLT) attenuate osmotically-induced drinking and vasopressin secretion in the dog. Endocrinology. 110, 1837-1839 (1982).

Thunhorst, R. L., Ehrlich, K. J. \& Simpson, J. B. Subfornical organ participates in salt appetite. Behav. Neurosci. 104, 637-642 (1990).

Thunhorst, R. L. \& Johnson, A. K. Renin-angiotensin, arterial blood pressure, and salt appetite in rats. Am. J. Physiol. 266, R458-R465 (1994).

Thunhorst, R. L., Beltz, T. G. \& Johnson, A. K. Effects of subfornical organ lesions on acutely induced thirst and salt appetite. Am. J. Physiol. 277, R56-65 (1999).

Timmermans, P. B., Chiu, A. T., Herblin, W. F., Wong, P. C. \& Smith, R. D. Angiotensin II receptor subtypes. Am. J. Hypertens. 6, 406-410 (1992).

Vivas, L., Chiaraviglio, E. \& Carrer, H. F. Rat organum vasculosum laminae terminalis in vitro: responses to changes in sodium concentration. Brain Res. 519, 294-300 (1990).

Vong, L., Ye, C., Yang, Z., Choi, B., Chua, S. Jr \& Lowell, B. B. Leptin action on GABAergic neurons prevents obesity and reduces inhibitory tone to POMC neurons. Neuron 71, 142-154 (2011).

Watanabe, E., Fujikawa, A., Matsunaga, H., Yasoshima, Y., Sako, N., Yamamoto, T., Saegusa, C. \& Noda, M. $\mathrm{Na}_{\mathrm{v}} 2 / \mathrm{NaG}$ channel is involved in control of salt-intake behavior in the CNS. J. Neurosci. 20, 7743-7751 (2000).

Watanabe, E., Hiyama, T. Y., Shimizu, H., Kodama, R., Hayashi, N., Miyata, S., Yanagawa, Y., Obata, K. \& Noda, M. Sodium-level-sensitive sodium channel $\mathrm{Na}_{\mathrm{x}}$ is expressed in glial laminate processes in the sensory circumventricular organs. Am. $J$. Physiol. Regul. Integr. Comp. Physiol. 290, 568-576 (2006).

Weiland, T. J., Voudouris, N. J. \& Kent, S. The role of $\mathrm{CCK}_{2}$ receptors in energy homeostasis: insights from the CCK2 receptor-deficient mouse. Physiol. Behav. 82, 471-476 (2004). 
Willis, G. L., Hansky, J. \& Smith, G. C. Ventricular, paraventricular and circumventricular structures involved in peptide-induced satiety. Regul. Pept. 9, 87-99 (1984).

Zardetto-Smith, A. M., Beltz, T. G. \& Johnson, A. K. Role of the central nucleus of the amygdala and bed nucleus of the stria terminalis in experimentally-induced salt appetite. Brain Res. 645, 123-134 (1994). 


\section{Acknowledgments}

I greatly thank my supervisor, Professor Masaharu Noda in the National Institute for Basic Biology (NIBB), for his guidance and suggestions to my research. The opportunity he gave me to work on this research has been an invaluable learning process for me.

I thank Dr. Takeshi Y Hiyama for the insightful comments, execution of electrophysiological experiments, and instruction of experimental techniques. I also thank Drs. Takafumi Shintani, Hiraki Sakuta, Akihiro Fujikawa, and other members of the Division of Molecular Neurobiology in NIBB for their help and valuable advice. I appreciate S. Miura and T. Hashimoto for their technical assistance and A. Kodama for her secretarial assistance.

I thank Dr. Y. Yanagawa (Gunma University, Japan) for provision of the GAD67-GFP mice and Dr. K. Deisseroth (Stanford University, USA) for provision of the $h \operatorname{ChR2}(H 134 R)$ gene.

This work was financially supported by MEXT/JSPS KAKENHI (Grant Numbers; 24220010, 25136723, 26293043, and 14J00037), Takeda Science Foundation, Brain Science Foundation, The Salt Science Research Foundation, and The NOVARTIS Foundation (Japan) for the Promotion of Science. This work was supported also by The Okazaki ORION project and Cooperative Study Program of National Institute for Physiological Sciences.

Finally, I would like to give sincere thanks to my dear family for their financial and mental supports. I am grateful to all the people who supported me. 